\title{
AIAA 2001-5236 \\ Internal Flow Simulation of Enhanced Performance Solid Rocket Booster for the Space Transportation System
}

R. A. Ahmad

ATK Thiokol Propulsion Corp.

Brigham City, UT

\section{7th AIAA/ASME/SAE/ASEE Joint Propulsion Conference and Exhibit July 8-11, 2001 Salt Lake City, UT}




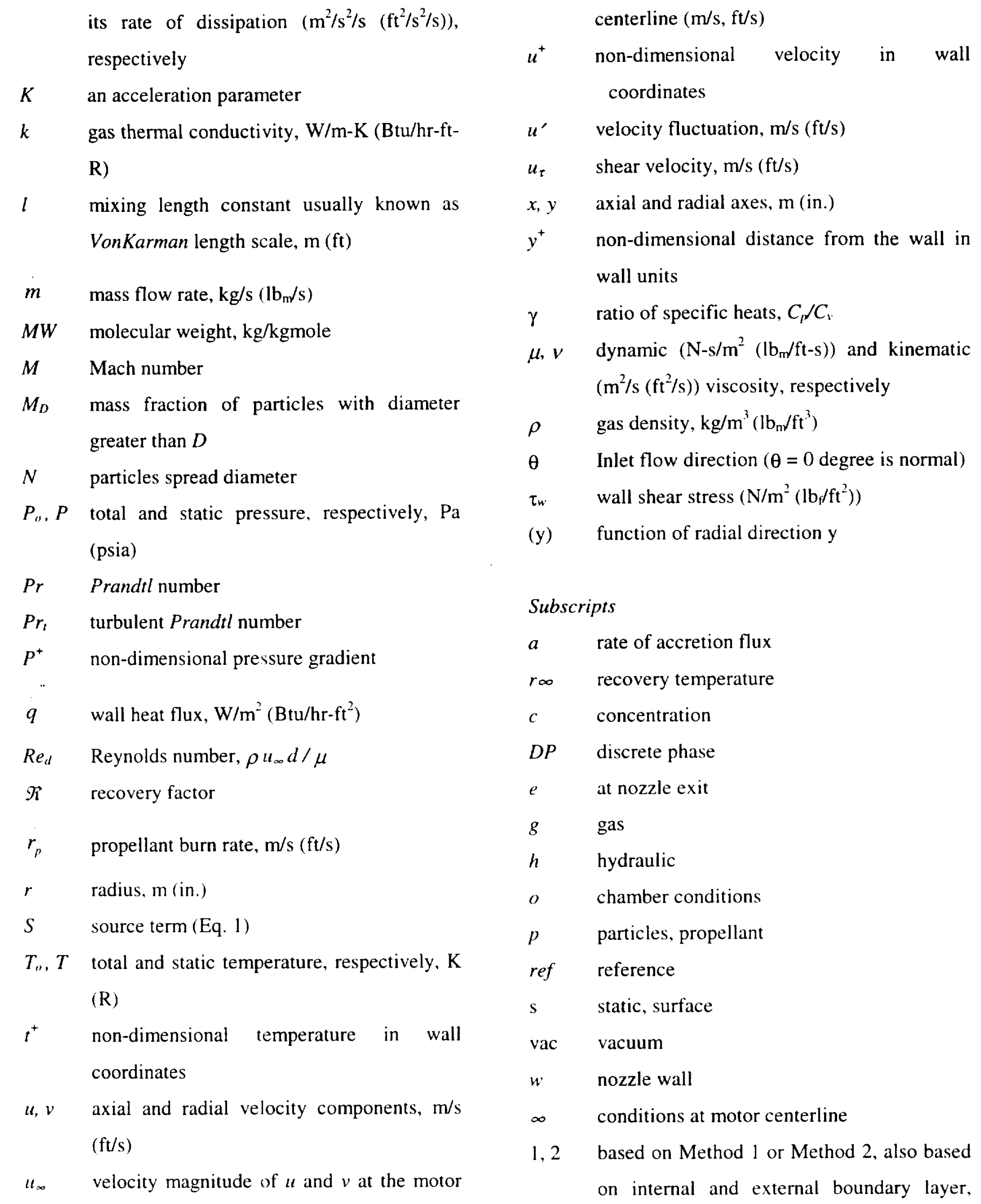




\title{
Internal Flow Simulation of Enhanced Performance Solid Rocket Booster for the Space Transportation System
}

\author{
Rashid A. Ahmad \\ Motor Performance Department, Gas Dynamics Section, M/S 252 \\ Science and Engineering \\ ATK Thiokol Propulsion Corp., Brigham City, Utah 84302
}

\begin{abstract}
An enhanced performance solid rocket booster concept for the space shuttle system has been proposed. The concept booster will have strong commonality with the existing, proven, reliable four-segment Space Shuttle Reusable Solid Rocket Motors (RSRM) with individual component design (nozzle, insulator, etc.) optimized for a five-segment configuration. Increased performance is desirable to further enhance safety/reliability and/or increase payload capability. Performance increase will be achieved by adding a fifth propellant segment to the current four-segment booster and opening the throat to accommodate the increased mass flow while maintaining current pressure levels. One development concept under consideration is the static test of a "standard" RSRM with a fifth propellant segment inserted and appropriate minimum motor modifications. Feasibility studies are being conducted to assess the potential for any significant departure in component performance/oading from the well-characterized RSRM. An area of concern is the aft motor (submerged nozzle inlet, aft dome, etc.) where the altered internal flow resulting from the performance enhancing features (25\% increase in mass flow rate, higher Mach numbers, modified subsonic nozzle contour) may result in increased component erosion and char. To assess this issue and to define the minimum design changes required to successfully static test a fifth segment RSRM engineering test motor, internal flow studies have been initiated. Internal aero-thermal environments were quantified in terms of conventional convective heating and discrete phase alumina particle impact/concentration and accretion calculations via Computational Fluid Dynamics (CFD) simulation. Two sets of comparative CFD simulations of the RSRM and the five-segment (FSM) concept motor were conducted with CFD commercial code FLUENT. The first simulation involved a two-dimensional axi-symmetric model of the full motor, initial grain RSRM. The second set of analyses included three-dimensional models of the RSRM and FSM aft motors with four-degree vectored nozzles.

Nomenclature

$\begin{array}{ll}A & \text { area, } \mathrm{m}^{2}\left(\mathrm{ft}^{2}\right) \\ A^{+} & \text {Van Driest constant } \\ C_{f} & \text { friction coefficient } \\ C_{p}, C_{v} & \text { specific heats at constant pressure and } \\ & \text { volume, respectively, } \mathrm{J} / \mathrm{kg}-\mathrm{K}\left(\mathrm{Btu} / \mathrm{lb}_{\mathrm{m}}-\mathrm{R}\right)\end{array}$

$\begin{array}{ll}d & \text { diameter, } \mathrm{m}(\mathrm{in} .) \\ F & \text { thrust, } \mathrm{N}(\mathrm{lbf}) \\ g & \text { acceleration due to gravity, } \mathrm{m} / \mathrm{s}^{2}\left(\mathrm{ft} / \mathrm{s}^{2}\right) \\ h & \begin{array}{l}\text { convective heat transfer coefficient, } \mathrm{W} / \mathrm{m}^{2}- \\ \end{array} \\ I & \mathrm{~K}\left(\mathrm{Btu} / \mathrm{hr}-\mathrm{ft}{ }^{2}-\mathrm{R}\right) \\ l_{s p} & \text { turbulence intensity, } u / u_{\infty}(\%) \\ \kappa, \varepsilon & \text { turbulence kinetic energy }\left(\mathrm{m}^{2} / \mathrm{s}^{2}\left(\mathrm{ft}^{2} / \mathrm{s}^{2}\right)\right) \text { and }\end{array}$
\end{abstract}

*Sr. Principal Engineer, Associate Fellow AIAA.

2001 ATK Thiokol Propulsion Corp. 
respectively

\section{Superscripts}

$\begin{array}{ll}n & \text { burn rate pressure exponent } \\ * & \text { throat conditions } \\ . & \text { flux } \\ -\quad \text { mean and time averaged }\end{array}$

\section{Introduction:}

Internal flow simulations of the proposed five segments motor were conducted in order to assess the aft motor aero-thermal environment differences between the five-Segment Motor (FSM) and the four-Segment Redesigned Solid Rocket Motor (RSRM). Design differences between the two systems indicated that any significant departure in component erosion/char from the RSRM would likely be manifest in the submerged and nozzle regions. Objectives of these analyses are:

- Compare the predicted aero-thermal environments in the aft motor region and nozzle.

- Identify any potential "show stoppers" associated with the five-segment concept.

- Flag those areas or phenomena that should be further scrutinized in the development phase of the program.

The five segments booster was proposed as an enhanced performance solid rocket booster concept for the space shuttle system. The concept booster will have strong commonality with the existing, proven, reliable four-segment RSRM's with individual component design (nozzle, insulator, etc.) optimized for a five-segment configuration. Increased performance is desirable to further enhance safety/reliability and/or increase payload capability. Performance increase will be achieved by adding a fifth propellant segment to the current four-segment booster and opening the throat to accommodate the increased mass flow while maintaining current pressure levels.

Feasibility studies are being conducted to assess the potential for any significant departure in component performance/loading from the wellcharacterized RSRM. An area of concern is the aft motor (submerged nozzle inlet, aft dome, etc.), where the altered internal flow resulting from the performance enhancing features $(25 \%$ increase in mass flow rate, higher Mach numbers, modified subsonic nozzle contour) may result in increased component erosion and char. Internal aero-thermal environments were quantified in terms of conventional convective heating and discrete phase alumina particle concentration and accretion calculations via CFD simulation.

\section{Discussion:}

The following literature survey is a discussion of what has and has not been dealt with in the world of solid rocket motors. Selected studies are discussed in the following paragraph and are referenced chronologically in [1-29]. Slag deposition process through flow modeling and the subsequent accumulation and pooling of slag material within the Space Shuttle solid rocket motor (SRM) was first 
documented by Boraas [1]. Flow field modeling consisted of a potential flow gaseous computation with a Lagrangian particle trajectory calculation. The separated flow region in the aft end of the submerged nozzle motor was approximated by a fictitious interface drawn between the submerged nozzle entrance and the aft dome recirculation region. Particle trajectories were computed by varying particle starting locations on the propellant surface. Murdock [2] discussed the ejection of a body that blocks the nozzle throat and may cause perturbation in the measured thrust-time histories of solid rocket motors. Traineau at al. [3] conducted cold-flow simulation tests of a nozzleless solid rocket motor using a two-dimensional porous-walled duct with an impermeable-walled diverging section. Beddini [4] conducted theoretical analysis of the flow in porous-walled tubes and channels with appreciable injection through the duct wall. The flow at large injection Reynolds numbers can undergo at least three flow regimes. Basset [5] compiled results of modeling of circumferential flow in the RSRM induced by potential nonaxisymmetric flow sources. It describes analytical and experimental results. The numerical techniques utilized eight $3 \mathrm{D}$ fluid-flow codes and two $3 \mathrm{D}$ heat flow codes, while the testing media included water, cold air, and hot combustion gas. Salita [6] suggested a bimodal log-normal droplet size distribution at a pressure of about 6.90 MPa (1000 psia) consisting of small droplets with $1.5 \mu \mathrm{m}$ mean and large droplets with a $100 \mu \mathrm{m}$ mean. Whitesides et al. [7] conducted a series of subscale cold flow tests to quantify the gas flow characteristics at the aft end of the RSRM. In specific, measurements of static pressure and gas velocities in the vicinity of the nozzle/case joint when nozzle is gimbaled at angles of $0,3.5$, and 7 degrees. Golafshani and Loh [8] conducted a time-dependent, axisymmetric numerical solution of the Navier-Stokes to analyze the viscous coupled gas-particle non-reacting flow in solid rocket motors. The solution assumed laminar internal flow. Waesche et al. [9] conducted flow-visualization tests in a $1 / 8$-scale model of the RSRM in a water tunnel to simulate (1) circumferential flow induced by asymmetric inhibitor stub in the port of the RSRM, (2) vortex formation in the aft-dome cavity with and without nozzle vectoring. Burning propellant was simulated through the introduction of a uniform distribution of water along simulated burn-back patterns. Vortices shed from protruding inhibitor were found to diminish by wall injection. Circumferential flow resulting from a flawed inhibitor was limited to region near the missing portion of the inhibitor. Strong circumferential flow in the aft dome was observed toward the end of burn. Boraas [10] used a water table to simulate flow in the aft dome of the RSRM. A thin layer of water was pumped across a table between sidewalls that simulated the motor centerline and its aft-dome-nozzle boundary in nonvectoring condition and late in burn. Lightweight dye was injected uniformly across the flow field at an upstream location. Entrainment of the dye into the cavity revealed a counter-rotating three vortices in the aft dome. Majumdar et al. [11] conducted 
three-dimensional CFD analyses to calculate circumferential pressure and velocity gradients in the vicinity of an asymmetric inhibitor stub in the port of the RSRM. The numerical predictions were compared with the measurements from a $7.5 \%$ scale, cold-flow model of the RSRM. A maximum of 0.34 atm (5 psid) has been shown. Waesche et al. [12] conducted a series of cold-gas tests in a 1/8-scale (18-in. dia.) model of the forward segment of candidate grain designs for the Advanced Solid Rocket Motor (ASRM). It was found that the effects of grain slots on the downstream flow are minimal. Effects dissipate quickly because of rapid mixing with the core flow. Carrier et al. [13] used an approximate and simple model for particle trajectories in a long-bore solid rocket motor. Heister and Landsbaum [14] described anomalies caused by mass ejection through the nozzle throat of Titan 34-D solid propellant rocket motor. Hess et al. [15] found that the accumulation of slag in the aft end for a short motor is less than accumulation of slag for the long motor. Numerical solution of a simple-Eulerian-potential - flow / Lagrangian particle - tracking formulation was obtained. It was found that gravity acceleration would be discernible only for larger particle sizes, above 200- $\mu \mathrm{m}$ diameter. Smith-Kent et al. [16] describe a potential flow based slag accumulation model with Lagrangian particle tracking. Key input parameters, namely, particle size, vortex definition, and capture criteria are based on empirical data. Johnston et al. [17] conducted quasisteady axisymmetric, inviscid, coupled two-phase (combustion gas and molten
$\mathrm{Al}_{2} \mathrm{O}_{3}$ ) flow calculations. Six burn back geometries $(0,30,55,80,110$, and $125 \mathrm{sec})$ that span the total burn time of $135 \mathrm{sec}$, and four different droplet sizes $(10,35,60$, and $100 \mu \mathrm{m})$ were carried out. They have simplified the bimodal distribution droplet size of Salita [6] to a flow with just two droplet sizes, namely 1.5 and $100 \mu \mathrm{m}$. Loh and Chwalowski [18] used particles of diameters of 1 to $100 \mu \mathrm{m}$ in converging-diverging nozzles and a mass loading of $28.8 \%$. Acceleration between $\mathrm{lg}$ and $3 \mathrm{~g}$ has a minimal effect on the particles' behavior in the nozzle. Whitesides et al. [19] conducted combined analytical and experimental studies to develop an understanding of the effects of slag ejection on motor performance. A simplistic quasi-steady analytical model was formulated for the purpose of determining the instantaneous slag flow rate and the total quantity of slag required to produce a given pressure perturbation. Salita [20] reported slag measurements of $58 \mathrm{~kg}(128 \mathrm{lbm}), 1980 \mathrm{~kg}(4366$ $\mathrm{lbm}$ ), and 1102 to $4365 \mathrm{~kg}$ (500 to $3500 \mathrm{lbm}$ ) in SICBM, SRMU, and RSRM, respectively. A flow model was proposed for use in predicting slag accumulation in these motors. Chauvot et al. [21] developed a model to predict slag weight deposited in the submerged nozzle of solid rocket motors. Inflight acceleration increases slag weight. Sabnis et al. [22]conducted two-phase three-dimensional flow field in the Titan IV SRM at 17.5 in. burn-back geometry using multi-phase Navier-Stokes analysis using CELMINT (Combined Eulerian Lagrangian Multidimensional Implicit Navier-Stokes Timedependent) code [23]. The geometry in the aft 
closure region is non-axisymmetric due to the nozzle being canted with respect to the chamber axis. The purpose of the analyses was to understand asymmetric insulation erosion in the aft closure observed in static and flight tests. Asymmetric geometry in the aft closure results in secondary flows that can significantly affect the impingement pattern of the aluminum oxide droplets on the aft closure insulation. Several two-dimensional axisymmetric calculations were performed before initiating the three-dimensional calculations. They were performed to (1) assess the grid resolution, (2) obtain consistent flow conditions at the inlet to the sixth segment so that the three-dimensional simulations could be limited to the region downstream of the fifth segment. The two-dimensional axisymmetric analyses comprised segments 1 through 7 , the aft closure propellant and the nozzle and solved on two grids. The first grid consisted of 900 and 90 cells in the axial and radial directions. respectively, yielding a total number of 81,000 cells. The second grid consisted of 1,175 and 90 cells in the axial and radial directions, respectively, yielding a total number of 105,750 cells. The viscous sublayer was resolved (i.e., the first point off the wall corresponds to $y^{+}<1$ ). Simulation 1 of the present study utilized many more cells (Table 1) than in Sabnis et al. [22] to obtain $y^{+}$around 5. This author used up to 300 cells in the radial direction in the converging-diverging section of the nozzle. The size of the cell adjacent to the wall was $10^{-4} \mathrm{~m}$ $\left(3.94 \times 10^{-3}\right.$ in.). A smaller size than this would generate negative areas which CFD can not handle.
Therefore, the iterative process between the grid and the calculated wall $\mathrm{y}^{+}$ceased. In the threedimensional analyses [22], a grid was used and consisted of 351,90 , and 19 in the axial, radial, and circumferential directions, respectively, yielding a total of 598,500 cells. A propellant combustion study conducted by Perkins et al. [24] has shown that propellant variability due to subtle raw ingredient can affect the quantity and distribution of slag formed. Quench bomb tests conducted by Brennan [25] at $3.44 \mathrm{MPa}$ (500 psia) chamber pressure and particles were quenched at $0.0127 \mathrm{~m}$ (0.5 in.) from the burning surface. The resulting particle size distribution was bi-modal with $50-70 \%$ (Fig. 10 of Brennan [25] of the particles by weight under $5 \mu \mathrm{m}$ and designated as smoke). The rest of the fraction in the $5-700 \mu \mathrm{m}$ range was designated as the coarse fraction. This coarse fraction comprised the discrete fraction used in the two-phase CFD analysis conducted by Whitesides et al. [26, 27]. Whitesides et al. [27] conducted a two-dimensional axisymmetric two-phase flow analysis using CELMINT code [23]. The overall objective was to determine the structure of the flow field in the recirculation region underneath the submerged nozzle nose and to define the gas flow and particle impingement environments along the surface of the aft case dome insulation. It was concluded that particles were impacting the area underneath the nozzle nose and forming a sheet of molten aluminum oxide or slag. The sheet flows afterwards, along the underneath nozzle nose surface as is the direction of the near surface 
velocity vector during the last half of motor burn. This slag layer is then sheared from the nozzle cowl/boot ring surface and impacts the aft dome case insulation at the location of severe erosion.

Sauvageau et al. [28] discussed the technical feasibility of the five-segment reusable solid rocket motor approach and quantified the subsequent STS capability improvements. The two-dimensional axisymmetric analysis (Simulation 1) has the same geometry and grid used by Laubacher [29]. The analysis in [29] considered adiabatic walls and the standard $\kappa-\varepsilon$ turbulence model solved by a coupled solver using in-house code, SHARP ${ }^{\circledR}$.

The previous citations are related to internal flow in solid rocket motors. They are focused on

- Internal flow characteristics such as injection Reynolds number, turbulence modeling, velocity profile, etc.

- Slag deposition, formation, collection and ejection and their relation to chamber pressure perturbation and case insulation, and

- Bore pressure drop.

- Circumferential pressure gradient in the aftdome of a vectored submerged nozzle.

- Effects of idealized asymmetric inhibitor stubs on circumferential flow.

- None of the previous studies have dealt with convective heat transfer coefficients.

When considering heat transfer in solid rocket motors, surface temperatures and heat fluxes are high and very difficult to measure. Ablative materials are used to dissipate and inhibit heat transfer by erosion and transpiration. It is usually estimated using three well-known methods. They are the modified Reynolds analogy for laminar flow over a flat plate, Dittus-Boelter correlation for fullydeveloped turbulent pipe flow, and the Bartz correlation for nozzle flows.

Related heat transfer studies are given in Refs. [3038]. Bartz [30] extended the well-known DittusBoelter correlation for turbulent pipe flow to account for mass flux and variations in velocity and temperature. Back et al. [31 and 33-35] conducted analytical and experimental convective heat transfer studies in the Jet Propulsion Laboratory (JPL) nozzle. Moretti and Kays [32] conducted experimental convective heat transfer to an essentially constant property turbulent boundary layer for various rates of free-stream acceleration. Back et al. and Moretti and Kays found that acceleration causes a depression in heat transfer rate below what would be predicted assuming a boundary-layer structure such as obtained for constant free-stream velocity. They attributed it to re-laminarization of the turbulent boundary layer. Moretti and Kays [32] state the above acceleration parameter was a result of experimental tests conducted in a two-dimensional channel. They further state, it is by no means obvious that the same acceleration parameter applicable to an axisymmetric flow. Wang [37] focused on the capability of general-purpose CFD codes in predicting convective heat transfer coefficients between a fluid and a solid surface. Effects of various parameters such as grid resolution, nearwall treatments, turbulence models, as well as 
numerical schemes on the accuracy of predicted convective heat transfer were studied. Test cases included flat plate, pipe flow, JPL nozzle, and impinging jets.

For the lack of reliable thermal conditions, the nozzle wall usually assumed to be adiabatic in CFD calculations. On the other hand, CFD calculations (velocity, density, pressure, temperature, viscosity, etc.) and geometry enable someone to calculate heat transfer.

\section{Analyses and Results:}

Two sets of comparative CFD simulations of the RSRM and the five-segment concept motor were conducted with CFD commercial code FLUENT $[39,40]$. The first set (Simulation 1) involved a two-dimensional axisymmetric model of a full motor initial grain RSRM. This analysis was performed to

- Maintain continuity with previous analyses

- Serve as a non-vectored baseline

- Provide a relatively simple checkout tool for various CFD solution schemes, grid sensitivity studies, turbulence modeling/heat transfer, etc. Complete three-dimensional analyses are time and cost prohibitive.

The second set of analyses (Simulation 2) included three-dimensional models of the RSRM and five segment aft motors with four-degree vectored nozzles. The model is composed of a 180degree segment starting at upstream of the aft dome and ending at the nozzle exit. This is done to halve the number of cells needed. Results of the two simulations are detailed in [38] using the turbulence
Model 1 (Table 1).

The attributes of the two-dimensional (2D) axisymmetric analyses (Simulation 1) are:

- Significant effort was made to assess grid sensitivity and grid consistency with turbulence models.

- Verifying flow/thermal solution quality represented by $u^{+}$vs. $y^{+}$and $t^{+}$vs. $y^{+}$against the velocity and thermal laws of the wall in turbulent flows.

- Calculations of nozzle heat transfer, including the assessment of turbulent boundary layer relaminarization. Additionally, the viscous sublayer thickness is calculated and discussed.

- Calculations of slag concentration and rate of accretion flux and their locations.

- Calculations of vacuum thrust and specific impulse for comparison with the threedimensional (3D) analyses in Simulation 2.

The attributes of the $3 D$ vectored nozzles (Simulation 2) are:

- Calculations of nozzle heat transfer in vectored nozzles.

- Calculations and presentations of local static pressure gradient in the submerged region.

- Calculations of slag concentration and rate of accretion flux sand their locations.

- Determination and evaluation of 3D effects due to nozzle vectoring on vacuum thrust and specific impulse in comparison with 2Daxisymmetric analysis (Simulation 1).

Simulation 1 will be discussed first followed by Simulation 2. 


\section{Simulation 1: 2D-Axisymmetric}

\section{Analysis for the RSRM at Ignition}

Simulation 1 involves the full motor with initial grain configuration. Governing equations, solution sensitivity to grid density, boundary conditions, computational schemes, numerical convergence (residuals), flow fields, turbulence modeling, convective heat transfer, and two-phase modeling are discussed next.

Governing Equations: The numerical studies considered the solution of the Navier-Stokes equations, energy equation, the turbulence kinetic energy with its rate of dissipation equations, and the necessary constitutive equations (ideal gas law, Sutherland's relation, etc.). The general governing equation was

$$
\nabla \cdot\left(\rho \bar{V} \phi-\Gamma_{\varphi} \nabla \phi\right)=S_{\phi}
$$

and the mass conservation equation

$$
\nabla .(\rho \bar{V})=0
$$

where $\phi$ can be velocity components $(u, v, w)$. enthalpy $(i)$, turbulence quantities $(\kappa, \varepsilon)$, and species concentrations; $\Gamma$ is an exchange coefficient for $\phi$; $S_{0}$ is a source term for $\phi$ per unit volume.

Solution Sensitivity to Grid Density: Grids used in Simulations 1 and 2 are summarized in Table 1. The grids used in the two-dimensional axisymmetric analyses (Simulation 1) are quadrilateral or triangular. The grids in the two-dimensional study were designed, solved, and iterated on to give the desired values for $y^{+}$so that consistency with the turbulence models was achieved as given in Table 1.
The grids used in the three-dimensional are hexahedral and/or tetrahedral. Grid adaption was used in some grids as given in Table 1. Adaption worked well in terms of generating similar flow fields (Mach number and pressure distributions) and lowering the wall $y^{+}$to the desired value. On the other hand, the calculated wall $y^{+}$and $h / C p$ profiles have no distinct trend or profile as known from measurements and approximate methods in nozzle flows. Therefore, it was discontinued in Grid 4 of Table 1. All the grids were generated by using GRIDGEN [41] and made orthogonal and smoothed from one domain to another in the case of quads and hexahedral.

For simple geometries, quadrilateral or hexahedral meshes can provide high quality solutions with fewer cells than comparable triangular or tetrahedral meshes [39]. For complex geometries, quadrilateral/hexahedral meshes show no numerical advantage, and time can be saved using triangular/tetrahedral mesh. This would enable refined grids in regions of interest along with the consistent turbulence model using adaption techniques based on wall $y^{+}$. The convective heat transfer coefficient and wall $y^{+}$are analogous and interdependent as will be shown.

Boundary Conditions: the boundary conditions in Simulation 1 are as follows:

At the propellant surface: mass flux is calculated as a function of the local static pressure as

$$
m=\alpha_{1} \rho_{p} a\left[P_{s}(x, y)\right]^{n}
$$

In addition, uniform chamber temperature, flow direction that is normal to the propellant surface, an 
assumed turbulence intensity [36], (I), and hydraulic diameter $\left(d_{h}\right)$ were specified.

References 42,43 and 44 give the chamber pressure as 6.30 MPa (913.85 psia), 6.24 $\mathrm{MPa}(905$ psia), and 6.27 $\mathrm{MPa}(910 \mathrm{psia})$, respectively.

The total pressure used in this study is $6.25 \mathrm{MPa}$ (906 psia). This chamber pressure along with propellant formulation was used as input to the NASA-Lewis program [45] or the ODE module of the SPP code [42] to obtain chamber temperature, gas molecular weight, dynamic viscosity, thermal conductivity, and specific heat at constant pressure. They are $3416.04 \mathrm{~K}(6148.87 \mathrm{R}), 28.482 \mathrm{~kg} / \mathrm{kgmole}$. $9.643 \times 10^{-5} \mathrm{~N}-\mathrm{s} / \mathrm{m}^{2}\left(6.48 \times 10^{-5} \mathrm{lbm} / \mathrm{ft}-\mathrm{sec}\right), 0.383$ $\mathrm{W} / \mathrm{m}-\mathrm{K} \quad(0.221 \mathrm{Btu} / \mathrm{hr}-\mathrm{ft}-\mathrm{R})$ and $2005.48 \mathrm{~J} / \mathrm{kg}-\mathrm{K}$ (0.479 Btu/lbm-R), respectively. The above properties yield a value for $\operatorname{Pr}$ of 0.51 . Propellant density is taken as $1743.83 \mathrm{~kg} / \mathrm{m}^{3}\left(0.063 \mathrm{lbm} / \mathrm{in}^{3}\right)$. The reference pressure is taken as $4.30 \mathrm{MPa}(625$ psia). The reference burn rate and exponent are taken as $9.347 \times 10^{-3} \mathrm{~m} / \mathrm{s}(0.368 \mathrm{in} / \mathrm{s})$ and 0.35 , respectively. The above parameters yield a value for $a$ in Eq. (3) of $0.07765 \mathrm{~kg}^{0.65} \mathrm{~m}^{-1.65} \mathrm{~s}^{-0.3}$. Turbulence intensity of 5\% [36] was specified.

At wall: No slip condition was specified as velocity boundary condition. Isothermal wall was specified $(3,000 \mathrm{~K}(5,400 \mathrm{R}))$ at the submerged wall. This is because calculations show the temperature to be uniform and the velocity is small in comparison with the accelerating flow in the nozzle. On the other hand, a specified axial surface temperature was assumed for the converging-diverging part of the nozzle and will be given later in the heat transfer section.

At exit: Supersonic boundary condition where the quantities $(P, T, u, v, \kappa, \varepsilon)$ are calculated from cells upstream of the exit was specified.

Computational Schemes: The segregated solver in the commercial code Fluent [40] was used. Differencing schemes utilized are $1^{\text {st }}$ and $2^{\text {nd }}$ order Upwind, Power law, and Quick schemes. The $1^{\text {st }}$ Upwind scheme was used to start the problem and the higher order schemes to obtain the final results. The $2^{\text {nd }}$ order Upwind and Quick schemes were found to give similar results in terms of mass flow rate and mass imbalance, head-end pressure, chamber pressure drop, and maximum Mach number at the nozzle exit.

Numerical Convergence (Residuals): Numerical convergence was achieved by satisfying four requirements in the following sequence. First, the residual error diminished as the number of iterations was increased. Second, the profiles of the variables ceased to change, at least qualitatively. Third, a first monitor on the total pressure at the propellant surface or at the flow inlet until the average total pressure ceased to change. Fourth, a second monitor on the mass imbalance between the inlet (propellant surface) and the outlet (nozzle exit) mass flow rates until it reached a small value $\left(10^{-3}-10^{-5} \mathrm{~kg} / \mathrm{s}\right)$.

Flow/Thermal Fields: Figure la shows the local Mach number distribution in the full motor. The maximum Mach number obtained is 3.56 at the nozzle exit plane at the centerline. Similarly, Figs. $1 \mathrm{~b}(1-5)$ shows the calculated Mach number in the cavity of the submerged region using the four 
turbulence Models (Table 1). They are plotted for the same range $(0<M \geq 0.01)$ and the same scale $(30,000)$ except Model 1 with the undersigned grid for $y^{+}$where the scale was reduced to a 1,000 . As the model is refined with the appropriate turbulence model, the re-circulation profile changed. Model 1 with the undersigned grid over-predicts the circulation motion. Models 1 and 2 are similar. Similarly, Models 3 and 4 are similar. Obviously, these models would have different effect on slag concentration and rate of accretion flux and will be discussed in relation to the discrete phase concentration and rate of accretion flux.

Figure $1 \mathrm{c}$ show the static temperature and stream function, respectively. A drop of $1750 \mathrm{~K}(3,150 \mathrm{R})$ in static temperature has occurred.

Bore Pressure Drop: Figure 2a shows the static pressure distribution in the whole motor. Figure $2 b$ shows the local axial static pressure along the centerline of the RSRM. The interest here is to compare the calculated pressure drop against measurements, matching head-end total pressure and numerical accuracy. Four solutions were conducted using a segregated solver along with a $2^{\text {nd }}$ orderUpwind differencing and in conjunction with the four turbulence models given in Table 2. A fifth solution was conducted using a coupled solver with the first turbulence model. The viscosity ratio (effective (laminar plus turbulent) to laminar) was limited to 10,000 to match the total pressure of 6.25 MPa (906 psia). Without limiting this viscosity ratio to 10,000 , the calculated chamber pressure (at some locations) is unrealistically higher than the known total chamber pressure with some differencing schemes.

Also shown the measurements of the local static pressure along QM-7 and QM-8 test motors. Qualitative agreement of the calculated local static pressure is achieved.

The ratio of the calculated head end pressure to the specified head end pressure $\left(P_{o, \max } / P_{o}\right)$ is calculated as $1.02,1.02,1.02,1.02$, and 1.06, respectively. Clearly, the head end pressure is overpredicted by 2 percent and 6 percent using the segregated and the coupled solver, respectively. Upstream of the nozzle throat, the ratio of the calculated head end pressure to the specified head end pressure $\left(P_{0}\left(x / r^{*} \equiv 64, \mathrm{y}=0\right) / P_{0}\right)$ is calculated as $0.8,0.80,0.80,0.80$, and 0.87 , respectively. Clearly, the head end pressure is over-predicted by 2 percent and 6 percent using the segregated and the coupled solver, respectively. Thus, the corresponding non-dimensional chamber pressure drops are $0.22, \quad 0.22,0.22,0.22$, and 0.19 . respectively. The first four solutions match the head-end pressure but not the pressure drop. The fifth solution over-predicts the head-end pressure but matches the chamber pressure drop. The recommended pressure drop is 18 percent as given from $[29,44]$. It is to be noted that the solution in [29] was conducted on Grid 1 (68,713 cells) with adiabatic walls, coupled solver (SHARP code), turbulence intensity of $5 \%$ and viscosity ratio of 10,000 .

Turbulence Modeling: Four turbulence models are 
utilized in this study and given in Table 2. Figure $3 a$ shows the calculated wall $y^{+}$along the convergingdiverging part of the nozzle using the four turbulence models. The non-dimensional velocity in wall coordinates $\left(u^{+}\right)$, non-dimensional distance from wall in wall coordinates $\left(y^{+}\right)$and frictional velocity are defined $[40,46]$ as

$$
\begin{aligned}
& u^{+}=\frac{u(y)}{u_{\tau}}, y^{+}=\frac{u_{\tau}\left(y_{w}-y\right)}{(\mu / \rho(y))} \\
& u_{\tau}=\left(\tau_{w} / \rho_{w}\right)^{1 / 2}
\end{aligned}
$$

The first two models give similar profiles and values from Grid 5. Since the values are between 20 and 100 , the first and second turbulence models used are consistent with grid resolution. The third and fourth turbulence models give similar profiles and values from Grid 6. The wall $y^{+}$calculated values using Grid 6 are shown to be below 8 ; therefore, using the third and fourth turbulence models are consistent with grid resolution. The results of calculated wall $y^{+}$for the third and fourth turbulence models are also shown separately in Fig. 3b for clarity. The calculated $y^{+}$could not be dropped without using a lot more cells in the stream-wise direction. The minimum spacing was specified as small as $10^{-4} \mathrm{~m}$ $\left(3.94 \times 10^{-3}\right.$ in. $)$.

Figure $3 \mathrm{c}$ shows the velocity law of the wall behavior of the boundary layer at the plane of the nozzle exit. The results using four turbulence models are shown. Also shown is the Spalding's velocity law of the wall [46] for incompressible flow:

$$
y^{+}=u^{+}+\exp (\kappa B)\left[\begin{array}{l}
\exp \left(\kappa u^{+}\right)-1 \\
-\kappa u^{+} \\
-\frac{\left(\kappa u^{+}\right)^{2}}{2} \\
-\frac{\left(\kappa u^{+}\right)^{3}}{6}
\end{array}\right]
$$

where $\kappa$ and $B$ are taken [46] as 0.4 and 5.5, respectively.

The first two models fall in the log-law and wake regions. The first flow cell is located at $y^{+}$of 22 . The third and fourth turbulence models compare well with the law of the wall in the inner layer but not in log-law region. The first flow cell is located at $y^{+}$of 1.5. Similarly, Fig. 3d shows the temperature law of the wall at the plane of the nozzle exit. The temperature law of the wall is given [47] as

$$
\begin{aligned}
& t^{+}=\operatorname{Pr} y^{+} ; y^{+} \leq 13.2 \\
& t^{+}=13.2 \operatorname{Pr}+\frac{\operatorname{Pr}_{t}}{\ell} \ln \left(\frac{y^{+}}{13.2}\right) ; \\
& y^{+} \geq 13.2
\end{aligned}
$$

where the non-dimensional temperature in wall coordinates is defined [47] as

$$
t^{+}=\frac{\left(\bar{T}-T_{s}\right)\left(\tau_{w} / \rho\right)^{1 / 2}}{q_{w}^{\prime \prime} /(\rho c)}
$$

and where $P r_{\text {, }}$ and $l$ are taken as 0.85 and 0.41 , respectively. The results using four turbulence models are shown. They fall on top of each other but they do not extend the same values of $y^{+}$. Also shown is the thermal law of the wall for air taken from Kays and Crawford [47] for turbulent flow.

Convective Heat Transfer: Figure 4a shows the submerged and nozzle walls and the specified 
surface temperature used as thermal boundary conditions. The submerged wall was assumed to be isothermal at $3,000 \mathrm{~K}(5,500 \mathrm{R})$. On the other hand, a specified axial surface temperature was assumed for the converging-diverging wall of the nozzle as shown in Fig. 4a. The surface temperature profile was taken from [48] and curve-fitted by this author using TableCirve2D [49] as

$$
T_{s}=\frac{a+c x+e x^{2}+g x^{3}+i x^{4}+k x^{5}}{1+b x+d x^{2}+f x^{3}+h x^{4}+j x^{5}}
$$

where $x$ is taken along the nozzle surface and where the coefficients are given as follows: $a=2789.03, b$ $=-4.61, c=-13307.21, d=11.96, e=32905.45, f=$ $-6.33, g=-20712.33, h=-0.916, j=1174.06$ and $k=815.51$. The correlation coefficient, $\mathrm{r}^{2}=0.997$. A user defined function (UDF) was used to compile the specified surface temperature profile. Assuming this surface temperature profile enables the calculation of the heat flux that in turn enables the calculation of the convective heat transfer coefficient depending on the assumption of a reference temperature. Calculated centerline and recovery temperatures are also shown and will be discussed shortly.

In the present study, the ratio of the convective heat transfer coefficient and the specific heat at constant pressure is calculated by two methods. This ratio is used as an input in the CMA code [50] for nozzle erosion predictions. In Method 1, it is calculated internally using the calculated heat flux based on the difference between the local specified surface temperature and the chamber temperature (used as a reference temperature for simplicity), i.e.,

$$
\frac{h_{1}(x)}{C_{p}} \equiv \frac{q_{w}(x)}{C_{p}\left[T_{o}-T_{s}(x)\right]}
$$

and shown in Fig. $4 b(1)$. Figure $4 b(2)$ is a magnification of the throat region and taken from Fig. $4 b(1)$ for clarity

In Method 2, it is calculated using the recovery temperature and defined as

$$
\frac{h_{2}(x)}{C_{p}} \equiv \frac{q_{w}(x)}{C_{p}\left[T_{r \infty}(x)-T_{s}(x)\right]}
$$

And shown in Fig. 4b(3). The recovery temperature [47] is given as

$$
T_{r \infty}(x) \equiv T_{\infty}(x)+\Re\left[T_{0}-T_{\infty}(x)\right]
$$

and where $\Re=P r^{1 / 3}$ is used for turbulent flow and is calculated to be 0.8 . The temperature at the edge of the boundary conditions has been replaced by the local axial static temperature along the motor centerline and shown Fig. 4a. The recovery temperature is calculated at the motor centerline and shown in Fig. 4a to be less than the chamber pressure. The chamber and recovery temperature are matched only by taking $\operatorname{Pr}$ as 1 which yields I for $\Re$ which correspond to an ideal situation. Figure $4 b(4)$ is a magnification of the throat region and taken from Fig. $4 b$ (3) for clarity.

The above two heat transfer coefficients are calculated in conjunction with the four turbulence models given in Table 2. Also shown, is the calculated $h / C_{p}$, from measured data [48] to match maximum measured erosion. This measured $h / C p$ is a result of heat transfer (convective, radiative and conductive), chemical, and particle impingement.

Furthermore, additional results from the Turbulent Boundary Layer (TBL) code [51] are also 
shown. The TBL predictions overestimate the ratio of $h / C p$ in most part of the converging-diverging part of the nozzle. The TBL routine [51] of the SPP code [42] is an integral method that uses the boundary-layer edge conditions from the twodimensional, two-phase flow program of SPP program [42]. On the other hand, it underestimates the ratio in the last one-third of the diverging section of the nozzle. This may be due to the lack of particle impingement treatment in the TBL code [51].

The measured values [48] of $h / C p$ are the net result of many effects such as convective, radiative. particle impingement, chemical reactions, and others. Therefore, calculating $h / C p$ from Methods 1 and 2 and comparing them with the measured data [48] in a relative manner would be a sound approach. The following is a discussion of the results of each turbulence model used.

\section{(A) Based on Method 1 (Eq. (6)):}

(1) Model 1, Grids 2 and 5: The first turbulence model on Grids 2 and 5 overestimates the ratio of $h / C p$ in the whole nozzle except in a small portion at the nozzle exit. It underestimates it in the diverging section of the nozzle. The ratio $h / C p$ drops at the nozzle throat and then increases then decreases in the convergent section of the nozzle.

(2) Model 2, Grid 5: The second turbulence model matches the measured ratio of $h / \mathrm{Cp}$ in the converging part of the nozzle. It drops significantly at the throat and increases again and underestimates it in the diverging section of the nozzle. Again, the calculated ratio $\mathrm{h} / \mathrm{Cp}$ does not include the effect of particle impingement.

(3) Model 3, Grid 6: The third turbulence model matches the measured ratio of $h / C p$ in the converging part of the nozzle. It underestimates it at the throat region. It underestimates it in the diverging section of the nozzle. Again, the calculated ratio $h / C p$ does not include the effect of particle impingement.

(4) Model 4, Grid 6: The fourth turbulence model behaves similarly to the third model.

It can be concluded that Model 2 on Grid 5 gives the best results in relative comparison with the measured data [48] as shown in Fig. $4 b(2)$. Furthermore, it does not require the grid refinement as required for the two-layer zonal model. Thus the execution time is much less.

\section{(B) Based on Method 2(Eq, (7)}

The results of Method 2 differ from Method 1 in the divergent section of the nozzle. Method 2 is more sensitive at the throat and downstream at the throat than Method 1. It overestimates the ratio $h / C p$ at the throat. Method 2 neither follows the profile qualitatively from the measured values nor follows the usual profile from Bartz correlation [30]. The author concludes the Method 1 is more appropriated than Method 2.

The four turbulence models show three common behaviors:

- First: the maximum convective heat transfer coefficient is upstream of the nozzle throat.

- Second: the profile of the calculated ratio $h / C p$ from Simulation 1 and along the nozzle wall is analogous to the $y^{+}$distribution shown in Fig. $3 \mathrm{a}$ 
and 3b. This confirms the interdependency of heat transfer on the turbulence model used, is directly consistent with the grid resolution.

- Third: in the vicinity downstream of the nozzle throat, the ratio $h / C p$ decreases suddenly and increases again.

The sudden drop in $h / C p$ is attributed to the large drop in the specified surface temperature (Fig. 4a). In the vicinity of the throat, the surface temperature dropped by $590 \mathrm{~K}$ within $0.5 \mathrm{~m}$ (1062 R within 1.64 $\mathrm{ft}$ ). This was easily verified by specifying uniform surface temperature at $2000 \mathrm{~K}$, respectively. The sudden drop in $h / C p$ was not calculated using an isothermal boundary condition. The nozzle wall is an ablating (transpiring) surface. The boundary layer adjacent to the nozzle wall would be oxidizerpoor that inhibit chemical reactions and heat transfer. A transpiring surface is not modeled in this study. It may show a drop in the convective heat transfer.

Figure $4 \mathrm{c}$ shows the local shear stress along the nozzle wall calculated using four turbulence models as given in Table 2. Figure $4 \mathrm{~d}$ shows the corresponding local skin friction coefficient along the nozzle wall. It has the following usual definition.

$$
\frac{C_{f}}{2}=\frac{\tau_{s}}{\rho_{\infty} u_{\infty}^{2}}
$$

Figure $4 \mathrm{e}$ shows the corresponding local Reynolds number along the centerline based on local nozzle diameter.

For fully developed pipe flow, the nondimensional pressure gradient along the nozzle wall is calculated as

$$
P_{1}^{+}=-\frac{14}{\operatorname{Re}_{d}\left(C_{f} / 2\right)^{1 / 2}}
$$

and shown in Fig. 4f. The Van Driest constant is a measure of viscous sublayer thickness and is given [47] as

$$
A_{1}^{+}=-\frac{26}{a\left[v_{0}^{+}+b\left(\frac{P_{1}^{+}}{1+c v_{0}^{+}}\right)\right]+1}
$$

where $a, b$, and $c$ are taken as $7.1,4.25$, and 10.0 [47], respectively. It is equal to 26 for a zero pressure gradient boundary layer without wall transpiration. Assuming no wall transpiration, $\mathrm{Al}_{l}^{+}$ was calculated and shown in Fig. $4 \mathrm{~g}$. It has the opposite profile of $P_{I}^{+}$.

The corresponding $\mathrm{P}_{2}^{+}$and $\mathrm{A}_{2}^{+}$for a simple external boundary layer are calculated respectively as

$$
P_{2}^{+}=\frac{K}{\left(C_{f} / 2\right)^{3 / 2}}
$$

and

$$
A_{2}^{+}=-\frac{25}{a\left[v_{0}^{+}+b\left(\frac{P_{2}^{+}}{1+c v_{0}^{+}}\right)\right]+1}
$$

and shown in Figs. $4 \mathrm{~h}$ and $4 \mathrm{i}$. In the above, $K$ is an acceleration parameter and is calculated from [47] as

$$
K=\frac{\mu_{\infty}}{\rho_{\infty} u_{\infty}^{2}}\left(\frac{d u_{\infty}}{d x}\right) \geq 3 \times 10^{-6}
$$
and shown in Fig. 4 j. The calculated values of $K$ are smaller then the transition value of $3 \times 10^{-6}$. Therefore, re-laminarization of the turbulent boundary layer did not occur. Additionally, the non- 
dimensional pressure gradient is defined as

$$
P^{+}=\frac{\mu(d \bar{P} / d x)}{\rho^{1 / 2} \tau_{s}^{3 / 2}}
$$

Two-Phase Modeling: The two phases are continuous phase (combustion gas) and a discrete phase (aluminum oxide droplets $\left.\left(\mathrm{Al}_{2} \mathrm{O}_{3}\right)\right)$. Since droplet agglomeration/breakup is not modeled, they are assumed spherical and of a constant size distribution anywhere in the motor. Solid spherical particles are injected at propellant surface (Simulation 1) and at the flow inlet (Simulation 2).

The particle size and distribution used in this study were based on investigation [25] into the effects of ingredient property variation on RSRM TP-H1148 production propellant. Aluminum oxide caps fraction is the total fraction of aluminum that is converted to large $\mathrm{Al}_{2} \mathrm{O}_{3}$ discrete phase particles after combustion is complete and is taken from [27] as:

$$
f_{\text {Alumina }}=0.2833
$$

The remaining aluminum oxide in the form of smoke is therefore

$$
f_{\text {smoke }}=1-f_{\text {Alu min a }}=0.7167
$$

The discrete phase portion of the total particulate population (Alumina) is taken as

$$
f_{D P}=f_{\text {Alu } \min a} / 3=0.0944
$$

The mass flow rate of the discrete phase is calculated in relation with the continuous phase (gas) as follows:

$$
\begin{aligned}
& \dot{m}_{D P}=\left(f_{D P}\right)\left(m_{g} \cdot C F D . \text { Culctuluted }\right) \\
& =0.0944\left(m_{g, \text { CFi). Cull witured }}\right)
\end{aligned}
$$

Inert particles of density of $1601.85 \mathrm{~kg} / \mathrm{m}^{3}$ (100 $\left.\mathrm{lbm} / \mathrm{ft}^{3}\right)$, thermal conductivity of $10.47 \mathrm{~W} / \mathrm{m}-\mathrm{K}(6.05$ Btu/hr-ft-R), and specific heat of $1800.32 \mathrm{~J} / \mathrm{kg}-\mathrm{K}$ (0.43 Btu/lbm-R) are specified. The molecular weight of the gas was calculated as

$$
M W=\frac{18.76+7.58 f_{\text {smoke }}}{0.926}
$$

which gives $26.07 \mathrm{~kg} / \mathrm{kgmole}$.

Particle size distribution for the alumina included in the discrete phase was defined by fitting the size distribution to the Rosin-Rammler equation [Chap. 14 of 40]. In this approach, the complete range of particle sizes is divided into a set of discrete size ranges, each to be defined by a single stream that is part of the group. The particle size data obeys the distribution shown in Fig. 5a and is curve-fitted as

$$
M_{D}=a \exp (-D / b)
$$

where the coefficients $a$ and $b$ are calculated to be 1.01475 and 86.5651 , respectively and with a coefficient of determination of 0.99 .

The Rosin-Rammler distribution function is based on the assumption that an exponential relationship exists between the particle diameter. $(D)$, and the mass fraction of particles with diameter greater than $D, M_{D}$ as

$$
M_{D}=\exp \left[-\left(\frac{D}{\bar{D}}\right)^{N}\right]
$$

where $\bar{D}$ is the mean diameter and $N$ is the spread parameter. The average diameter is obtained by noting that the value of $D$ at which $M_{D}=\exp (-1)=$ 0.368 . From the above figure, the average diameter is $87.53 \mu \mathrm{m}$. The numerical value of the spread parameter is calculated from the above relationship 
as

$$
N=\frac{\ln \left(-\ln M_{D}\right)}{\ln (D / \bar{D})}
$$

Substituting the values, an average value for $N$ was calculated to be 1.1426 . In summary, 8 discrete particle sizes ranging from 10 to 600 microns with a mean diameter of $87.80 \mu \mathrm{m}$ and a spread of 1.1428 were specified.

In Simulation 1, particles are injected at zero velocity and at $0 \%$ temperature lag (equal to gas temperature). The walls of the submerged region and nozzle are set as trap walls for particles upon impact as boundary conditions. Propellant surface was set as a reflecting surface for particles.

Particle concentration is a flow quantity that exists in the flow field and at the wall. The particle trajectories and their local $\mathrm{Al}_{2} \mathrm{O}_{3}$ concentrations are of interest to understand the submerged region and nozzle environments in terms of insulation performance and possibly $\mathrm{Al}_{2} \mathrm{O}_{3}$ slag rate of accretion flux or accumulation. Figures $5 b$ and $5 c$ show the calculated $\mathrm{Al}_{2} \mathrm{O}_{3}$ local concentration along the submerged and nozzle walls, respectively. The maximum calculated concentrations are found to be $6.28 \mathrm{~kg} / \mathrm{m}^{3} \quad\left(0.39 \mathrm{lbm} / \mathrm{ft}^{3}\right)$ and $0.3 \mathrm{~kg} / \mathrm{m}^{3} \quad(0.02$ $\left.\mathrm{lbm} / \mathrm{ft}^{3}\right)$, respectively.

Figures $5 \mathrm{~d}$ and $5 \mathrm{e}$ show the calculated $\mathrm{Al}_{2} \mathrm{O}_{3}$ rates of accretion fluxes along the submerged and nozzle wall, respectively. The maximum calculated rate of accretion fluxes are found to be $15 \mathrm{~kg} / \mathrm{m}^{2}-\mathrm{s}(3.07$ $\left.\mathrm{lbm} / \mathrm{ft}^{2}-\mathrm{s}\right)$ and $12 \mathrm{~kg} / \mathrm{m}^{2}-\mathrm{s} \quad\left(2.46 \mathrm{lbm} / \mathrm{ft}^{2}-\mathrm{s}\right)$, respectively. The maximum occurs further upstream on the submerged wall.

\section{Simulation 2: Four-degree Vectored Nozzles for the RSRM and FSM}

Results similar to those for Simulation 1 are sought in Simulation 2. Additionally, the effects of nozzle vectoring on the above parameters are also included and discussed.

Simulation 2 involves two three-dimensional aft motors with vectored nozzles for the RSRM and the FSM as shown Figs. $6 \mathrm{a}$ and $6 \mathrm{~b}$, respectively. The solution domain extends from 0 to 180 degrees segment with a plane of symmetry boundary conditions were used for the 0 to 180 degrees. Table 1 gives motor chamber, nozzle throat, and nozzle exit diameters and the corresponding area ratios. Differences in motor geometries are not clear in these two figures. Therefore, Figs. $6 \mathrm{c}$ and $6 \mathrm{~d}$ are shown to give the details of the $3 \mathrm{D}$ grid on the symmetry planes of the RSRM and the FSM motors, respectively. The two nozzles are vectored downward. This causes the bottom halves of the RSRM and FSM nozzles, to protrude ahead in the flow field. In addition, the cavity at the bottom becomes larger than the cavity on the top side. Similarity between the grids will be verified by the calculated wall $y^{+}$and will be given later.

Grid-independent results in the three-dimensional analyses are cost and time prohibitive. In addition, since the interest is in comparing the results of the two motors (in terms of an increase or decrease), the approach was taken to make the two grids as comparable as possible in terms of similar number of cells (approximately 325,000 hexahedral cells 
each) and similar local clustering of cell sizes in the gridding process. A finer grid for the FSM motor was conducted for sensitivity studies and given in Table 1.

Boundary Conditions: The geometry considered is a representative of late burn time. The boundary conditions in Simulation 2 are as follows:

At the inlet: An assumed uniform total pressure and temperature, calculated velocity that is normal to inlet, an assumed turbulence intensity $(I)$, and a hydraulic diameter $\left(d_{h}\right)$ were specified

$$
P_{0}=c, T_{0}=c, \theta=0
$$

A total pressure (4.25 $\mathrm{MPa}(616 \mathrm{psia}))$ and total temperature ( $3368 \mathrm{~K}(6062.4 \mathrm{R})$ ), turbulent intensity of $5 \%$ and the hydraulic diameters (Table 1) were specified. The velocity components are calculated. This chamber pressure along with propellant formulation was used as input to the NASA-Lewis program [45] or the ODE module of the SPP code [42] to obtain chamber gas temperature, molecular weight, dynamic viscosity, thermal conductivity, and specific heat at constant pressure. They are $\left.\begin{array}{llllll}\text { respectively } & 3368.32 & \mathrm{~K} & (6062.96 & \mathrm{R}\end{array}\right), \quad 28.378$ $\mathrm{kg} / \mathrm{kgmole}, 9.582 \times 10^{-5} \mathrm{~N}-\mathrm{s} / \mathrm{m}^{2}\left(6.439 \times 10^{-5} \mathrm{lbm} / \mathrm{ft}-\right.$ $\mathrm{sec}), 0.383 \mathrm{~W} / \mathrm{m}-\mathrm{K}(0.22 \mathrm{Btu} / \mathrm{hr}-\mathrm{ft}-\mathrm{R})$ and 2002.97 $\mathrm{J} / \mathrm{kg}-\mathrm{K}(0.478 \mathrm{Btu} / \mathrm{lbm}-\mathrm{R})$. The reference pressure is taken as $4.3 \mathrm{MPa}$ (625 psia). Turbulent intensity of $5 \%$ [36] and the hydraulic diameter were specified.

At wall: No slip condition for the velocity. The submerged wall was assumed to be isothermal at $3,000 \mathrm{~K}(5,500 \mathrm{R})$. On the other hand, a specified axial surface temperature was assumed for the converging-diverging wall of the nozzle as shown in Fig. $4 \mathrm{a}$ as in Simulation 1.

At exit: Supersonic boundary condition where the quantities $(P, T, u, v, w, \kappa, \varepsilon)$ are calculated from cells upstream of the exit.

Computational Schemes: A segregated solver was used. Differencing schemes utilized are $1^{\text {st }}$ and $2^{\text {nd }}$ order Upwind, Power law, and Quick schemes. The $1^{\text {st }}$ Upwind scheme was used to start the problem and the higher order schemes to obtain the final results. The $2^{\text {nd }}$ order Upwind and Quick schemes were found to give similar results in terms of mass flow rate and mass imbalance, head-end pressure, chamber pressure drop, and maximum Mach number at the nozzle exit.

\section{Numerical Convergence (Residuals): Numerical} convergence was achieved by satisfying four requirements in the following sequence. First, the residual error diminished as the number of iterations was increased. Second, the profiles of the variables ceased to change, at least qualitatively. Third, a first monitor on the total pressure at the propellant surface or at the flow inlet until the average total pressure ceased to change. Fourth, a second monitor on the mass imbalance between the inlet (propellant surface) and the outlet (nozzle exit) mass flow rates until it reached a small value $\left(10^{-3}-10^{-5} \mathrm{~kg} / \mathrm{s}\right)$.

Flow Fields: Figures $7 \mathrm{a}$ and $7 \mathrm{~b}$ show the flow field depicted in terms of the velocity magnitude in the RSRM and the FSM motors respectively. A circumferential flow developed from the bottom half (due to a circumferential pressure gradient) to the upper half (lower pressure) in the submerged 
regions of the two motors. The circumferential flow emanates from the bottom half and moves to the upper half. This means that, under vectoring, the upper and lower halves experience different flow/thermal environments. The flow originates at bottom, moves circumferentially, and is flushed from the top half.

Figures $7 \mathrm{c}$ and $7 \mathrm{~d}$ show the velocity magnitude in the aft motor chamber for the vectored nozzle simulations of the RSRM and the FSM, respectively. Average inlet velocities are calculated to be $116 \mathrm{~m} / \mathrm{s}(380.6 \mathrm{ft} / \mathrm{s})$ and $93 \mathrm{~m} / \mathrm{s}(305.1 \mathrm{ft} / \mathrm{s})$ in the FSM and RSRM, respectively. The resulting ratio between the inlet velocity magnitudes is 1.25 . In the case where the chamber pressure and temperatures are the same as in this analysis, this translates into an increase of $25 \%$ in the mass flow rate of the FSM in comparison with the RSRM. This is only due to the opening of the throat in the FSM in comparison to the RSRM. Vortices have developed in the bottom halves of the two motors and not in the top.

Figures $8 \mathrm{a}$ and $8 \mathrm{~b}$ show the Mach number distributions in the vectored nozzles of the RSRM and the FSM, respectively. The overall profiles in the two motors are qualitatively similar. The maximum Mach numbers were calculated to be 3.33 and 3.25 in the RSRM and FSM, respectively. They are respectively $93 \%$ and $91 \%$ of the maximum Mach number (3.54) calculated in the 2-D axisymmetric (Simulation 1). The FSM geometry has a larger throat and a smaller expansion area ratio in comparison with the RSRM. Grid 3 of the FSM comprises 1,129,104 hexahedral and uniform cells which are approximately 3.5 times larger than the cells in Grid 1 (324,000 hexahedral cells). It is not designed to lower wall $y^{+}$as in other grids. Rather, it is to verify sensitivity of the decrement in maximum exit Mach number. The maximum calculated Mach number on a larger grid (Grid 3) for the FSM is calculated to be 3.25. Therefore, the difference in exit Mach numbers between the 2Daxisymmetric and $3 \mathrm{D}$ appears to be because of vectoring and not the grid size or refinement.

Figures $9 \mathrm{a}$ and $9 \mathrm{~b}$ show the local static pressure distributions in the vectored nozzle simulations of the RSRM and the FSM, respectively. The overall profiles are qualitatively similar. The total boundary condition was set at the inlet of both motors to be the same. As expected, the overall static pressure distribution is the same in the two chambers. The minimum static pressure at the exit of the RSRM (0.23 atm (3.39 psia)) is lower than the minimum static pressure at the exit of the FSM (0.31 atm (4.52 psia)). This is because of the slight difference in expansion area ratio. The static pressure is approximately equal to the total pressure set at the flow inlet boundary condition, which is approximately 4.25 MPa (616 psia).

Figures $9 \mathrm{c}$ and $9 \mathrm{~d}$ show the local circumferential static pressure distributions in the vectored nozzles of the RSRM and the FSM, respectively. The planar distributions are selected in the submerged region of each motor. They are geometrically parallel to the flow inlet and perpendicular to the flow direction. They show the pressure to vary axially and 
circumferentially. The variation increases as the axial distance increases in the submerged region. The max variation of static pressure in the cavity volume amounts to 0.14 to $0.27 \mathrm{~atm}$ ( 2 to 4 psid). The circumferential static pressure in the deepest plane is a fraction of this maximum.

\section{Pressure Gradient in the Submerged Region of} the Nozzle: Figures $9 \mathrm{c}$ and $9 \mathrm{~d}$ show the static pressure gradient in the submerged regions of the nozzles of the RSRM and FSM. It varies axially, radially and circumferentially. Figure $9 \mathrm{e}$ is a simplified version. The deepest plane has been reduced to a ring to narrow the circumferential pressure gradient.

In the axial direction: In the RSRM, the present results show a maximum axial drop in the static pressure (at $\left.\theta=40^{\circ}\right)$ of $0.06 \mathrm{~atm}(0.87 \mathrm{psid}$ ). In the FSM, the corresponding maximum axial drop in the static pressure (at $\theta=40^{\circ}$ ) of 0.11 atm (1.68 psid) was calculated.

In the radial direction: A maximum of $0.01 \mathrm{~atm}$ $(0.1 \mathrm{psid})$ and $0.01 \mathrm{~atm}(0.18 \mathrm{psid})$ circumferential pressure gradient occurred in the RSRM and the FSM, respectively.

In the circumferential direction: In the RSRM, the present results show a maximum axial drop in the static pressure (between $\theta=-90^{\circ}$ and $40^{\circ}$ ) of 0.0 atm $(0.02$ psid $)$. In the FSM, the corresponding maximum axial drop in the static pressure (between $\theta=-90^{\circ}$ and $\left.40^{\circ}\right)$ of 0.07 atm (1.0 psid) was calculated. For engineering design, the circumferential pressure differential between the chamber pressure at the angle of $\theta=-90^{\circ}$ to the angle of $\theta=30^{\circ}$ should be considered. This would result in a maximum circumferential pressure differential of $0.06 \mathrm{~atm}(0.87 \mathrm{psid})$ and $0.11 \mathrm{~atm}$ (1.68 psid) in the RSRM and FSM, respectively.

Also shown in the figure, cold flow experimental results from Whitesides et al [7]. The tests were conducted in the NASA Marshall Space Flight Center Air flow facility with a 7.5 percent scale model of the aft segment of the RSRM. Static and dynamic pressure were measured in the model for nozzle vector angles of $0^{\circ}, 3.5^{\circ}$, and $7^{\circ}$ with propellant configuration corresponding to motor burn times of $0,9,19$, and $114 \mathrm{~s}$. The experimental results [7] as given assume no axial pressure drop. The maximum circumferential pressure gradient occurs at $19 \mathrm{sec}$ and amounts to $0.07 \mathrm{~atm}(1.05$ psid). This is larger than the calculated value in the present calculation.

Turbulence Modeling: Figures 10a and 10b show the local calculated wall $y^{+}$of the RSRM and the FSM, respectively. Two curves are shown for the submerged wall and 2 curves for the nozzle wall. One curve pertains to the bottom surface and the second pertains to the top surface and 180 degrees apart. The two surfaces lie on the symmetry plane. Note the lower half protrudes slightly ahead of the upper half. Since most of the calculated wall $y^{+}$are higher than 100 on this coarse grid, the standard $\kappa-\varepsilon$ model with the standard wall functions (high $R e \kappa-\varepsilon$ turbulence model) and $\kappa-\varepsilon$ RNG (renormalization group theory) with standard wall functions were used to calculate the final results on Grid 1. The similarity of the calculated $y^{+}$values for the two 
motors indicates the similarity of the two grids. This is not fortuitous or accidental. Two simultaneous GRIDGEN sessions were active. Adjustments made (number of cells and spacing) for one grid were duplicated on the other and vice versa. The wall $y^{+}$is a function of Mach number and cell size adjacent to the wall. The maximum calculated wall $y^{+}$in the submerged regions of the RSRM and the FSM are 1871 and 1986, respectively. Similarly, the maximum calculated wall $y^{+}$in the nozzle regions of the RSRM and the FSM are 1861 and 1852 , respectively.

Heat Transfer: The specified surface temperatures at the submerged and nozzle walls used in the twodimensional axisymmetric analysis (Simulation 1) are used here in the $3 \mathrm{D}$ vectored nozzle of the RSRM and FSM, respectively. It is shown in Fig. $4 \mathrm{a}$ and calculated as a function of only the axial location for each motor. It is invariant in the circumferential direction.

The calculated profiles are shown in Figs. $11 \mathrm{a}$ and $11 \mathrm{~b}$ for the RSRM and FSM, respectively. The maximum calculated $h / C p$ in the submerged regions of the RSRM and the FSM are $4.59 \mathrm{~kg} / \mathrm{m}^{2}-\mathrm{s}(0.94$ $\left.\mathrm{lbm} / \mathrm{ft}^{2}-\mathrm{s}\right)$ and $4.54 \quad \mathrm{~kg} / \mathrm{m}^{2}-\mathrm{s} \quad\left(0.93 \quad \mathrm{lbm} / \mathrm{ft}^{2}-\mathrm{s}\right)$, respectively. Comparable convective heat transfer environment in the chambers of the RSRM and the FSM have been calculated. Similarly, the maximum calculated $h / C p$ in the nozzle regions of the RSRM and the FSM are $4.20 \mathrm{~kg} / \mathrm{m}^{2}-\mathrm{s}\left(0.86 \mathrm{lbm} / \mathrm{ft}^{2}-\mathrm{s}\right)$ and $4.74 \mathrm{~kg} / \mathrm{m}^{2}-\mathrm{s}\left(0.97 \mathrm{lbm} / \mathrm{ft}^{2}-\mathrm{s}\right)$, respectively. An increase in the convective heat transfer environment of $13 \%$ in the FSM in comparison of the RSRM has occurred.

Two-Phase Modeling: Same assumptions and treatments used in Simulation 1 were used in Simulation 2 with one exception. In Simulation 2, particles are injected at the flow inlet (vs. propellant surface as done in Simulation 1). In both simulations, particles are injected at approximately zero velocity lag and zero temperature lag. This is because at that axial location (flow inlet), it is assumed the particles have accelerated and assumed the gas velocity with very small velocity lag.

Figures $12 \mathrm{a}$ and $12 \mathrm{~b}$ show the local discrete phase model (DPM) of $\mathrm{Al}_{2} \mathrm{O}_{3}$ concentration calculated in the RSRM and FSM, respectively. It shows local variation between the top and bottom sides in each motor and between the two motors. The maximum $\mathrm{Al}_{2} \mathrm{O}_{3}$ concentrations in the submerged regions of the RSRM and FSM were calculated to be $6.51 \mathrm{~kg} / \mathrm{m}^{3}\left(0.41 \mathrm{lbm} / \mathrm{ft}^{3}\right)$ and 3.37 $\left(0.21 \mathrm{lbm} / \mathrm{ft}^{3}\right)$ in the RSRM and FSM, respectively. The maximum $\mathrm{Al}_{2} \mathrm{O}_{3}$ concentration occurred at the converging part of nozzle and on the half that is protruding ahead in the flow due to vectoring. The maximum $\mathrm{Al}_{2} \mathrm{O}_{3}$ concentrations in the nozzle regions of the RSRM and FSM were calculated to be 0.35 $\mathrm{kg} / \mathrm{m}^{3}\left(0.02 \mathrm{lbm} / \mathrm{ft}^{3}\right)$ and $0.43\left(0.03 \mathrm{lbm} / \mathrm{ft}^{3}\right)$ in the RSRM and FSM, respectively.

Figures $13 \mathrm{a}$ and $13 \mathrm{~b}$ show the discrete phase model (DPM) $\mathrm{Al}_{2} \mathrm{O}_{3}$ rates of accretion fluxes in the RSRM and FSM, respectively. The slag rates of accretion fluxes in the submerged regions of the RSRM and FSM were calculated to be $41.52 \mathrm{~kg} / \mathrm{m}^{2}-$ $\mathrm{s}\left(8.50 \mathrm{lb}_{\mathrm{m}} / \mathrm{ft}^{2}-\mathrm{s}\right)$ and $42.2 \mathrm{~kg} / \mathrm{m}^{2}-\mathrm{s}\left(8.64 \mathrm{lb}_{\mathrm{m}} / \mathrm{ft}^{2}-\mathrm{s}\right)$, 
respectively. Similarly, slag rates of accretion fluxes in the nozzle regions of the RSRM and FSM were calculated to be $6.50 \mathrm{~kg} / \mathrm{m}^{2}-\mathrm{s}\left(1.33 \mathrm{Ib}_{\mathrm{m}} / \mathrm{ft}^{2}-\mathrm{s}\right)$ and $7.6 \mathrm{~kg} / \mathrm{m}^{2}-\mathrm{s}\left(1.56 \mathrm{lb}_{\mathrm{m}} / \mathrm{ft}^{2}-\mathrm{s}\right)$, respectively. $\mathrm{A}$ similar rate of accretion flux occurred in the FSM and in the RSRM.

It is to be noted that no particle break-up was modeled. Therefore, the calculated concentrations or rates of accretion fluxes may not be accurate in the nozzle past the throat. They are meant to show the trend.

Vacuum Thrust and Specific Impulse Calculations: The nozzle thrust was calculated [52] as

$$
F=\oiint u(\rho V \cdot n) d A+\left(P_{e}-P_{\infty}\right) A_{e} \quad(12 \mathrm{a})
$$

and vacuum thrust was calculated as

$$
F_{\text {vac }}=\oiint u(\rho V . n) d A+P_{e} A_{e}
$$

and the vacuum $I_{s p}$ is calculated as

$$
I_{s p \text {.vac }}=\frac{F_{v a c}}{m g}
$$

A user defined function (UDF) was written to calculate mass flow rate, thrust, and vacuum $I_{s p}$ on demand. Chamber pressures and nozzle expansion ratios used are shown in Figs. $14 a$ and $14 b$, respectively. The calculated mass flow rates, vacuum thrust and vacuum specific impulse are shown in Figs. 14c, 14d, and 14e, respectively. The calculated mass flow rates shown in Fig. $14 \mathrm{c}$ for the $3 \mathrm{D}$ analyses are lower that the values calculated in the $2 \mathrm{D}$ axisymmetric analyses. This is because they were conducted at a later burn time that corresponds to a lower chamber pressure of $4.25 \mathrm{MPa}$ (616 psia).
The 2D-axisymmetric analyses were conducted at a higher chamber pressure of $6.25 \mathrm{MPa}$ (906 psia). Thus, the calculated values for the thrust shown (Fig. 14d) have similar behavior. The ratio of the above is shown as a specific impulse and shown in Fig. 14e. The 3D results show lower specific impulse because of $3 D$ vectoring of the nozzle. The FSM has a higher specific impulse because of the higher mass flow rate.

\section{Summary and Conclusions}

Based on the 2D-axisymmetric analyses (Simulation 1), the following conclusions have been reached:

- Significant effort has been expended in gridding and calculation of the wall $y+$ in conjunction of consistent turbulence models.

- Convective heat transfer coefficients have been calculated using two methods and 4 turbulence models. They have been compared with measurements, turbulent boundary layer (TBL) theory code. Based on the present results of heat transfer coefficients and economy, turbulence Model 2 on Grid 5 ( $\kappa-\varepsilon$ RNG with standard wall functions as given in Tables 1 and 2) gives the best results in relative comparison with the measured data [48]. Models 3 and 4 (Table 2) also give similar results but time and cost prohibitive.

Based on the $3 D$ four-degree vectored nozles (Simulation 2), the following conclusions have been reached:

- Chamber: Calculated chamber velocity magnitude in the FSM is $25 \%$ higher in comparison 
with the RSRM. This is mainly due to the slight opening of the nozzle throat. A side from issues concerning erosive burning and maximum chamber head-end pressure, the overall behavior of the two motors is similar in terms of Mach number and static pressure drop.

Submerged Region: Static pressure varies axially, radially, and circumferentially in the submerged region of the FSM and the RSRM. A maximum circumferential pressure differential of $0.06 \mathrm{~atm}$ (0.87 psid) and $0.11 \mathrm{~atm}$ (1.68 psid) have occurred in the RSRM and FSM, respectively. The submerged region in the FSM would see a similar convective thermal environment in comparison with the RSRM. $\mathrm{Al}_{2} \mathrm{O}_{3}$ concentration and rate of accretion are similar in the FSM and the RSRM.

Nozzle: Slight decrease in the maximum Mach number at the nozzle exit. The nozzle in the FSM would see a $12 \%$ increase in the convective thermal environment in comparison with the RSRM. $\mathrm{Al}_{2} \mathrm{O}_{3}$ concentration is much higher in the FSM than in the RSRM. $\mathrm{Al}_{2} \mathrm{O}_{3}$ rate of accretion flux in the FSM is about $20 \%$ higher than in the RSRM.

\section{References}

1. Boraas, S., "Modeling Slag Deposition in the Space Shuttle Solid Rocket Motor," Journal of Spacecraft and Rockets, Vol. 21, No. 1, Jan.-Feb. 1984, pp. 47-54.

2. Murdock, J.W., "Rocket Thrust Perturbation from Discharge of an Inert Body," Journal of Propulsion and Powers, Vol. 2, No. 2, March - April 1986, pp. 117-123.
3. Traineau, J-C. Hervat, P. and Kuentzmann, P., "Cold-Flow Simulation of a Two-Dimensional Nozzleless Solid Rocket Motor," AIAA Paper 86-1447, AIAA/ASME/SAE/ASEE $22^{\text {nd }}$ Joint Propulsion Conference, Huntsville, AL, June 16-18, 1986.

4. Beddini, R.A., "Injection-Induced Flows in Porous-Walled Dusts," AIAA J., Vol. 24, No. 11, Nov. 1986, pp. 1766-1773.

5. Bassett, T., "Redesigned Solid Rocket Motor Circumferential Flow Technical Interchange Meeting Final Report," Morton Thiokol Inc., Space Operations, TWR-17788, Feb. 1988, pp. ???.

6. Salita, M., "Quench Bomb Investigation of $\mathrm{Al}_{2} \mathrm{O}_{3}$ Formation from Solid Rocket Propellants (Part II): Analysis of Data, " 25th JANNAF Combustion Meeting, NASA MSFC, Oct. 28, 1988, pp. ???-???.

7. Whitesides, R.H., Ghosh, A., Jenkins, S.L. and Bacchus, D.L., "Cold Flow Determination of the Internal Flow Environment Around the Submerged TVC Nozzle for the Space Shuttle SRM," 1989 JANNAF Propulsion Meeting (CPIA Pub. 515), Vol. 1, Cleveland, OH, May 23-25, 1989, pp. 57-69.

8. Golafshani, M. and Loh, H.T., "Computation of Two-Phase Viscous Flow in Solid Rocket Motors Using a Flux-Split EulerianLagrangian Technique," AIAA Paper 892785, AIAA/ASME/SAE/ASEE 25th Joint Propulsion Conference, Monerey, CA, July 10-12, 1989. 
9. Waesche, R.H.W., Sargent, W.H., and Marchman III, J.F., "Space Shuttle Solid Rocket Motor Aft-End Internal Flows," Journal Propulsion and Power, Vol. 5, No. 6, Nov.-Dec. 1989, pp. 650-656.

10. Boraas, S., "Water Table Reactivation to aid ASRM Nozzle Design,” Thiokol Corp., Space Operations, TWR-62050, Nov. 3, 1990, pp. 13.

11. Majumdar, A.K., Whitesides, R.H., Jenkins, S.L. and Bacchus, D.L., "Effect of Idealized Asymmetric Inhibitor Stubs on Circumferential Flow in the Space Shuttle SRM," Journal of Propulsion and Power, Vol. 6, No. 1, Jan.-Feb., 1990, pp. 5-10.

12. Waesche, R.H.W., Marchman III, J.F., and Kuppa, S., "Effects of Grain Slots on Flow in a Solid Rocket Motor," J. Propulsion and Power, Vol. 7, No. 2, March-April, 1991, pp. 171-177.

13. Carrier, G., Fendell, F.. Brent, D., Kimbrough, C., Loucks, S., Hess, E., and Acosta, P., "Simple Modeling of Particle Trajectories in Solid Rocket Motors," Journal of Propulsion and Power, Vol. 7, No. 2, March-April 1991. pp. 185-195.

14. Heister, S.D. and Landsbaum. E.M. "Analysis of Ballistic Anamalies in Solid Rocket Motors," Journal of Propulsion and Power, Vol. 7, No. 6, Nov. - Dec. 1991, pp. 887-893.

15. Hess, E., Chen, K., Acosta, P., Brent, D., and Fendell, F., "Effect of Aluminized-Grain Design on Slag Accumulation," Journal of
Spacecraft and Rockets, Vol. 29, No. 5, Sep.Oct. 1992, pp. 697-703.

16. Smith-Kent, R., Perkins, F. and Abel, R., "A Potential, Two-Phase Flow Model for Predicting Solid Rocket Motor Slag," AIAA Paper 93-2307, AIAA/SAE/ASME/ASEE 29th Joint Propulsion Conference, Monterey, CA, June 28-30, 1993

17. Johnston, W.A., Murdock, J.W., Koshigoe, S., and Than, P.T., "Slag Accumulation in the Titan SRMU," AIAA Paper 94-3287, AIAA/SAE/ASME/ASEE 30th Joint Propulsion Conference, Indianapolis, IN, June 27-29, 1994.

18. Loh, H.T. and Chwalowski, P., "One and Two-Phase Converging-Diverging Nozzle Flow Study," AIAA Paper 95-0084, AIAA/SAE/ASME/ASEE 33rd Aerospace Sciences Meeting, Reno, NV, Jan. 9-12, 1995.

19. Whitesides, H.R., Purinton, D.C., Hengel, J.E., and Skelley, S.E., "Effects of Slag Ejection on Solid Rocket Motor Performance," AIAA Paper 95-2724, AIAA/SAE/ASME/ASEE 31st Joint Propulsion Conference, San Diego, CA, July 10-12, 1995.

20. Salita, M., "Predicted Slag Deposition Histories in Eight Solid Rocket Motors Using the CFD Model "EVT"," ALAA Paper 952728, AIAA/SAE/ASME/ASEE 31st Joint Propulsion Conference, San Diego, CA, July 10-12, 1995.

21. Chauvot, J.F., Dumas, L., and Schmeisser, K., 
"Modeling of Alumina Slag Formation in Solid Rocket Motors," AIAA Paper 95-2729, AIAA/SAE/ASME/ASEE 31st Joint Propulsion Conference, San Diego, CA, July 10-12, 1995.

22. Sabnis, J.S. and Madabhushi, R.K., "Simulation of Flow and Particle Impingement Patterns in Titan IV SRM Aft Closure,"

ALAA-95-2879, AIAA/ASME/SAE/ASEE 31st Joint Propulsion Conference, San Diego, CA, July 10-12, 1995

23. Giebeling, H.J., de Jong, F.J., Sabnis, J.S. and Madabhushi, R.K., "Advanced Flow Field Model," Air Force Phillips Laboratory Report No. PL-TR-3005, March 1993.

24. Perkins, F.M., May, D.H., and Beus, R.W., "Assessment of Propellant Relative Slag Potential by Direct Measurement of Slag in Subscale Motors," AIAA Paper 96-2781, AIAA/ASME/SAE/ASEE 32nd Joint Propulsion Conference, Lake Buena Vista, FL, July 1-3, 1996.

25. Brennan, M., "Recent Combustion Bomb Testing of RSRM Propellant," ALAA Paper 96-3270, AIAA/ASME/SAE/ASEE 32nd Joint Propulsion Conference, Lake Buena Vista, FL, July 1-3, 1996.

26. Whitesides, R.H., Dill, R.A., Purinton, D.C. and Sambamurthi, J.K., "Design of a Subscale Propellant Slag Evaluation Motor Using TwoPhase Fluid Dynamic Analysis," AIAA Paper 96-2780, AIAA/ASME/SAE/ASEE 32nd Joint
Propulsion Conference, Lake Buena Vista, FL, July 1-3, 1996.

27. Whitesides, R.H., Dill, R.A. and Purinton, D.C., "Application of Two-Phase CFD Analysis to the Evaluation of Asbestos-Free Insulation in the RSRM," AIAA-97-2861, AIAA/ASME/SAE/ASEE 33rd Joint Propulsion Conference, Seattle, WA, July 6-9, 1997.

28. Sauvageau, D.R., Sutton, J.L. and Worley, E., "Space Transportation System Upgrade Alternative Using the Five-Segment Reusable Solid Rocket Booster," 1998 JANNAF Propulsion Meeting (CPIA Pub. 675), Vol. 1, Cleveland, OH, July 15-17, 1998, pp. 231239.

29. Laubacher, B.A., "Internal Flow Analysis of Large L/D Solid Rocket Motors," AIAA Paper 2000-3803, AIAA/ASME/SAE/ASEE 36th Joint Propulsion Conference, Huntsville, AL, July 16-19, 2000.

30. Bartz, D.R.. "A Simple Equation for Rapid Estimation of Rocket Nozzle Convective Heat Transfer Coefficients," Jet Propulsion, Vol. 27, No. 1, pp. 49-51, Dec. 1957.

31. Back, L.H., Massier, P.F., and Gier, H.L.. "Convective Heat Transfer in a ConvergentDivergent Nozzle," Intern. Journal. Heat Mass Transfer, Vol. 7. pp. 549-568, May 1964.

32. Moretti, P.M. and Kays, W.M., "Heat Transfer to a Turbulent Boundary Layer With Varying Free-Stream Velocity and Varying 
Surface Temperature - An Experimental Study," Intern. Journal. Heat Mass Transfer, Vol. 8, pp. 1187-1202, 1965.

33. Back, L.H., Massier, P.F., and Cuffel, R.F., "Some Observations on Reduction of Turbulent Boundary-Layer Heat Transfer in Nozzles," AIAA J., Vol. 4, No. 12, Dec. 1966 pp. 2226-2229.

34. Back, L.H., Massier, P.F., and Cuffel, R.F., "Flow Phenomena and Convective Heat Transfer in a Conical Supersonic Nozzle," Journal of Spacecraft and Rockets, Vol. 4. No. 8, Aug. 1967, pp. 1040-1047.

35. Back et al., Cuffel, R.F., and Massier, P.F., "Laminarization of a Turbulent Boundary Layer in Nozzle Flow - Boundary Layer and Heat Transfer Measurements with Wall Cooling," Journal of Heat Transfer, Vol. ??, No. ??, Aug. 1970, pp. 333-344.

36. Ahmad, R.A., "Discharge Coefficients for Axisymmetric Supersonic Nozzles," to appear in Heat Transfer Engineering.

37. Wang, Q., “On the Prediction of Convective Heat Transfer Coefficients Using GeneralPurpose CFD Codes," ALAA Paper 20010361, AIAA $39^{\text {th }}$ Aerospace Sciences Meeting, Reno, NV, Jan. 8-11, 2001.

38. Ahmad. R.A., "Preliminary Internal Flow Simulation of Enhanced Performance Solid Rocket Booster for the Space Transportation System," Thiokol Propulsion, TWR-74235, March 2001.

39. FLUENT 5 Solver Training Notes, Fluent
Inc., TRN-1998-006, Dec. 1998.

40. FLUENT 5 User's Guide, Fluent Inc., July 1998, Chaps. 9 and 14.

41. GRIDGEN User Manual Version 13" by Pointwise, Inc. 1998.

42. Nickerson, G.R., Coats, D.E., Dang, A.L., Dunn, S.S., Berker, D.R., Hermsen, R.L., and Lamberty, J.T., "The Solid Propellant Rocket Motor Performance Prediction Computer Program (SPP)," Version 6.0, Vol. 1-4, AFAL-TR-87-078, Dec. 1987.

43. A user's Guide for Computer program No. SCB02 - An Internal Ballistics Program for Segmented Solid Propellant Rocket Motors," Thiokol Propulsion, 1982.

44. Gruet, L., "QM-7 and QM-8 Transient Axial Pressure Calculated from Strain Gauge Data," TWR-636954, Thiokol Corporation, 30 March 1992.

45. McBride, B.J., Reno, M.A., and Gordon, S., "CET93 and CETPC: An Interim Updated Version of the NASA Lewis Computer Program for Calculating Complex Chemical Equilibria With Applications," NASA Technical Memorandum 4557, 1994. Design Data Book for Space Shuttle Reusable Solid Rocket Motor. Thiokol Corp., TWR-16881, Rev. A., July 1997.

46. White, F.M., Viscous Fluid Flow, McGrawHill, New York, Chap. 6, 1974.

47. Kays, W.M. and Crawford. M.E.. Convective Heat and Mass Transfer, $3^{\text {rd }}$ ed., McGrawHill, New York, Chaps. 11 and 13, 1993. 
48. Maw, J.F., "Aero/Thermal Analysis of the RSRM Nozzle," TWR-17219, Rev. D, Thiokol Corp., Feb. 20, 1997, p. 22.

49. TableCurve ${ }^{\circledR} 2 \mathrm{D}$ V 5.0/3D V 3.0 automated surface fitting software, Jandel Scientific, 1993.

50. McBride, B.J., Reno, M.A., and Gordon, S., “CMA- Charring Material Thermal Response and Ablation Program, SEE01, version 1.6," May 1994.

51. "A User's Guide for Program SFC11 Calculation of Turbulent Boundary Layer Growth and Heat Transfer in Axisymmetric Nozzles," Thiokol Propulsion, June 1993.

52. Hill, P.G. and Peterson, C.R., Mechanics and Thermodynamics of Propulsion, AddisonWesley, Massachusetts, Chap. 6, 1965. 
Table 1: Summary of geometry, operating chamber conditions, simulations conducted, grid types and sizes, turbulence models used and some pertinent results

\begin{tabular}{|c|c|c|c|}
\hline Item & $\begin{array}{l}\text { Simulation 1: RSRM, 2-D Axisymmetric, } \\
\text { Initial Burn }\end{array}$ & $\begin{array}{l}\text { Simulation 2a: RSRM, 3D, } \\
\text { four-degree Vectored Nozzle }\end{array}$ & $\begin{array}{l}\text { Simulation 2b: FSM, 3D, } \\
\text { four-degree Vectored Nozzle }\end{array}$ \\
\hline$D_{a}(m$, in. $)$ & $1.558,61.35$ & $3.635,143.11$ & $3.594,141.50$ \\
\hline$D^{*}(\mathrm{~m}$, in. $)$ & $1.37,53.86$ & $1.364,53.684$ & $1.502,59.146$ \\
\hline$D_{e}(\mathrm{~m}, \mathrm{in})$. & $3.801,149.64$ & $3.792,149.29$ & $3.865,152.173$ \\
\hline$A_{d} d^{*}, A d A^{*}$ & $1.298,7.72$ & $7.10,7.73$ & $5.73,6.619$ \\
\hline$P_{a}(\mathrm{MPa}$, psia $)$ & $6.25,906$ & $4.25,616$ & $4.25,616$ \\
\hline$T_{o}(\mathrm{~K}, \mathrm{R})$ & $3416.04,6148.87$ & $3368.31,6062.96$ & $3368.31,6062.96$ \\
\hline Grid 1 & $\begin{array}{l}\text { Model 1: } \kappa-\varepsilon \text {, standard, standard wall } \\
\text { functions, } N x=1200, N y=50, \text { plus sub- } \\
\text { domains yielding } 65.449 \text { cells (S. Q), } \\
\text { (1) AD } \\
\text { (2) UST }=2644 \mathrm{~K} \\
\text { (3) SST } \\
1<y^{+}<1400 \text {, used in }[29]\end{array}$ & $\begin{array}{l}\text { Model 1: } \kappa-\varepsilon, \text { standard, } \\
\text { standard wall functions, } \\
\text { Block } 1 \text { (chamber - inner): } \\
41 \times 57 \times 33, \text { Block } 2 \text { (chamber } \\
\text { - outer): } 85 \times 57 \times 33 \text {, Block } 3 \\
\text { (nozzle): } 101 \times 33 \times 33 \text { yielding } \\
324,608 \text { cells }(S, H) \\
(1) \text { SST } \\
1<y^{+}<1800,\end{array}$ & $\begin{array}{l}\text { Model 1: } \kappa-\varepsilon, \text { standard, } \\
\text { standard wall functions } \\
\text { Block } 1 \text { (chamber }- \text { inner): } \\
41 \times 57 \times 33 \text {, Block } 2 \text { (chamber - } \\
\text { outré): } 85 \times 57 \times 33, \text { Block } 3 \\
\text { (nozzle): } 101 \times 33 \times 33 \text { yielding } \\
324.608 \text { cells }(S, H), \text { SST) } \\
1<y^{+}<1800,\end{array}$ \\
\hline Grid 2 & $\begin{array}{l}\text { Model 1: } \kappa-\varepsilon \text {, standard, standard wall } \\
\text { functions, (a) Nx=1200, Ny=100, plus } \\
\text { sub-domains yielding } 132.323 \text { cells (S, Q) } \\
\text { (1) AD } \\
\text { (2) UST }=2644 \mathrm{~K} \\
\text { (3) UST }=3033 \mathrm{~K} \\
\text { (4) S, Q, SST } \\
\text { (b) } 132000 \rightarrow 327599 \text { (S, H, A) } \\
1<y^{+}<700 \\
\end{array}$ & $\begin{array}{l}\text { Model 1: } \kappa-\varepsilon, \text { standard, } \\
\text { standard wall functions } \\
324.608 \rightarrow 953,138 \text { (S. H. A) } \\
\text { (1) SST } \\
y^{+}<303\end{array}$ & $\begin{array}{l}\text { Model 1: } \kappa \cdot \varepsilon \text {, standard, } \\
\text { standard wall functions } \\
324,608 \rightarrow 1,101,636(\mathrm{~S}, \mathrm{H}, \mathrm{A}) \\
\text { (1) SST } \\
y^{+}<341\end{array}$ \\
\hline Grid 3 & $\begin{array}{l}\text { Model 1: } \kappa-\varepsilon, \text { standard, standard wall } \\
\text { functions, } \mathrm{Nx}=500, \mathrm{Ny}=200 \text {, plus sub- } \\
\text { domains yielding } 31370 \text { cells - adapted to } \\
105161 \text { (S. T, A) } \\
\text { SST } \\
1<y^{+}<1800\end{array}$ & $\begin{array}{l}y^{+} \leq 2 \text { would require millions } \\
\text { of cells }\end{array}$ & $\begin{array}{l}\text { Model 1: } \kappa-\varepsilon, \text { standard, } \\
\text { standard wall functions, to } \\
\text { check exit Mach number } \\
1,129104 \text { (S, H) } \\
\text { (1) SST } \\
y^{+}<2000\end{array}$ \\
\hline Grid 4 & $\begin{array}{l}71376 \text { (S. T), SST } \\
?<y^{+}<? ? ? ?\end{array}$ & & \\
\hline \multirow[t]{2}{*}{ Grid 5} & $\begin{array}{l}\text { Model 1: } \kappa \cdot \varepsilon, \text { standard, standard wall } \\
\text { functions, } N x=460, N y=200 \text {, plus sub- } \\
\text { domains yielding } 95550 \text { cells (S, Q) } \\
\text { SST } \\
22<y^{+}<100\end{array}$ & & \\
\hline & $\begin{array}{l}\text { Model 2: } \kappa-\varepsilon, \text { RNG, standard wall } \\
\text { functions, } \mathrm{Nx}=460, \mathrm{Ny}=200 \text {, plus sub- } \\
\text { domains yielding } 95550 \text { cells } \text { (S, Q) } \\
\text { (1) } \mathrm{SST} \\
22<\mathrm{y}^{+}<100\end{array}$ & & \\
\hline \multirow[t]{2}{*}{ Grid 6} & $\begin{array}{l}\text { Model 3: } \kappa-\varepsilon, \text { RNG, two-layers zonal } \\
\text { model, 601450 (S, Q) } \\
\text { (1) SST } \\
y^{+}<5\end{array}$ & & \\
\hline & $\begin{array}{l}\text { Model 4: } \kappa-\varepsilon, \text { Standard, two-layers zonal } \\
\text { model, } 601450(S, Q) \\
\text { (1) SST } \\
\mathrm{V}^{+}<7.5\end{array}$ & & \\
\hline
\end{tabular}

$A$ : with grid adaption (shortcoming: calculated $y^{+}$and $W C P$ profiles have no distinct trend or profile as shown in Figs. $3 \mathrm{a}$ and $4 \mathrm{~b}$. respectively). $A D$ : Adiabatic wall. $H$ : Hexahedral (3D), $Q$ : Quadrilateral (2D), $R N G$ : renormalization group theory. $S$ : structured (not triangles), SST: Specified Surface Temperature as shown in Fig. 4a, $T$ : Triangular, UST: Uniform Surface temperature. 
Table 2: Turbulence models used in this study

\begin{tabular}{|c|c|c|c|c|c|}
\hline Model, Grid & $\begin{array}{c}\text { Viscous } \\
\text { Model }\end{array}$ & $\kappa-\varepsilon$ Model & Near Wall Treatment & Solver & $\begin{array}{c}\text { Calculated wall } \\
y^{+}\end{array}$ \\
\hline Model 1, Grid 2 & $\kappa-\varepsilon$ & Standard & Standard Wall Functions & Segregated & $2<y^{+}<700$ \\
\hline Model 1, Grid 5 & $\kappa-\varepsilon$ & Standard & Standard Wall Functions & Segregated & $22<y^{+}<100$ \\
\hline Model 2, Grid 5 & $\kappa-\varepsilon$ & RNG & Standard Wall Functions & Segregated & $22<y^{+}<100$ \\
\hline Model 3, Grid 6 & $\kappa-\varepsilon$ & RNG & Two-Layer Zonal Model & Segregated & $y^{+}<8$ \\
\hline Model 4, Grid 6 & $\kappa-\varepsilon$ & Standard & Two-Layer Zonal Model & Segregated & $y^{+}<8$ \\
\hline Model 1, Grid 5 & $\kappa-\varepsilon$ & Standard & Standard Wall Functions & Coupled & $20<y^{+}<100$ \\
\hline
\end{tabular}

${ }^{2}:$ undersigned for $y^{+}, R N G$ : renormalization group theory 


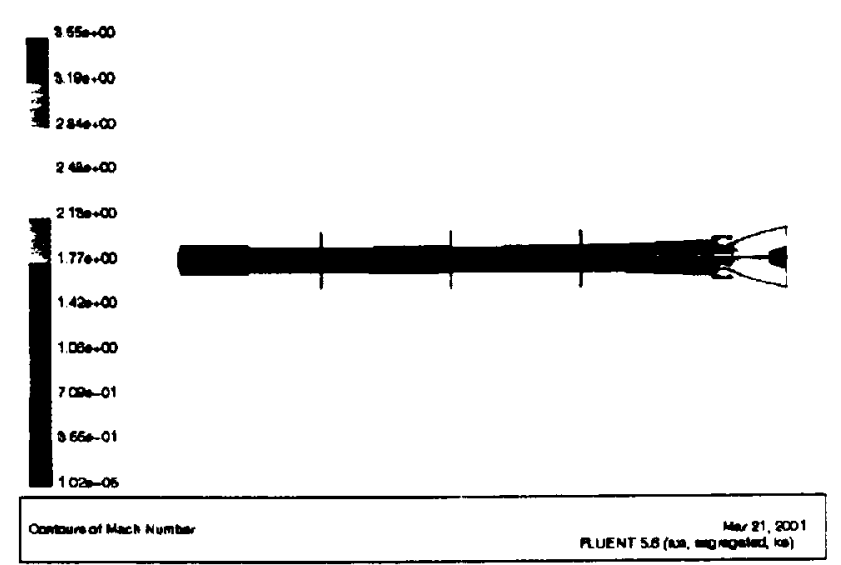

Fig. 1a Local Mach number distribution in the RSRM at ignition time, Grid 5 (95,550 quadrilateral cells).

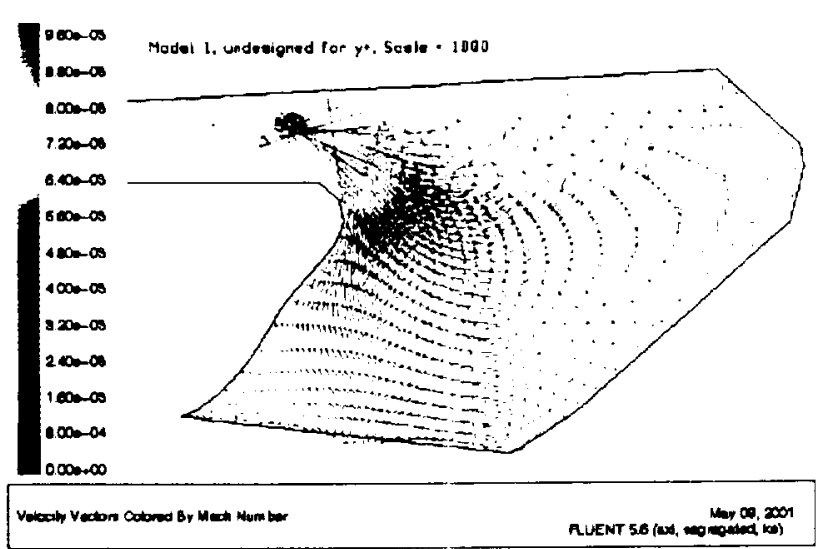

Fig. 1b(1) Local Mach number distribution in the cavity of the RSRM at ignition time calculated using turbulence Model 1, undersigned for $y^{+}$.

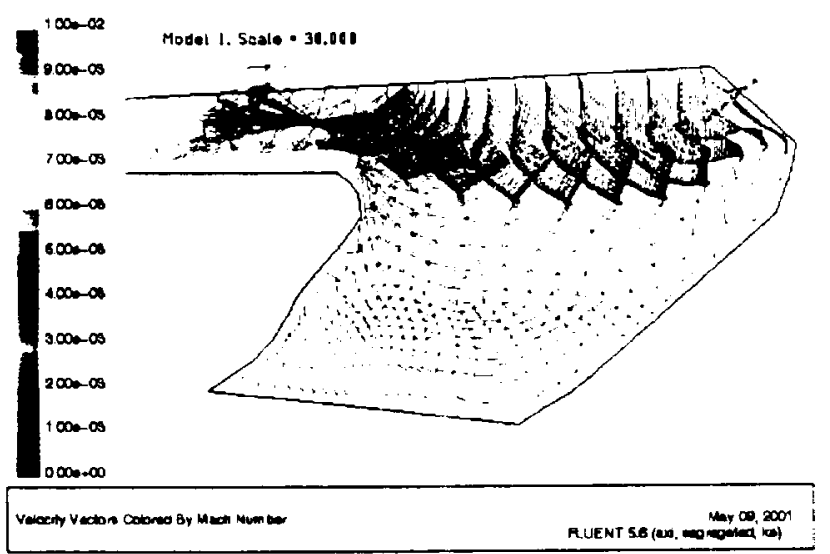

Fig. 1b(2) Local Mach number distribution in the cavity of the RSRM at ignition time calculated using turbulence Model 1.

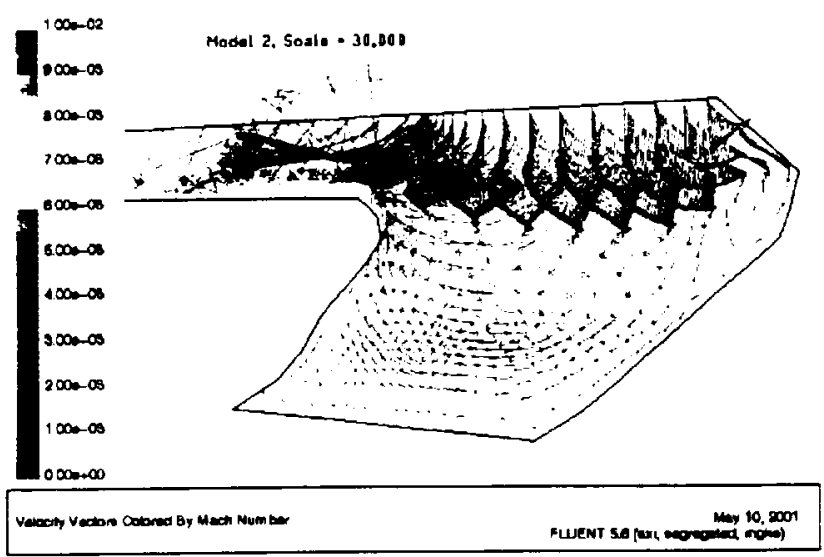

Fig. 1b(3) Local Mach number distribution in the cavity of the RSRM at ignition time calculated using turbulence Model 2.

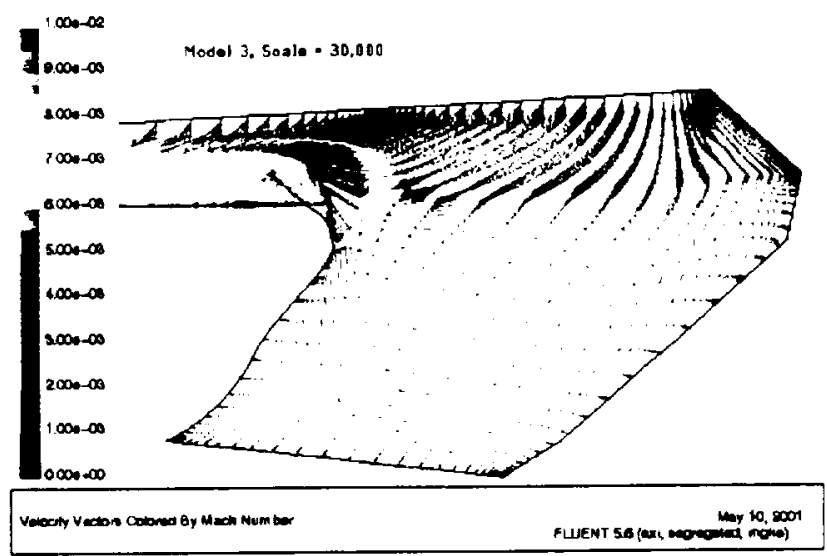

Fig. 1b(4) Local Mach number distribution in the cavity of the RSRM at ignition time calculated using turbulence Model 3.

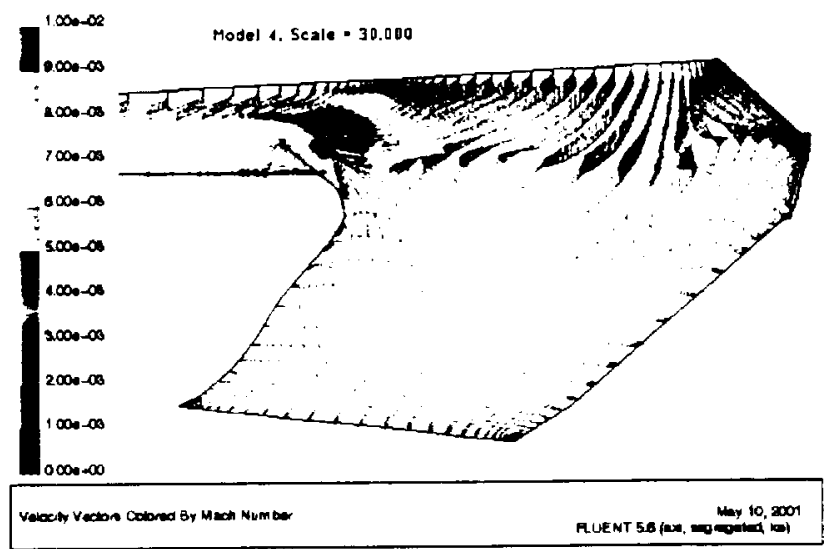

Fig. 1b(5) Local Mach number distribution in the cavity of the RSRM at ignition time calculated using turbulence Model 4. 


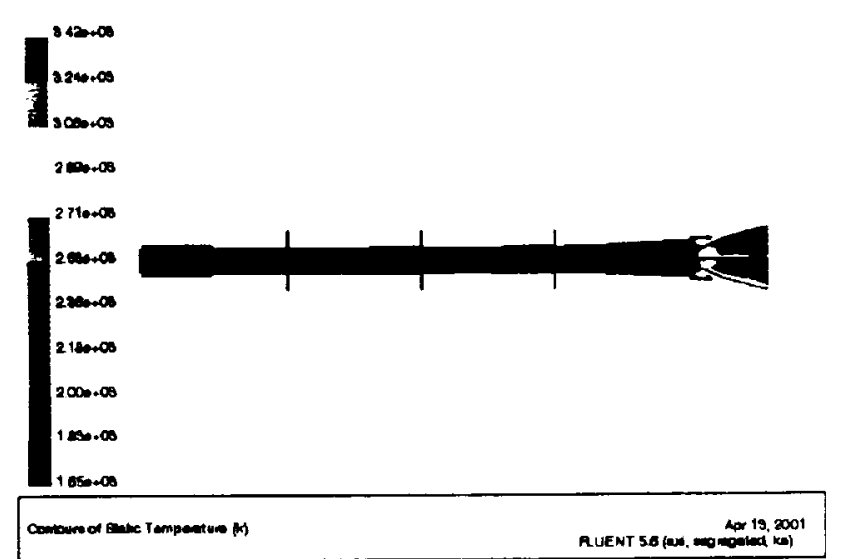

Fig. 1c Local static temperature distribution in the RSRM at ignition time Grid 5(95,550 quadrilateral cells).

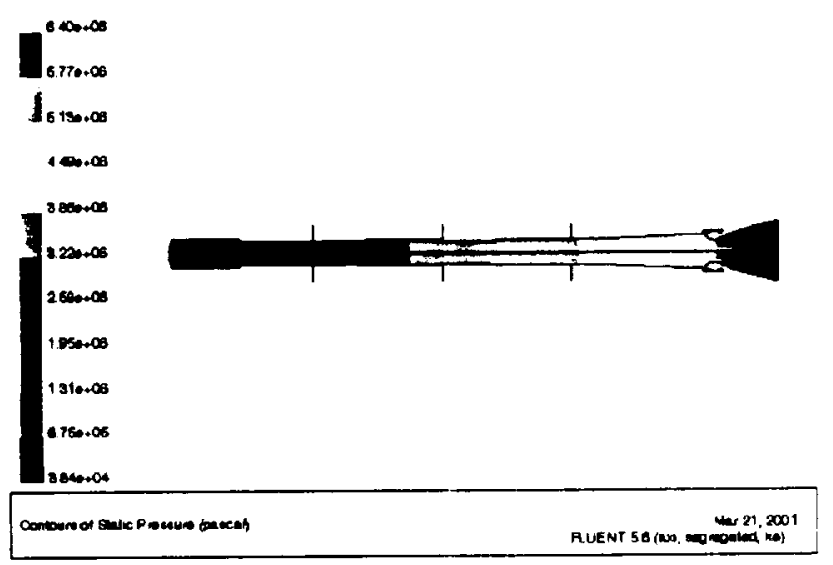

Fig. 2a Local static pressure distribution in the RSRM at ignition time, Grid 5 (95,550 quadrilateral cells).

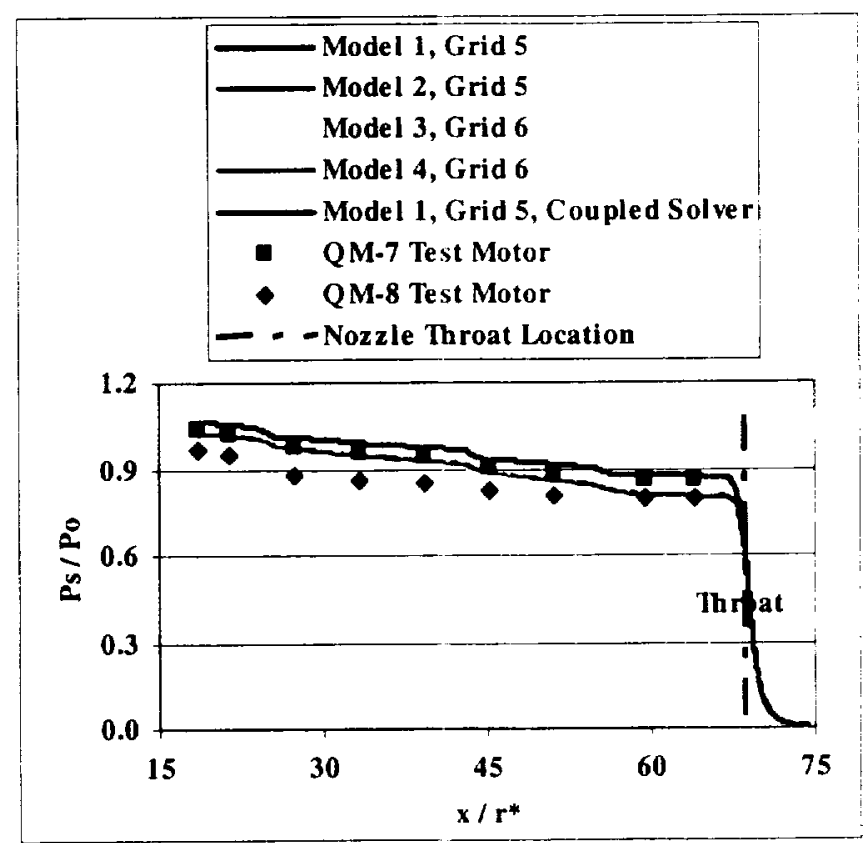

Fig. 2b Local axial static pressure along the centerline of the RSRM at ignition time.

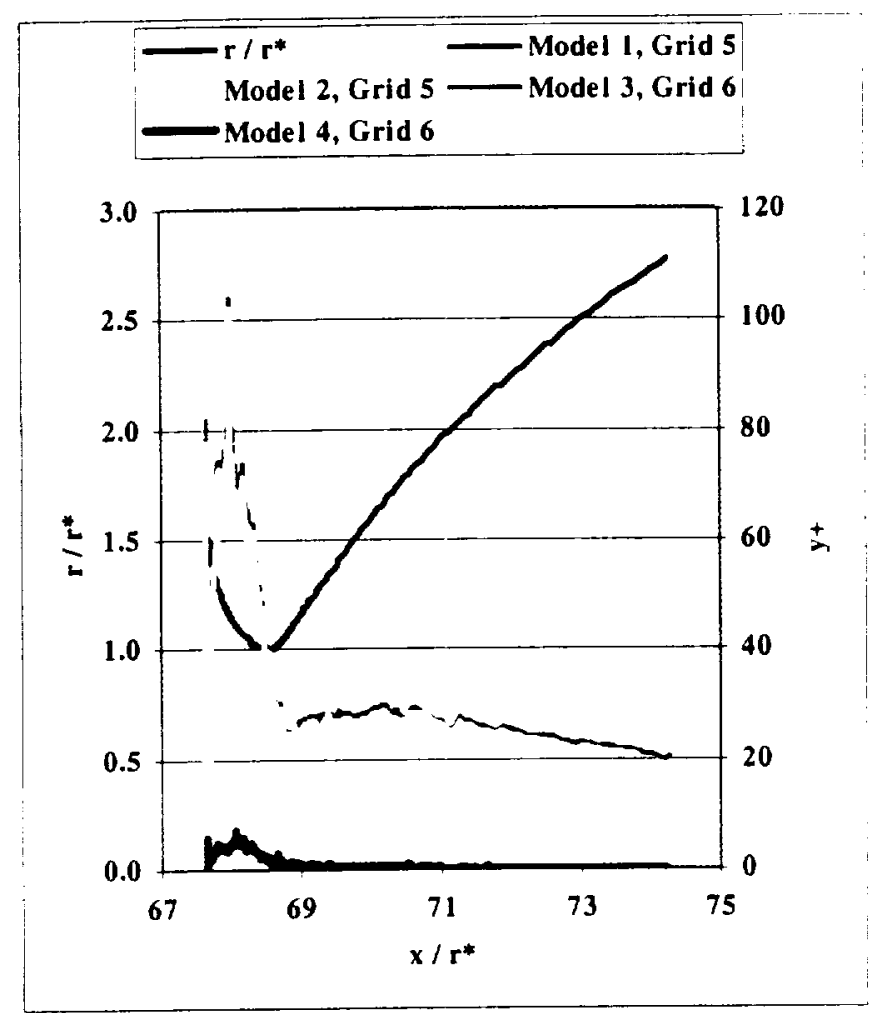

Fig. 3a Local wall $y^{+}$along the converging-diverging section of in the RSRM nozzle at ignition time.

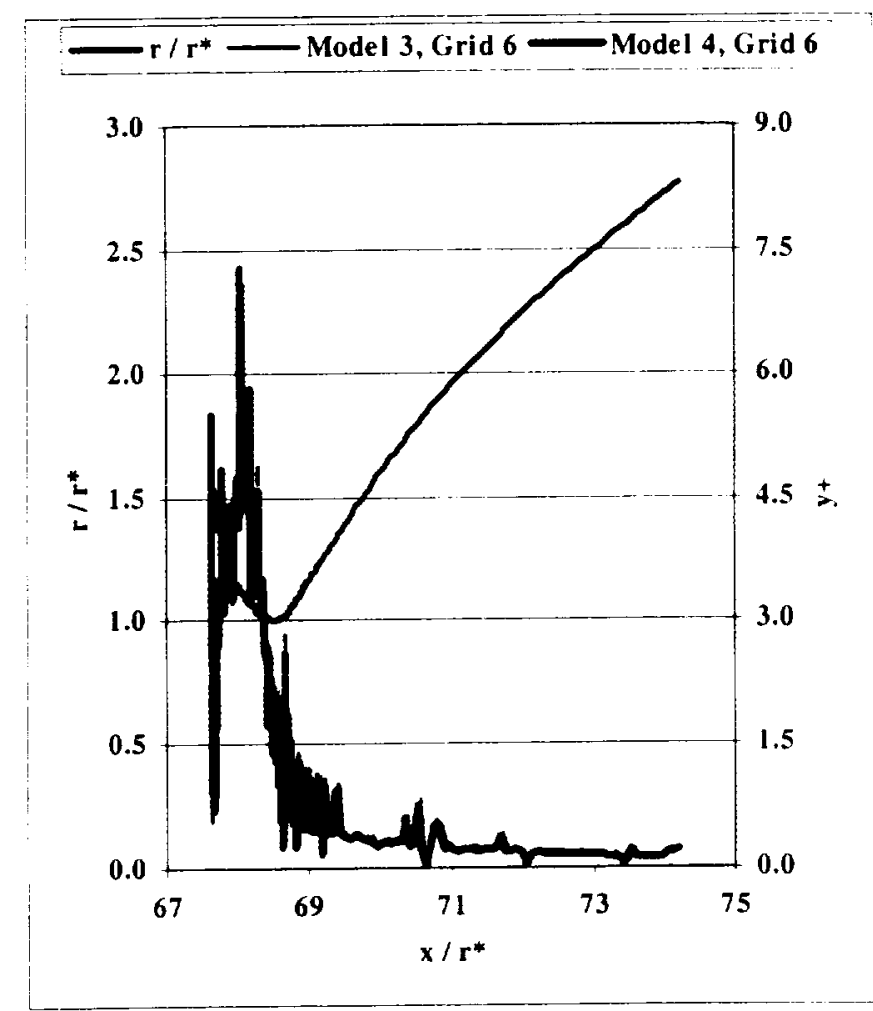

Fig. 3b Local wall $y^{+}$along the converging-diverging section of in the RSRM nozzle at ignition time from turbulence models 3 and 4 (magnified from previous figure). 


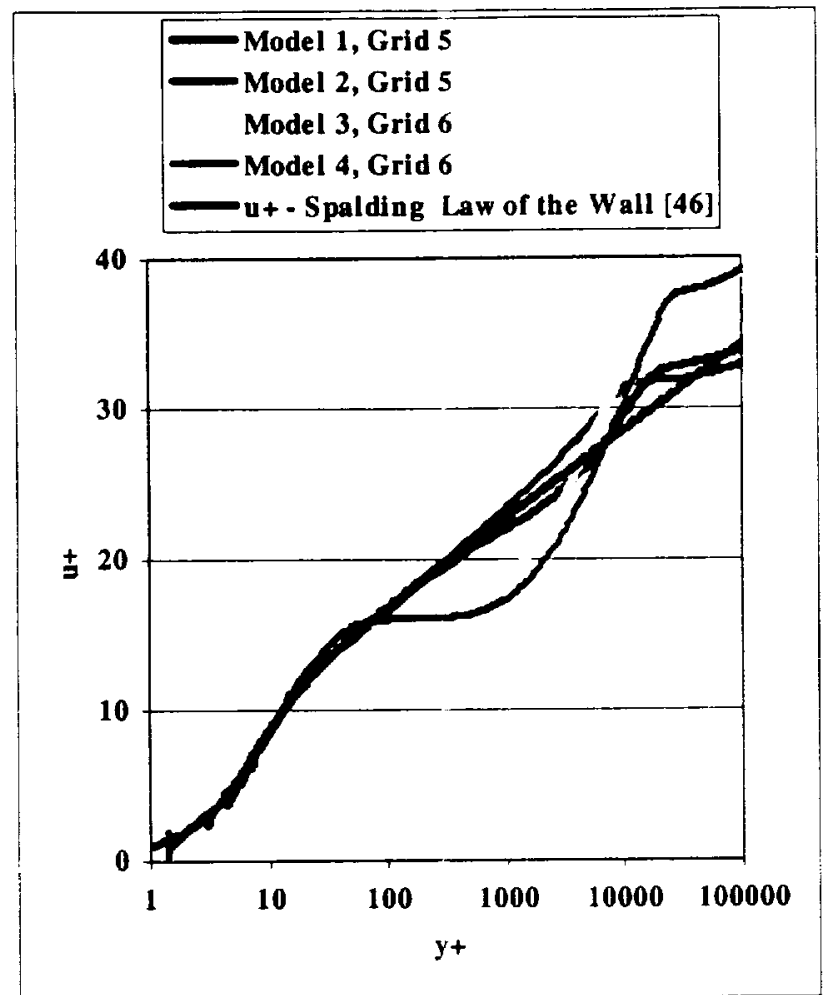

Fig. 3c Comparison of the velocity law of the wall (Spalding) with the RSRM nozzle calculations at exit

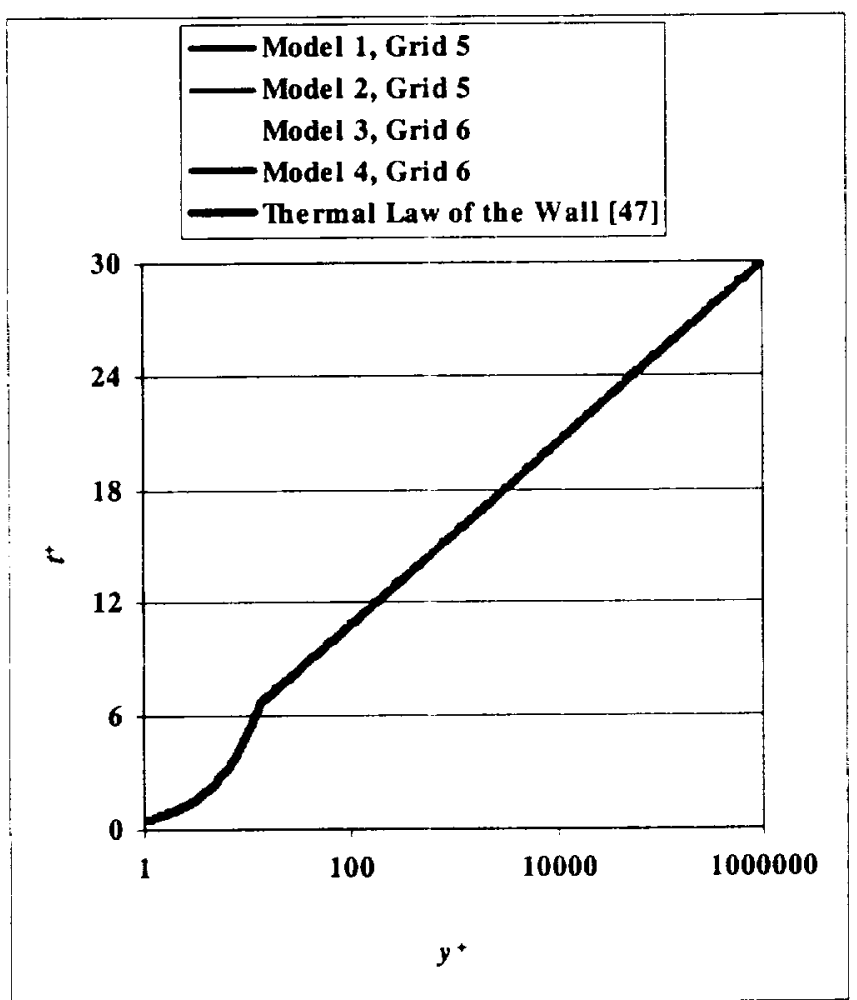

Fig. 3d Comparison of the temperature law of the wall with the RSRM nozzle calculations at exit.

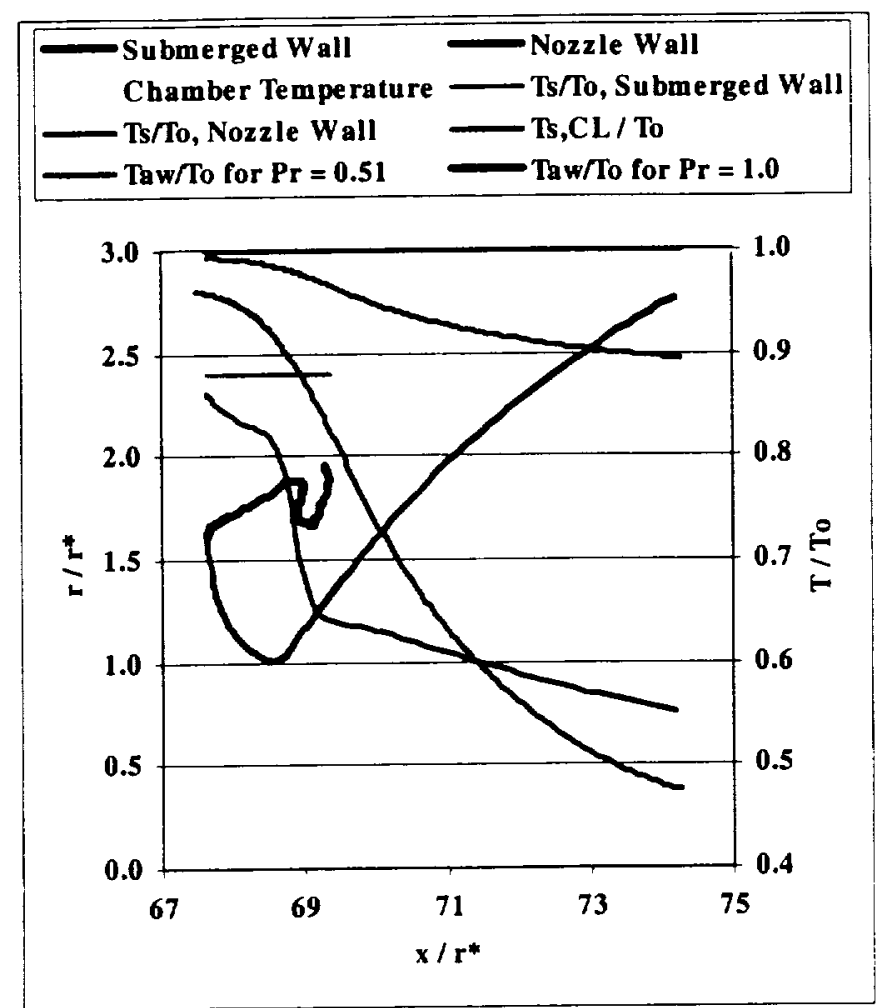

Fig. 4a Local specified surface temperature and calculated temperatures in the RSRM at ignition time.

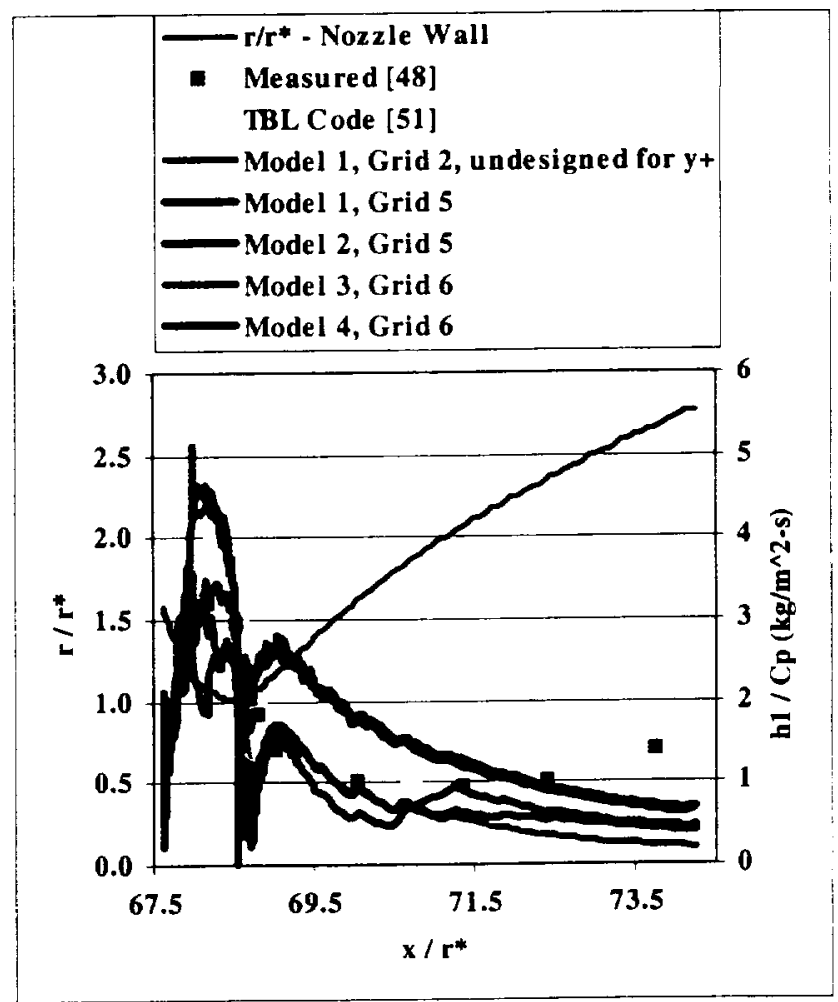

Fig. $4 b(1)$ Local convective heat transfer on the nozzle of the RSRM at ignition time (Method 1). 


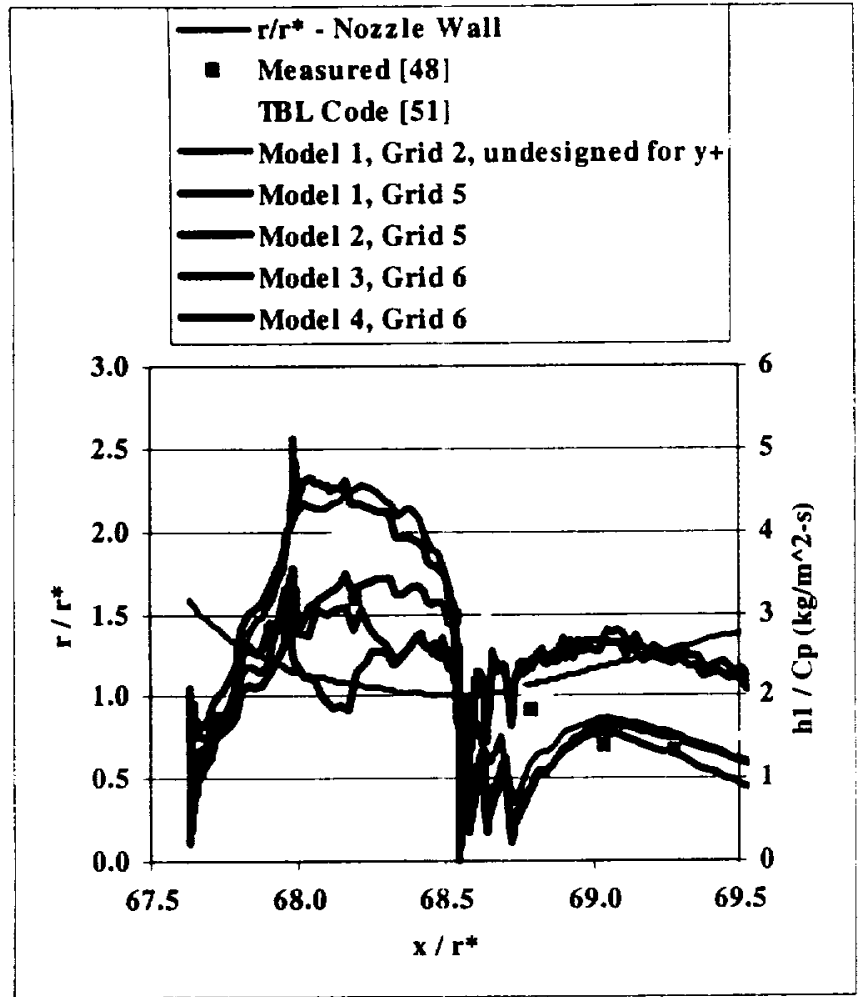

Fig. $4 b(2)$ Local convective heat transfer on the nozzle of the RSRM at ignition time (Method 1, magnified from previous figure).

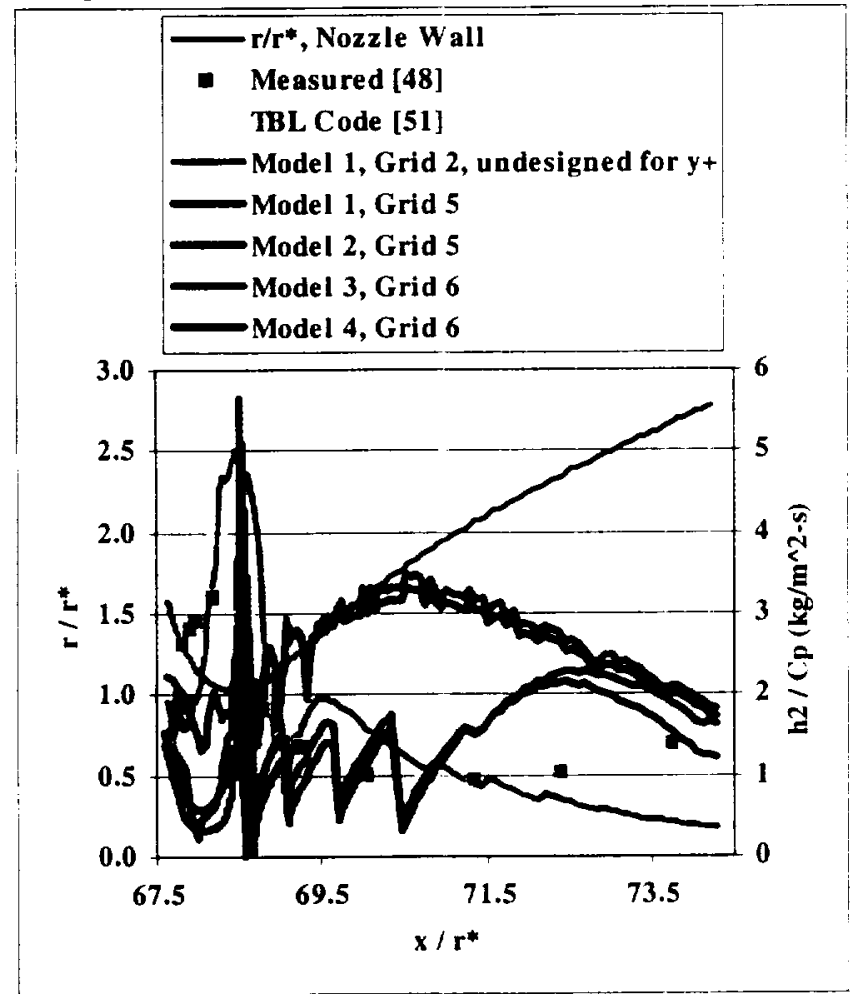

Fig. $4 b(3)$ Local convective heat transfer on the nozzle of the RSRM at ignition time (Method 2).

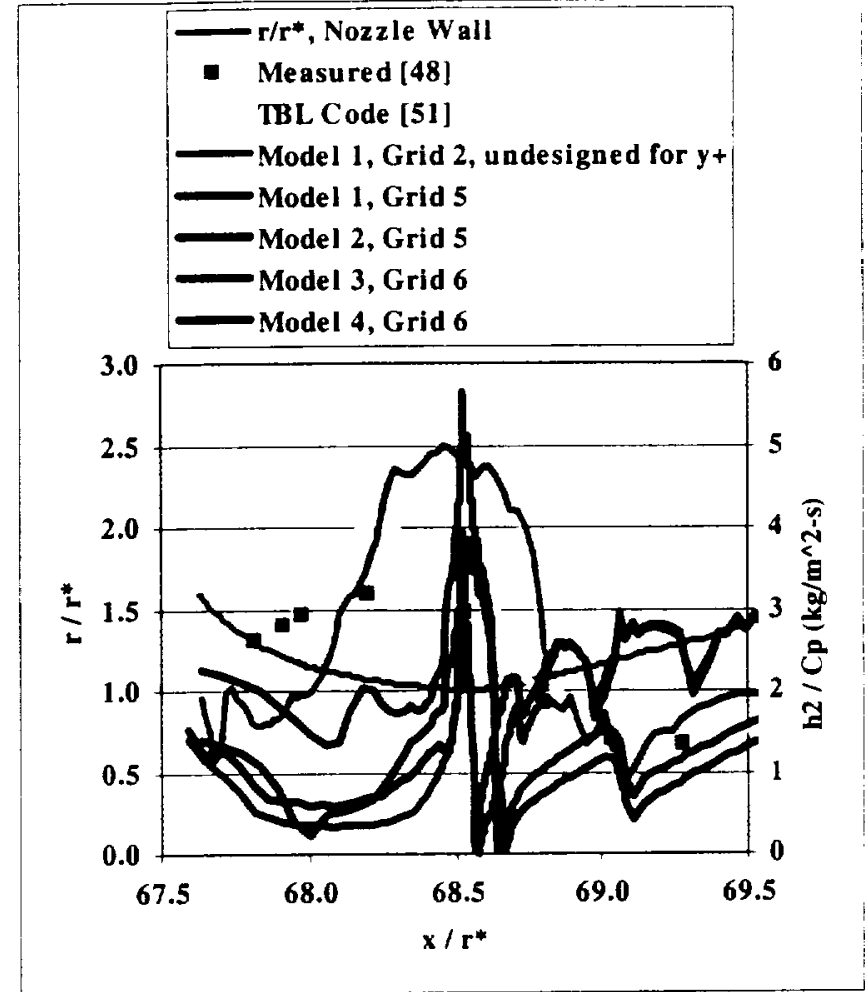

Fig. $4 b(4)$ Local convective heat transfer on the nozzle of the RSRM at ignition time (Method 2, magnified from previous figure).

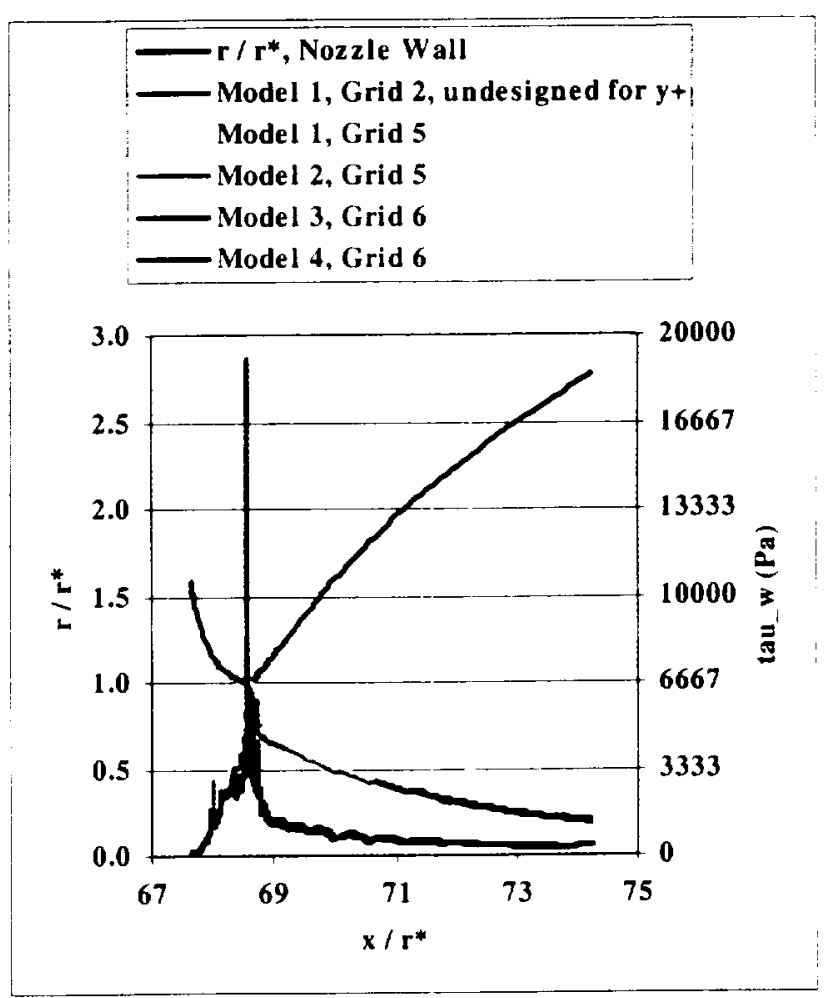

Fig. 4c Shear stress profile along the nozzle wall of the RSRM at ignition time. 


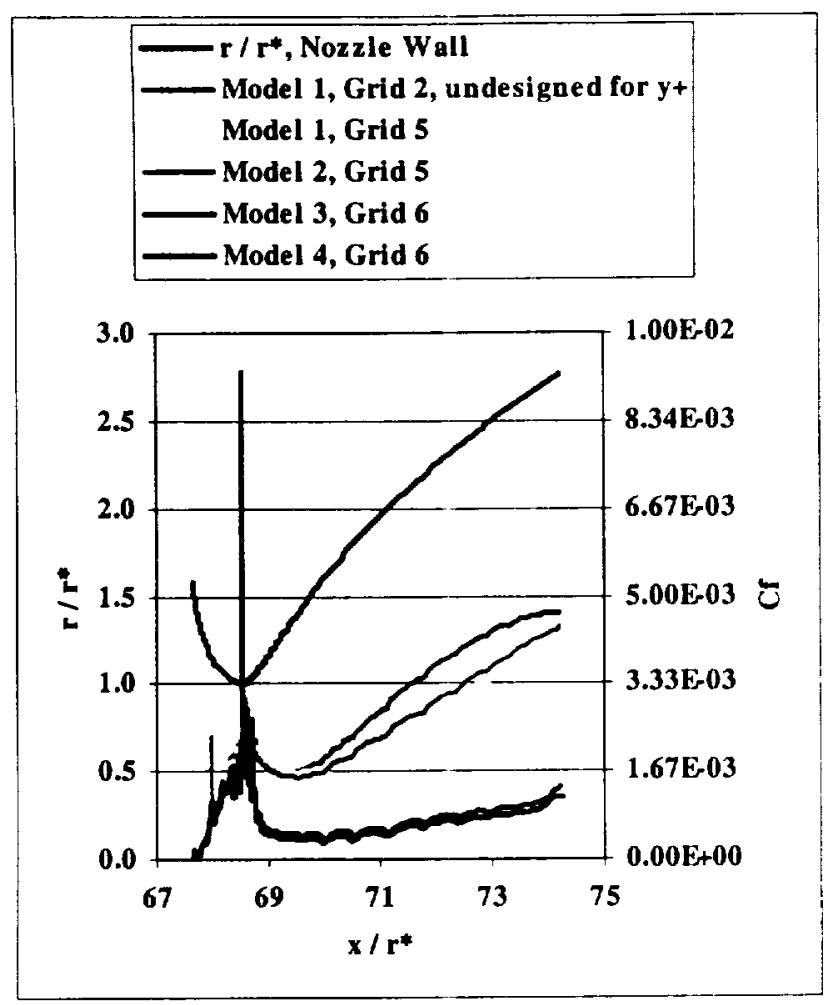

Fig. 4d Skin friction coefficient along the nozzle centerline of the RSRM at ignition time.

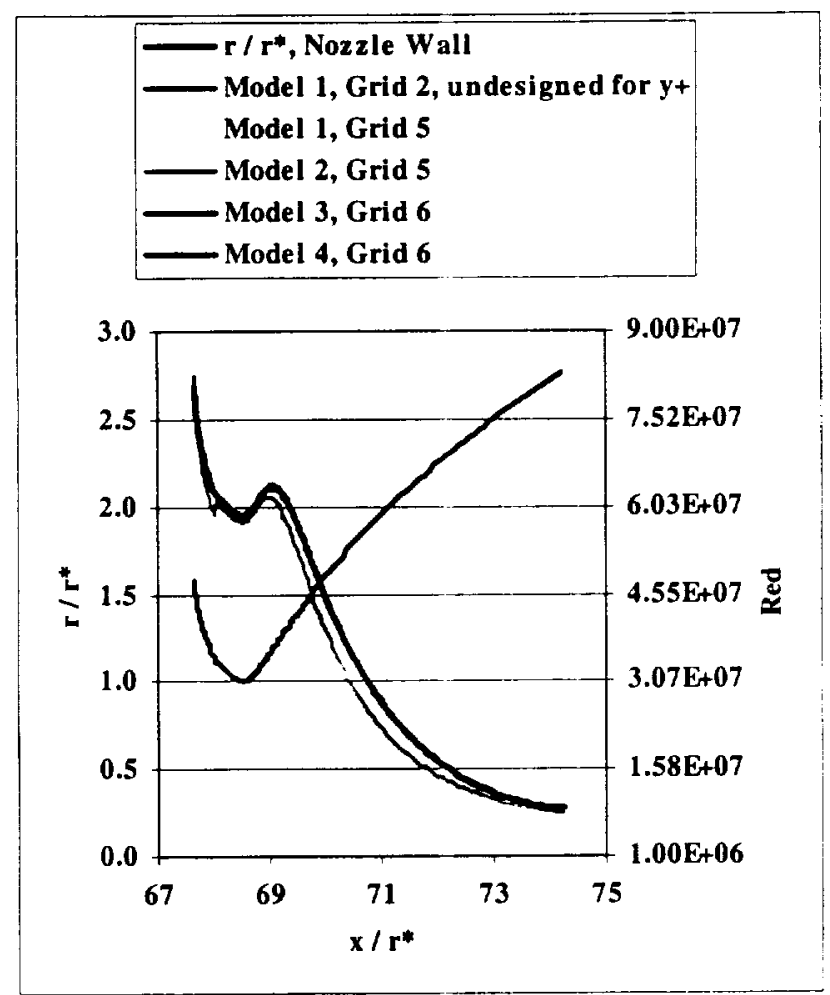

Fig. 4e Local Reynolds number along the nozzle centerline of the RSRM at ignition time.

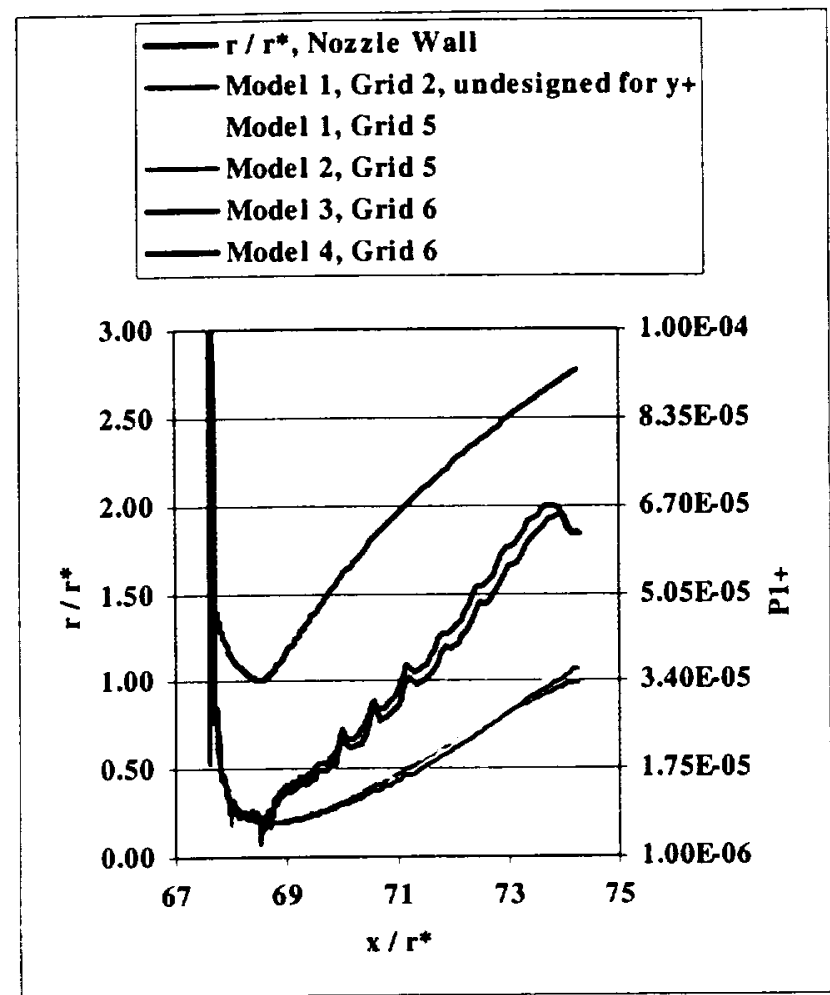

Fig. 4f Non-dimensional pressure gradient $\left(P_{l}^{+}\right)$along the nozzle of the RSRM at ignition time based on internal boundary layer.

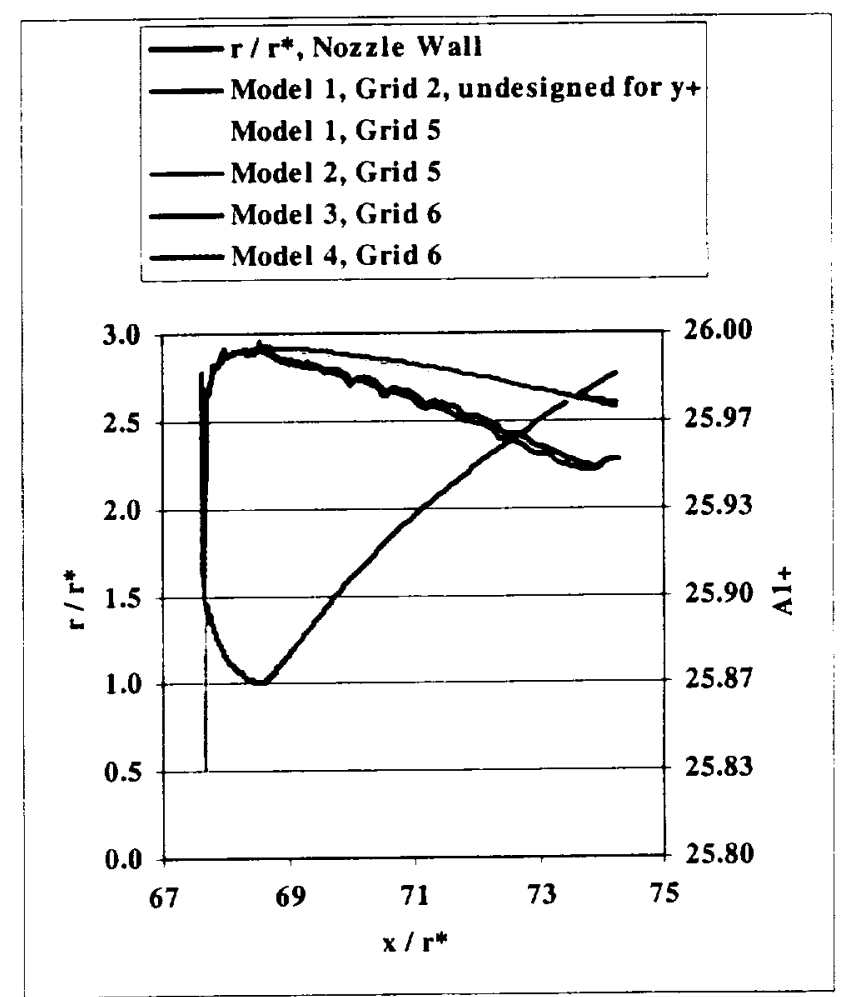

Fig. $4 \mathrm{~g}$ Effective thickness of the viscous sublayer $\left(\mathrm{Al}_{\mathrm{l}}^{+}\right)$along the nozzle centerline of the RSRM at ignition time based on internal boundary layer. 


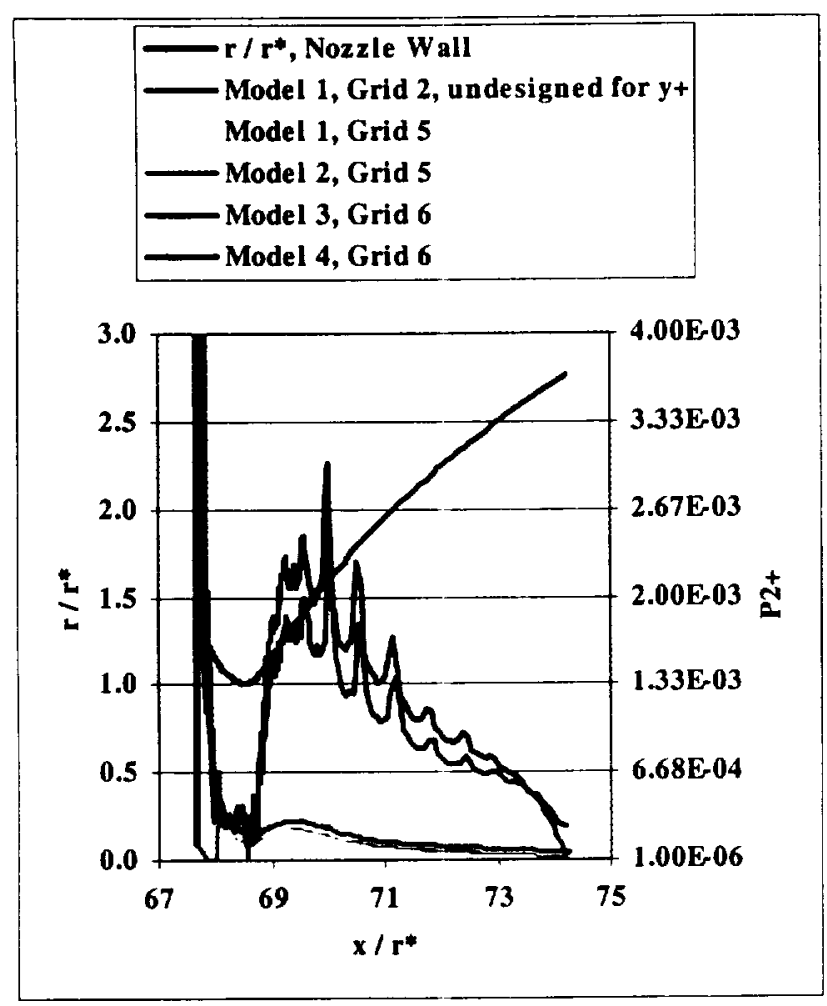

Fig. 4h Non-dimensional pressure gradient $\left(\mathrm{P}_{2}^{+}\right)$along the nozzle of the RSRM at ignition time based on external boundary layer.

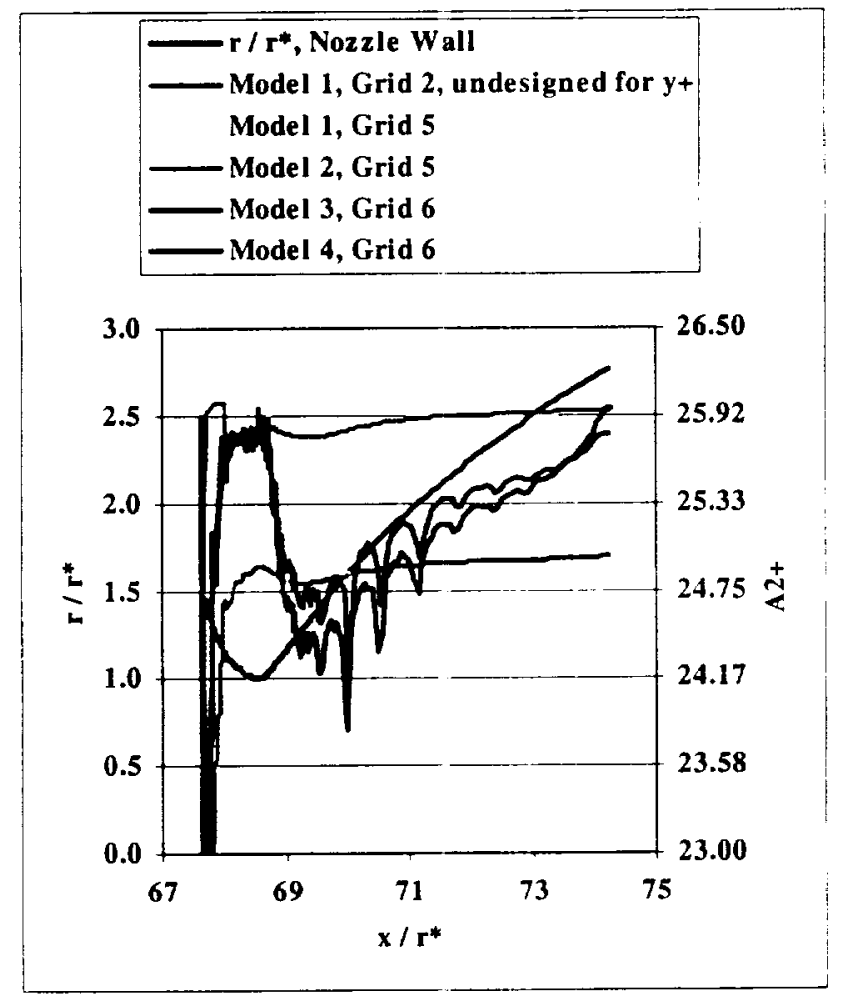

Fig. 4i Effective thickness of the viscous sublayer $\left(A_{2}^{+}\right)$ along the nozzle centerline of the RSRM at ignition time based on external boundary layer.

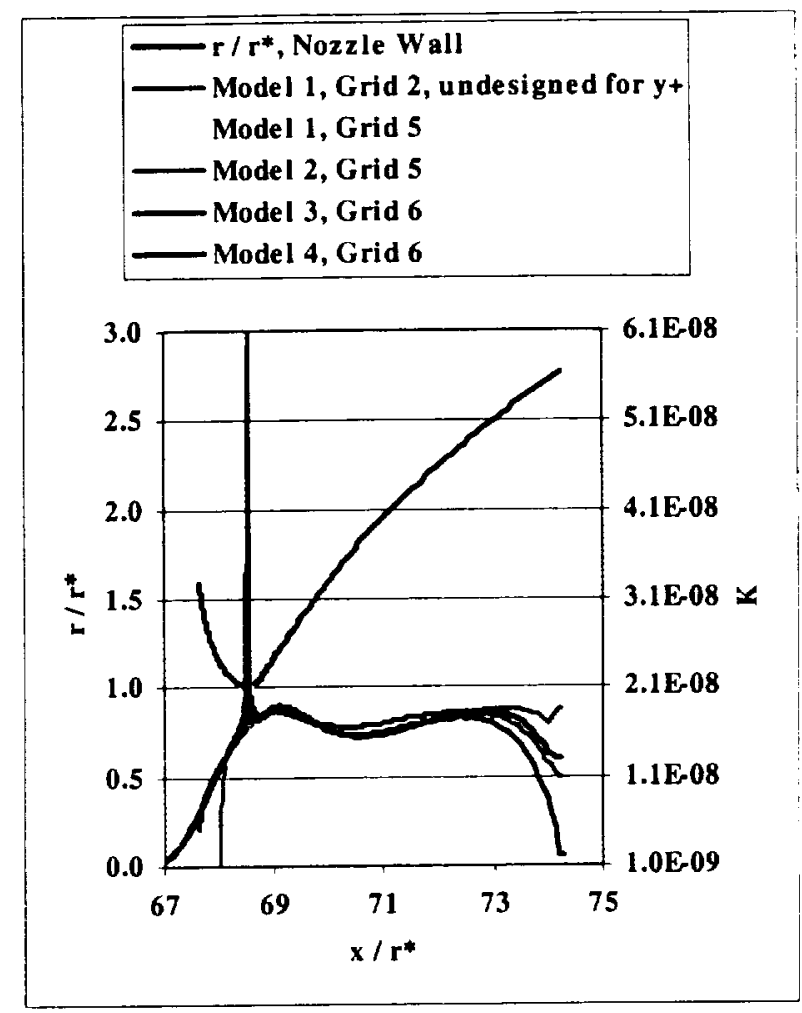

Fig. 4j An acceleration parameter $(K)$ along the nozzle centerline of the RSRM at ignition time.

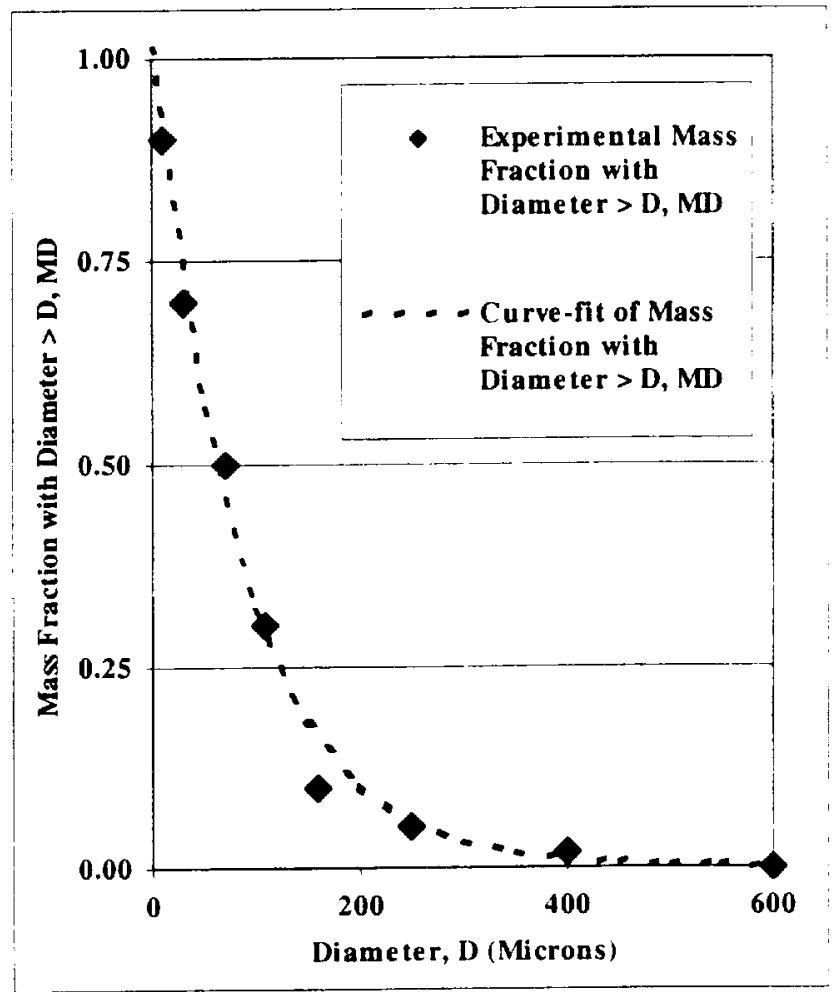

Fig. 5a Rosin-Rammler curve for particle size data. 


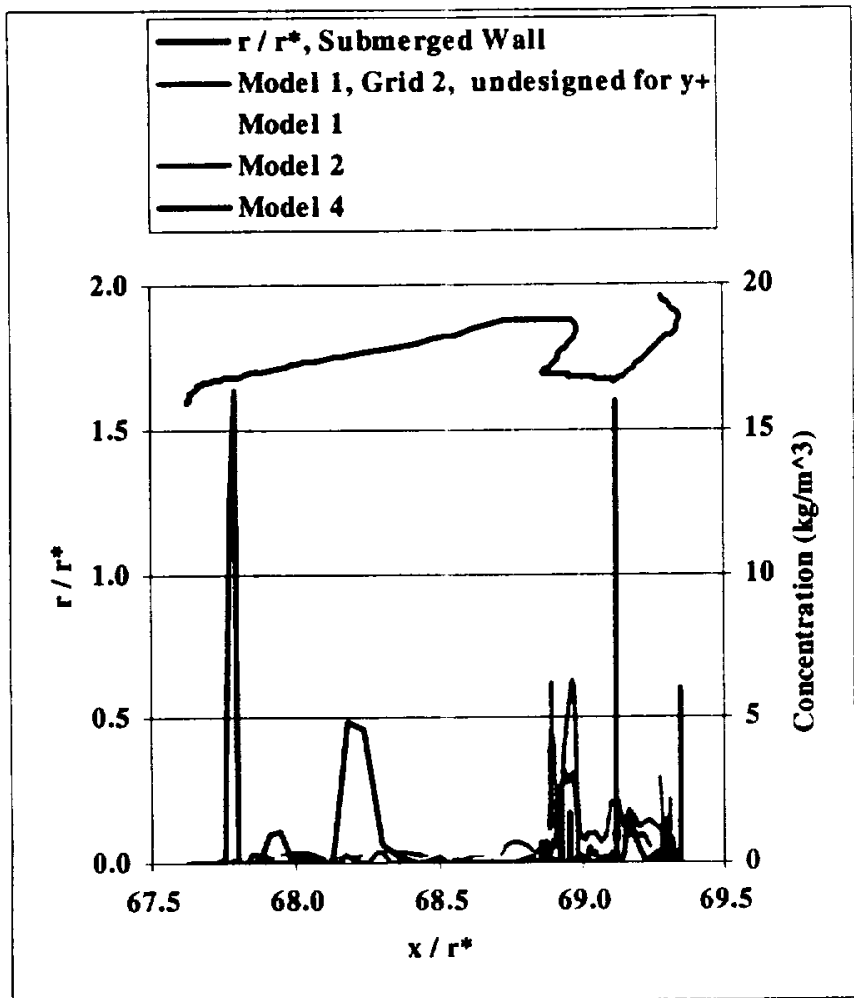

Fig. 5b Local discrete phase concentration on the submerged wall of the RSRM at ignition.

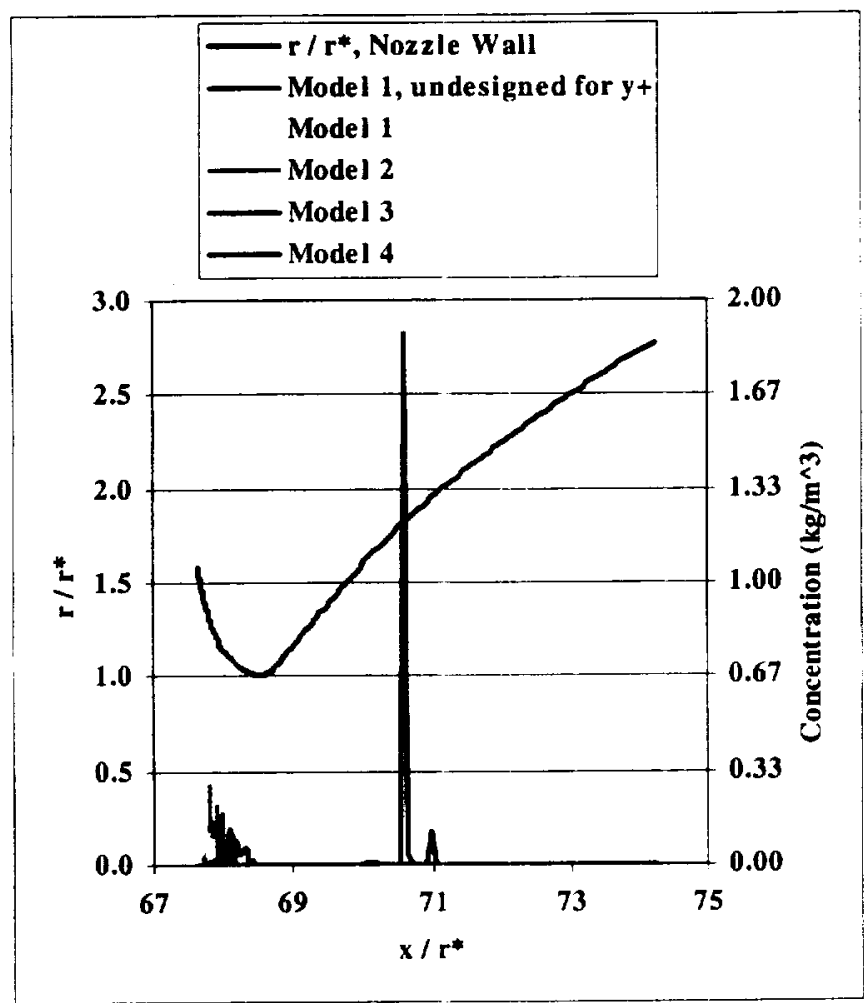

Fig. 5c Local discrete phase concentration on the converging-diverging part of the nozzle wall of the RSRM at ignition.

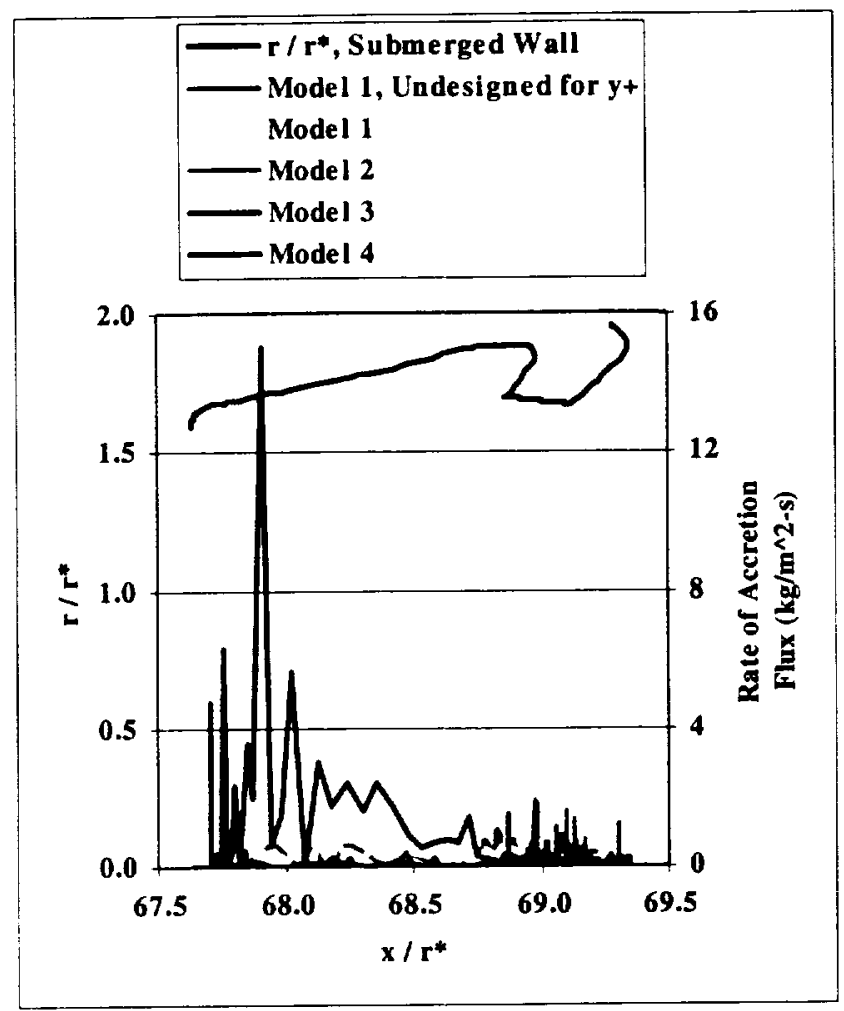

Fig. 5d Local discrete phase rate of accretion flux in the submerged wall of the RSRM at ignition.

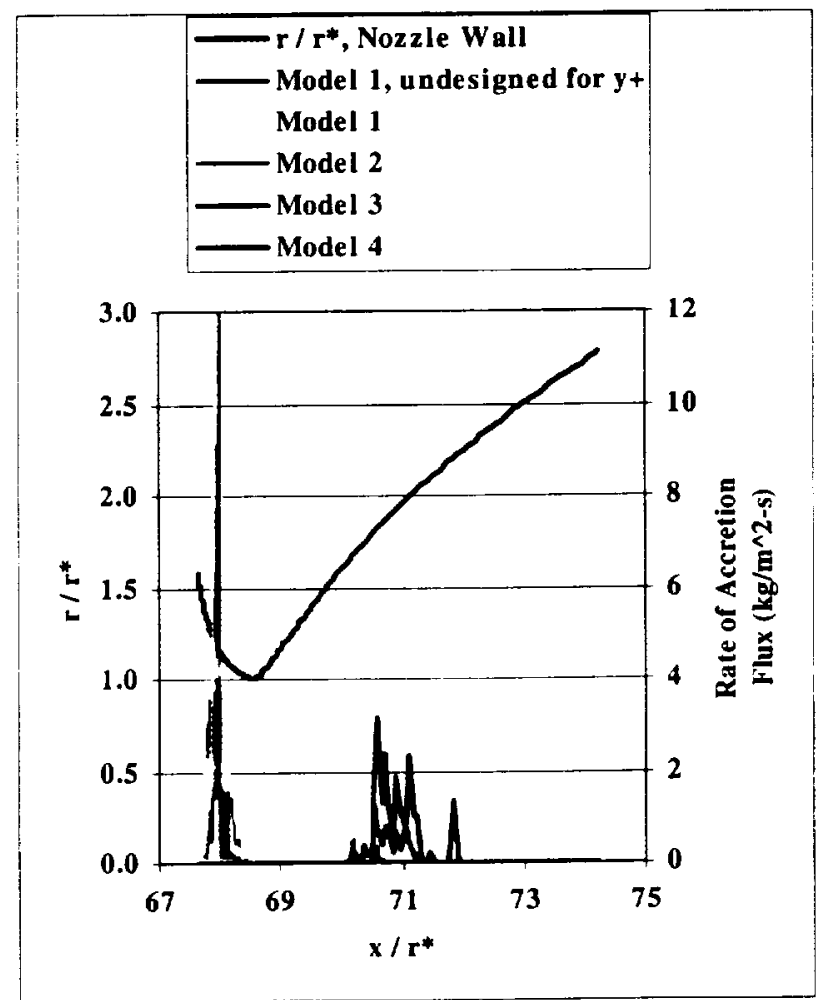

Fig. Se Local discrete phase rate of accretion flux on the converging-diverging part of the nozzle wall of the RSRM at ignition. 


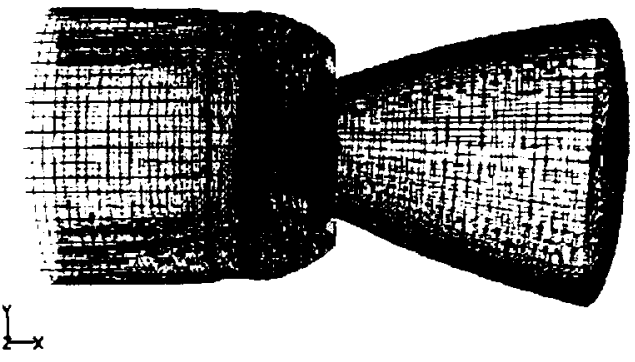

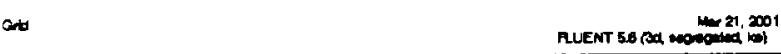

Fig. 6a Three-dimensional grid (Grid 1: 325000 hexahedral cells) for the RSRM.

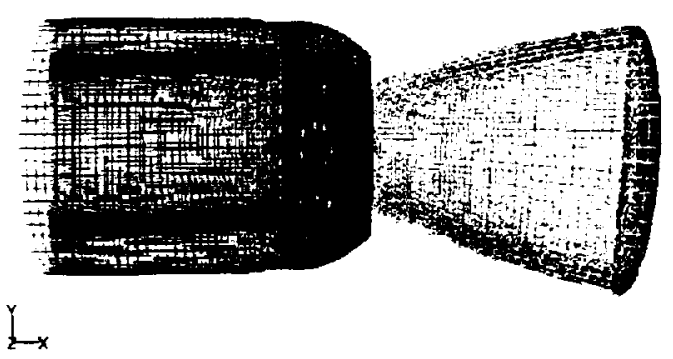

and

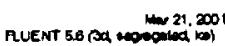

Fig. 6b Three-dimensional grid (Grid 1: 325000 hexahedral cells) for the FSM.

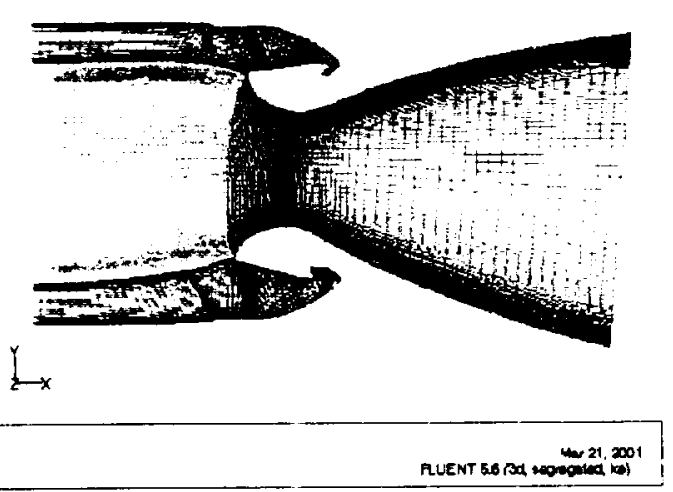

Fig. 6c Details of the symmetry plane of the threedimensional grid (Grid 1: 325,000 hexahedral cells) for the RSRM.

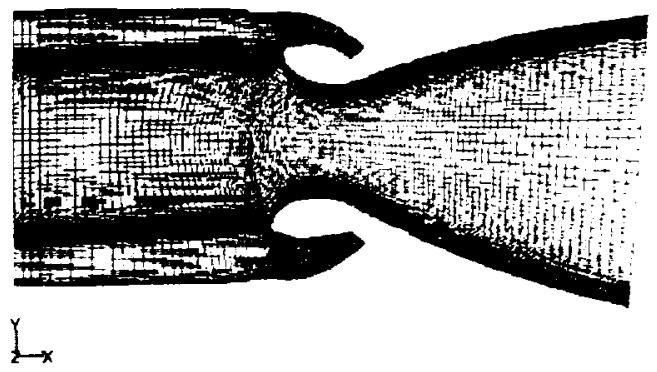

and

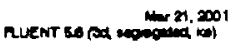

Fig. 6d Details of the symmetry plane of the threedimensional grid (Grid 1: 325,000 hexahedral cells) for the FSM.

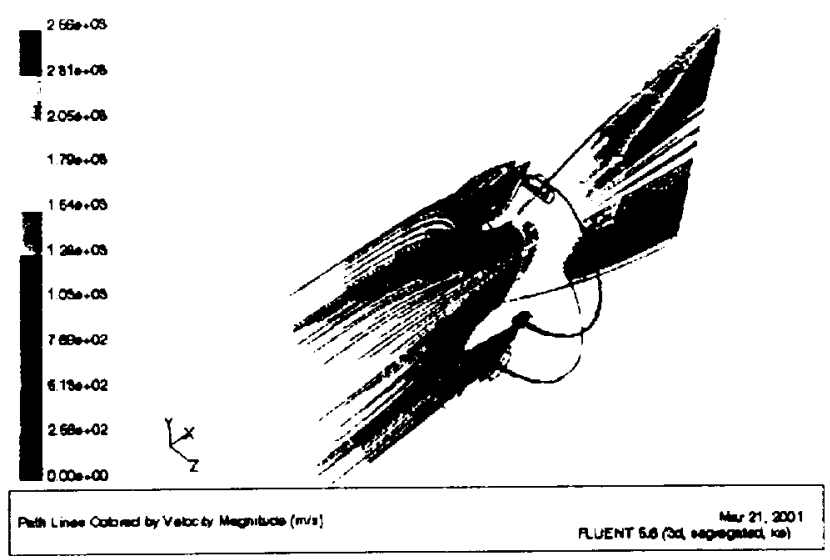

Fig. 7a Local flow field in the RSRM on Grid 1.

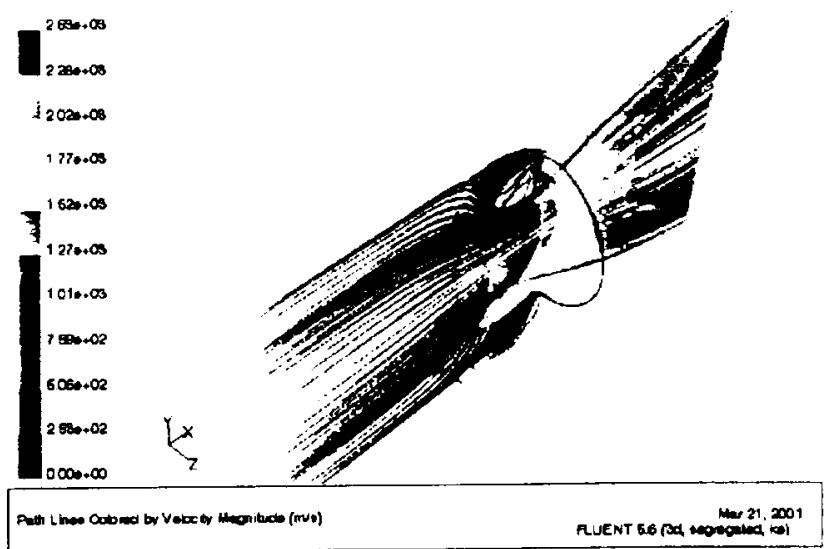

Fig. 7b Local flow field in the FSM on Grid 1. 


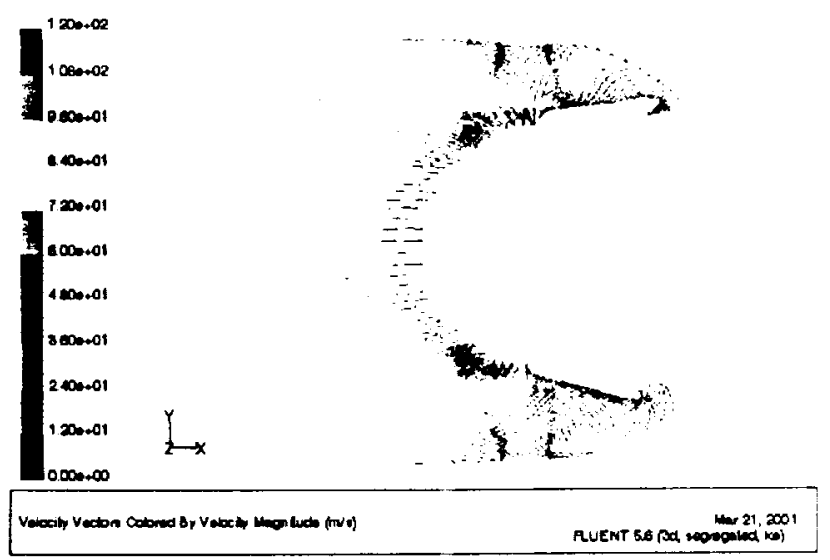

Fig. 7c Local velocity magnitude distribution at nozzle upstream in the RSRM on Grid 1.

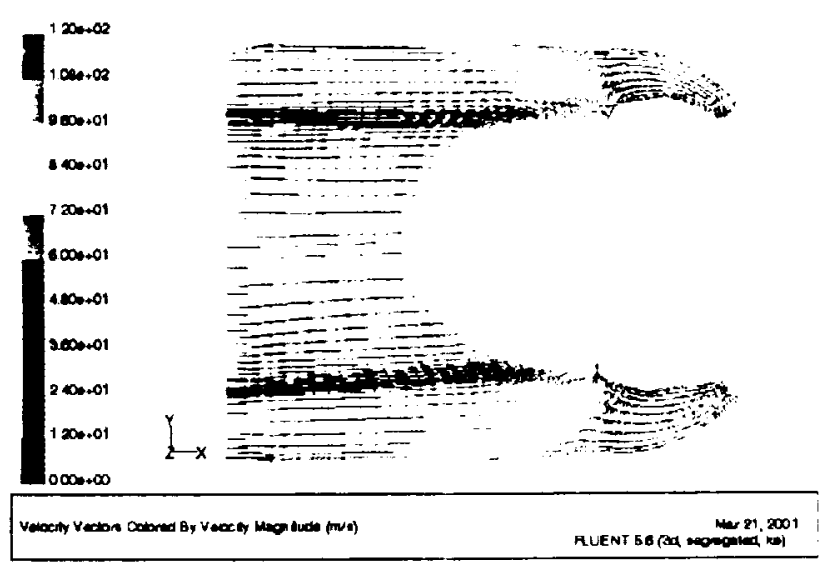

Fig. 7d Local velocity magnitude distribution at nozzle upstream in the FSM on Grid 1.

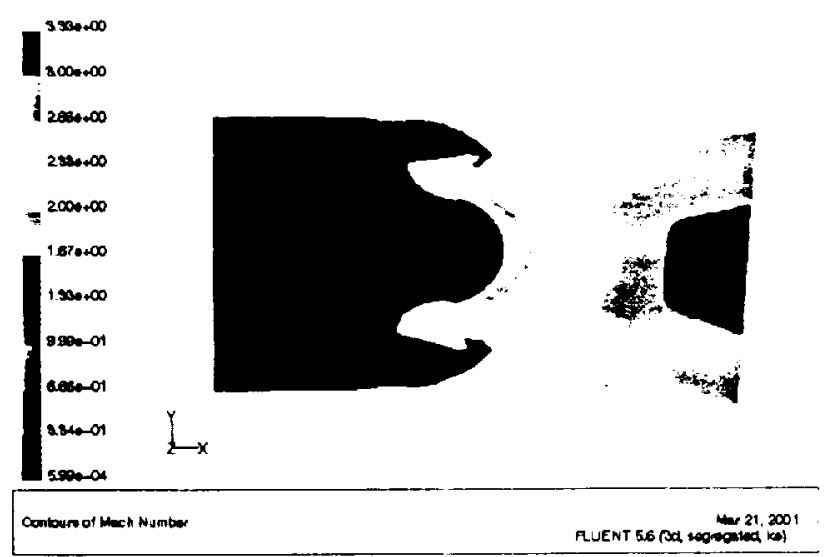

Fig. 8a Local Mach number distribution in the RSRM on Grid 1.

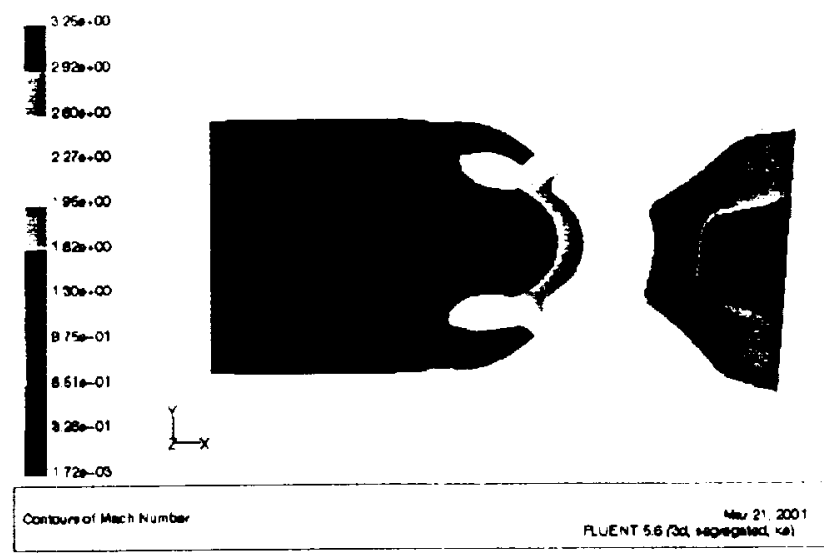

Fig. 8b Local Mach number distribution in the FSM on Grid 1.

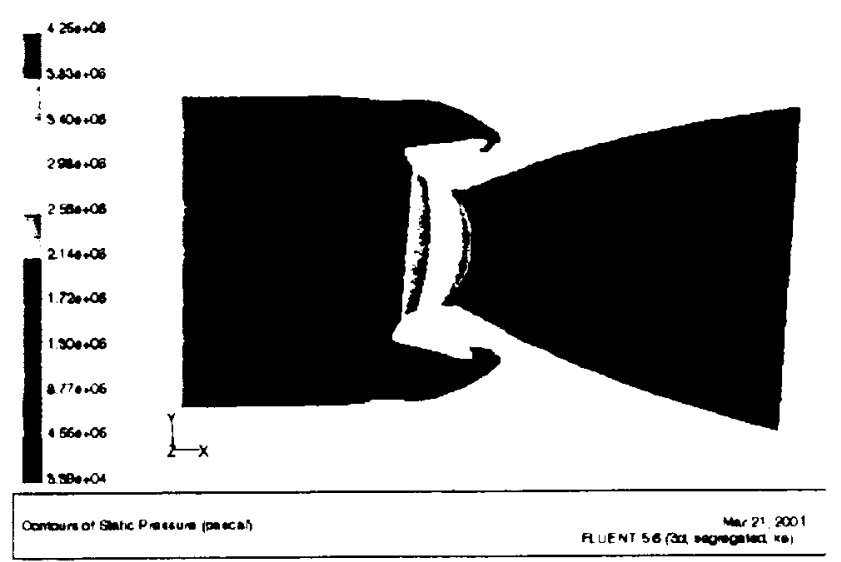

Fig. 9a Local static pressure distribution in the RSRM on Grid 1.

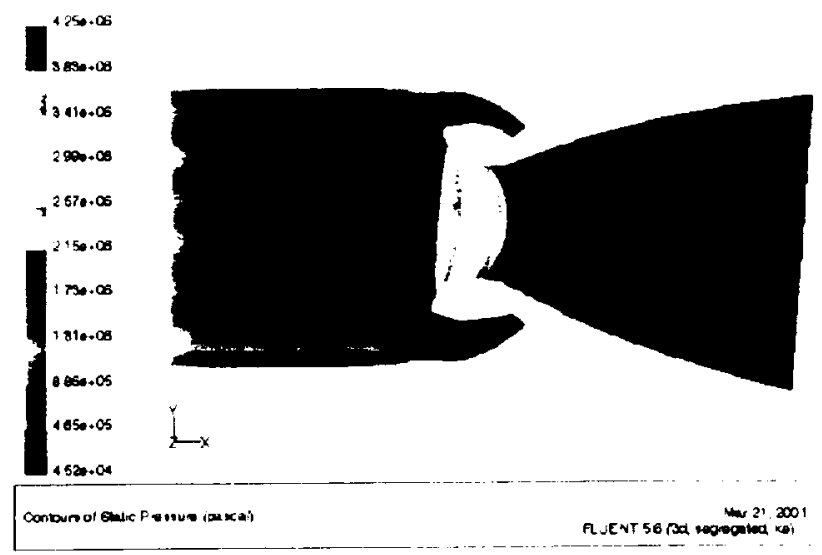

Fig. 9b Local static pressure distribution in the FSM on Grid 1. 


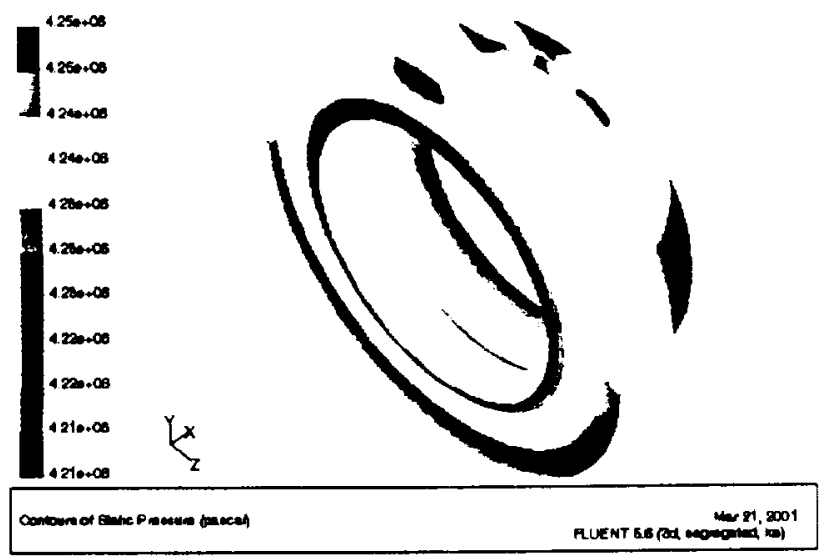

Fig. 9c Local static pressure gradient distribution (five planes in the submerged region and parallel to inlet) in the RSRM on Grid 1.

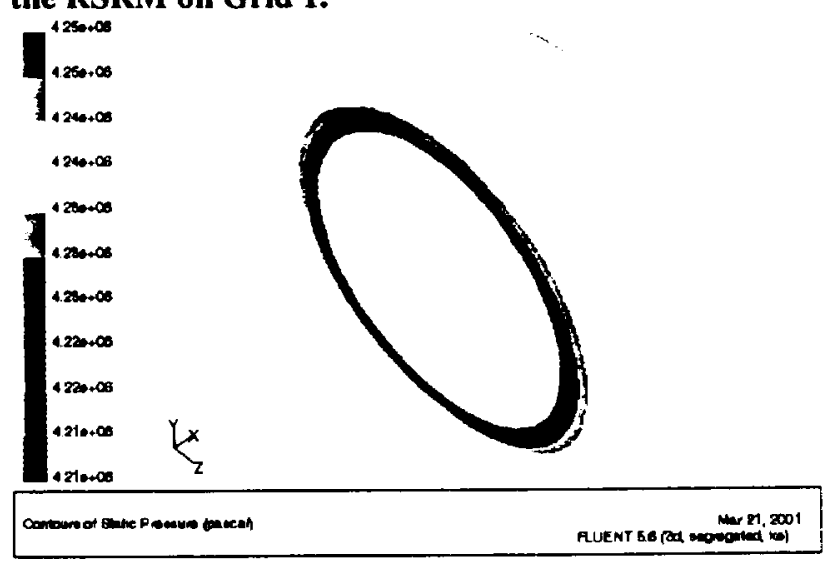

Fig. 9d Local static pressure gradient distribution (four planes in the submerged region and parallel to inlet) in the FSM on Grid 1.

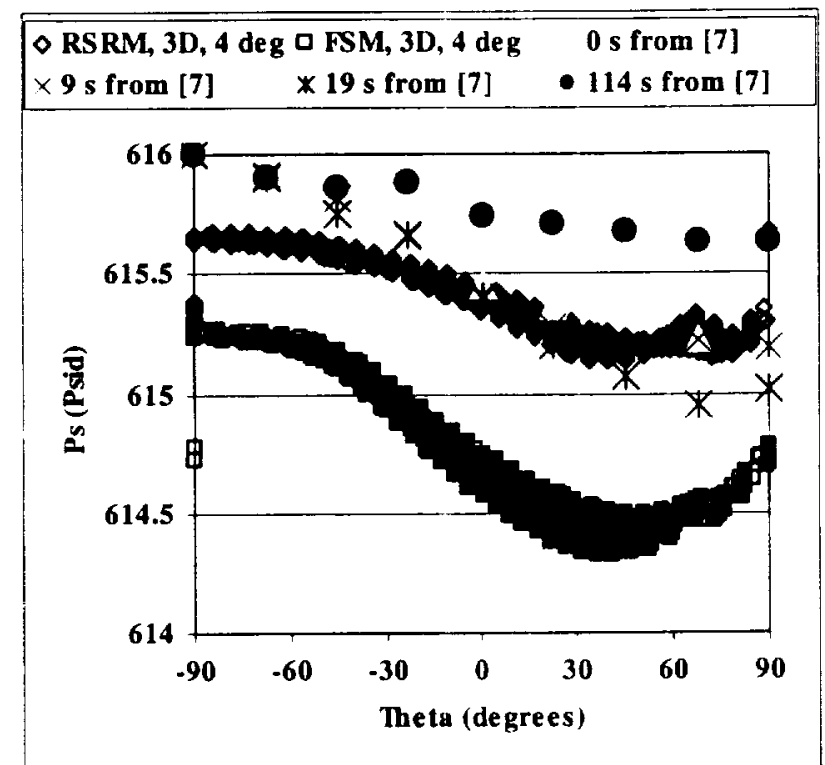

Fig. 9e Local static pressure gradient in the RSRM and FSM on Grid 1 along with cold flow experiments of Whitesides et al. [7]

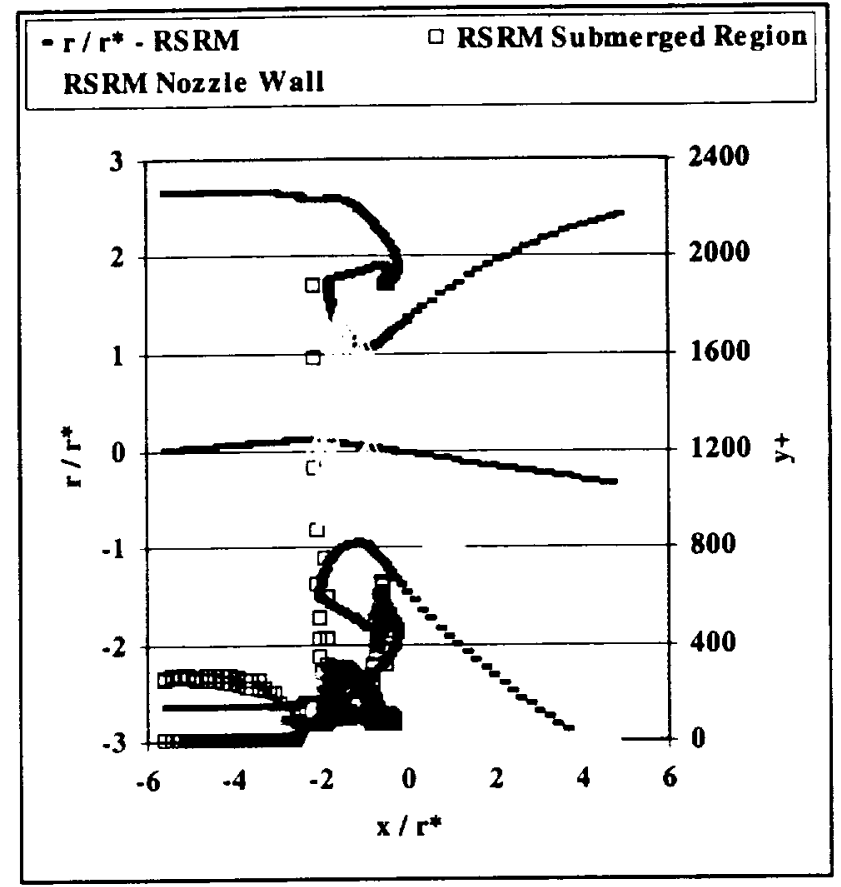

Fig. 10a Local values of wall $y^{+}$in the RSRM on Grid 1.

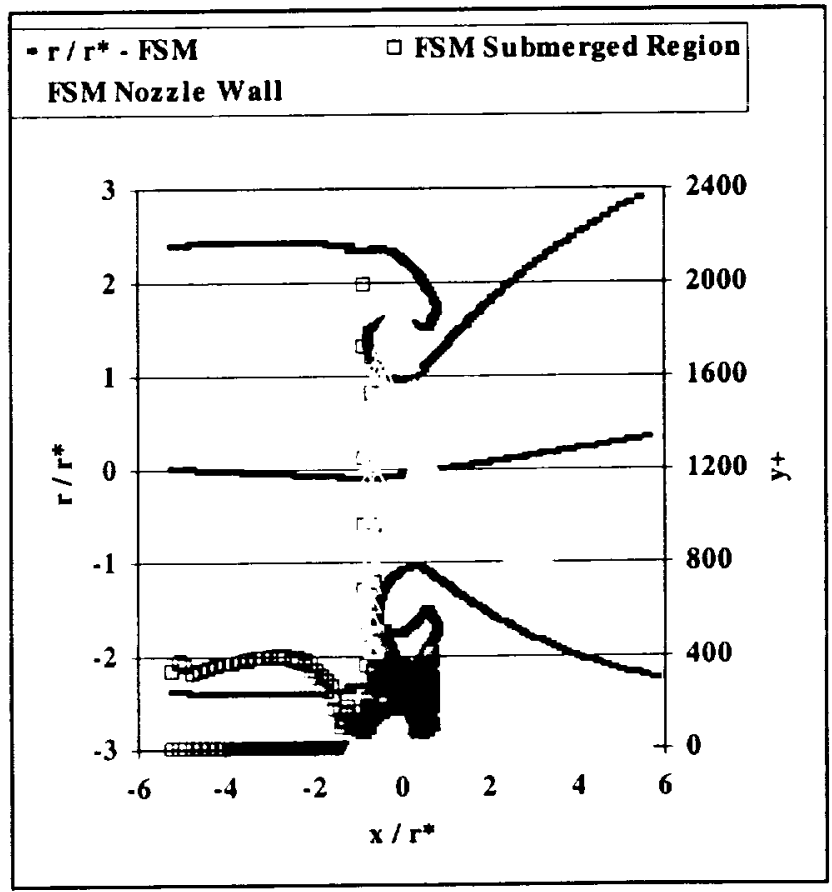

Fig. 10b Local values of wall $y^{+}$in the FSM on Grid 1. 


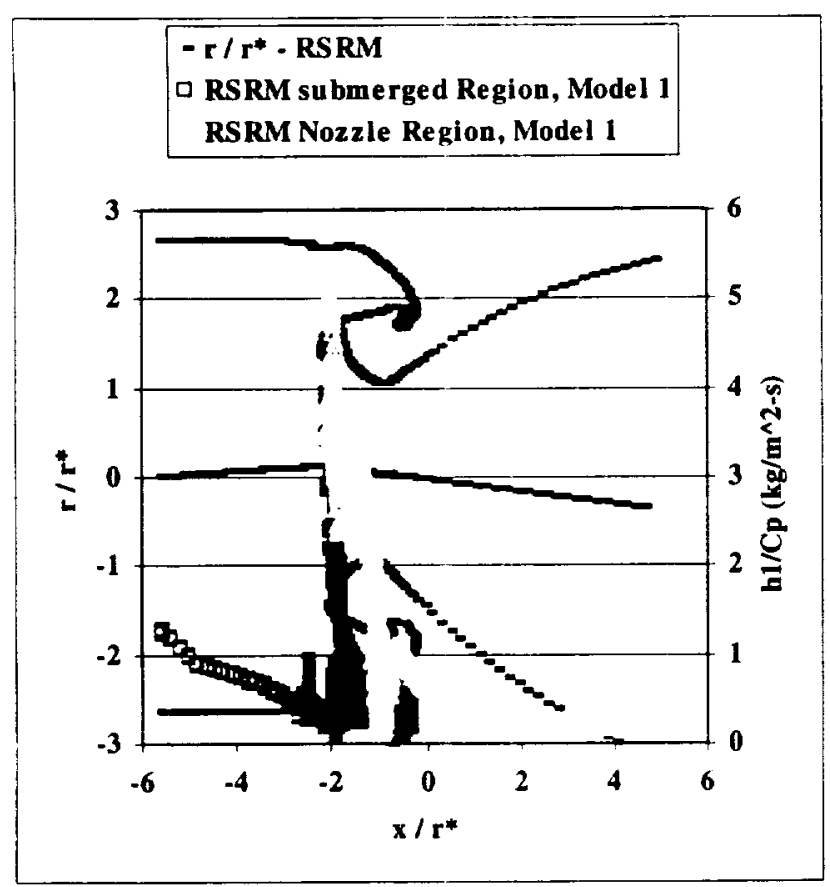

Fig. 11a Local convective heat transfer in the RSRM on Grid 1.

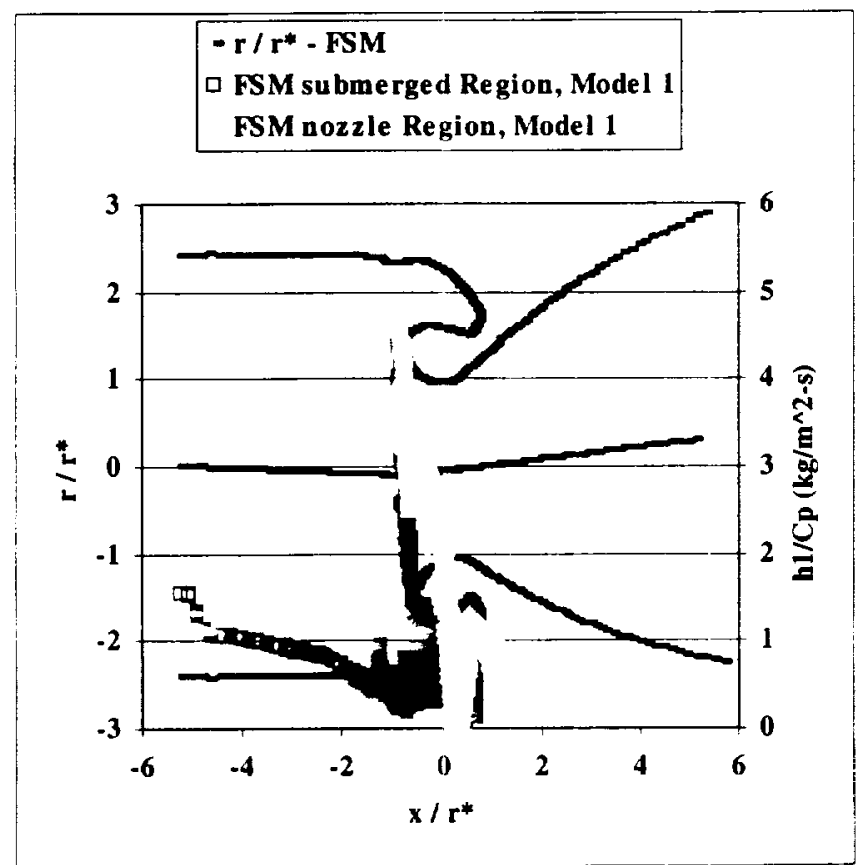

Fig. 11b Local convective heat transfer in the FSM on Grid 1.

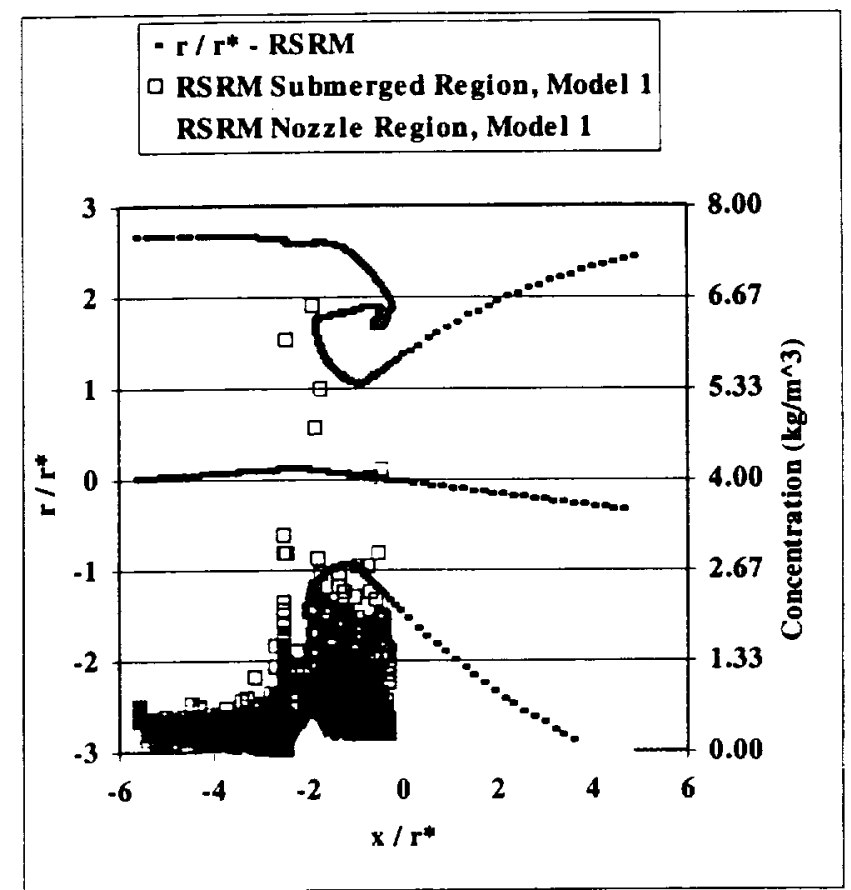

Fig. 12a Local discrete phase concentration in the RSRM on Grid 1.

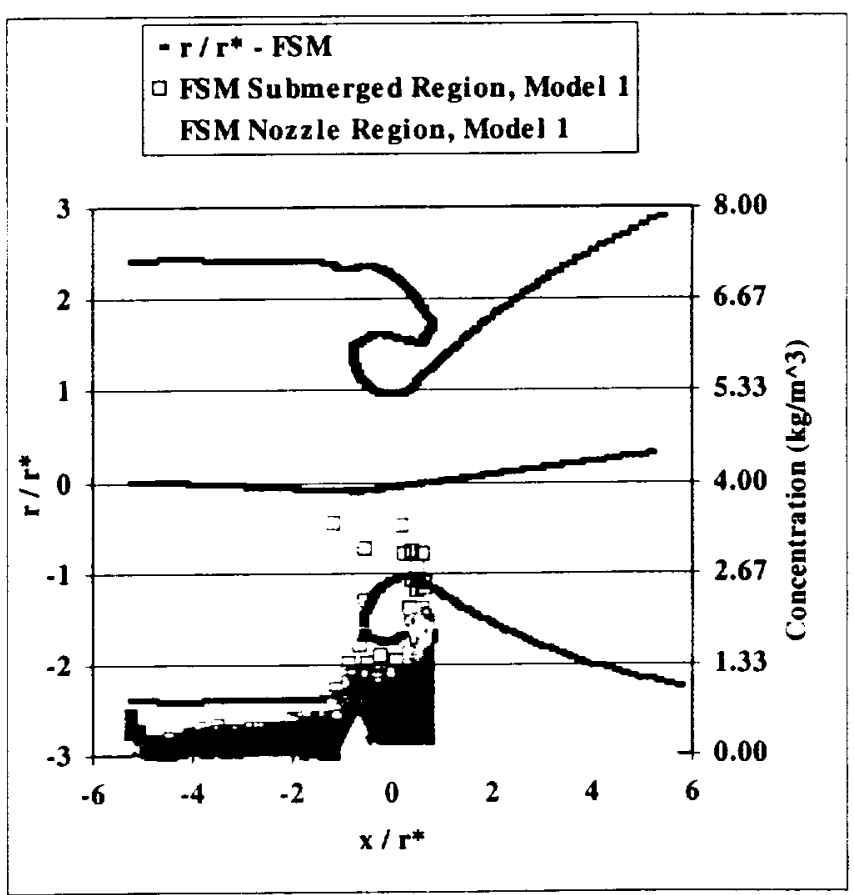

Fig. 12b Local discrete phase concentration in the FSM on Grid 1. 


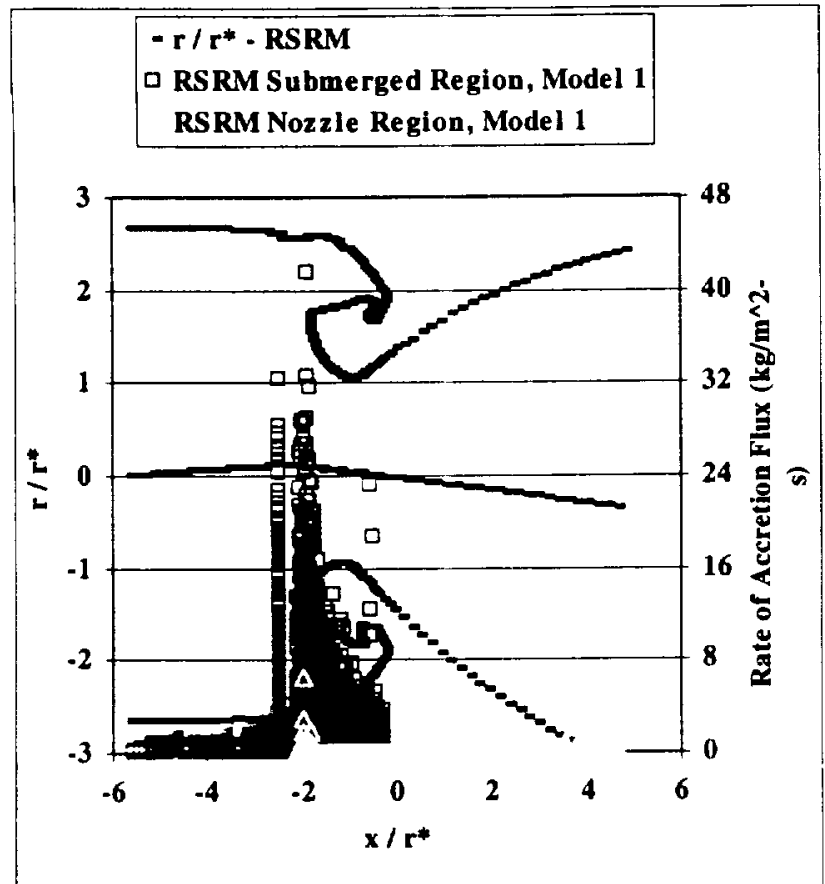

Fig. 13a Local discrete phase rate of accretion flux in the RSRM on Grid 1.

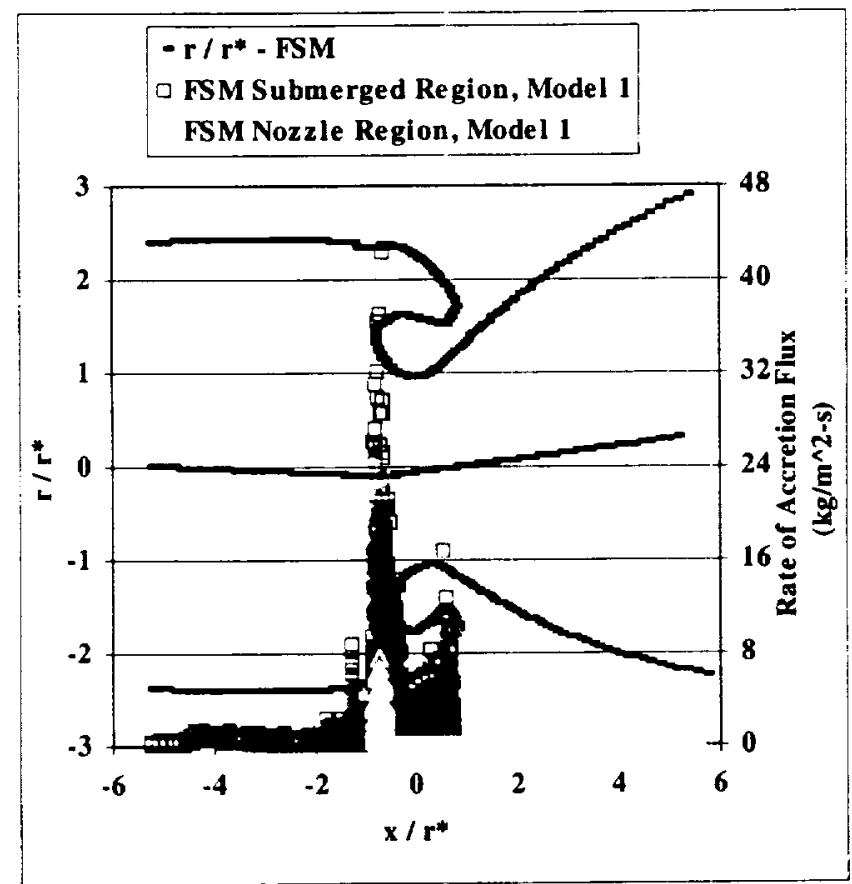

Fig. 13b Local discrete phase rate of accretion flux in the FSM on Grid 1.

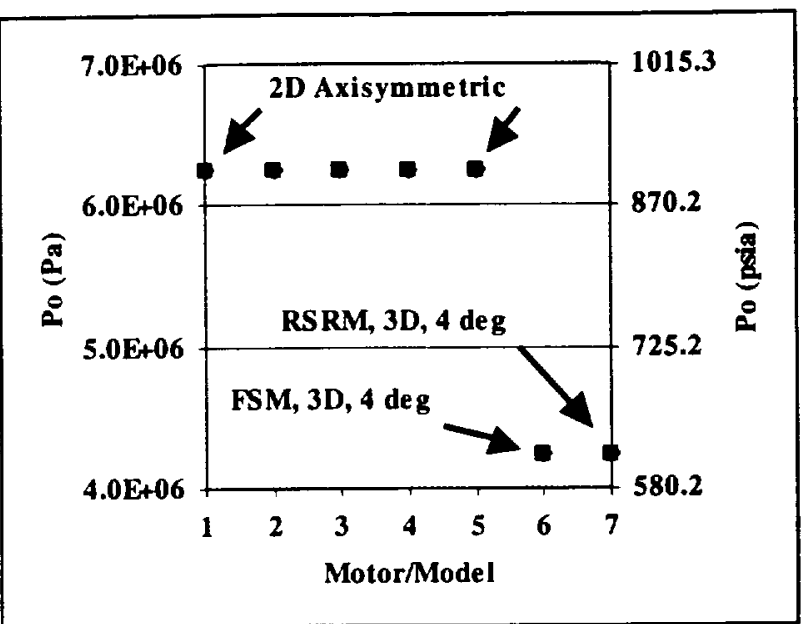

Fig. 14a Chamber pressures.

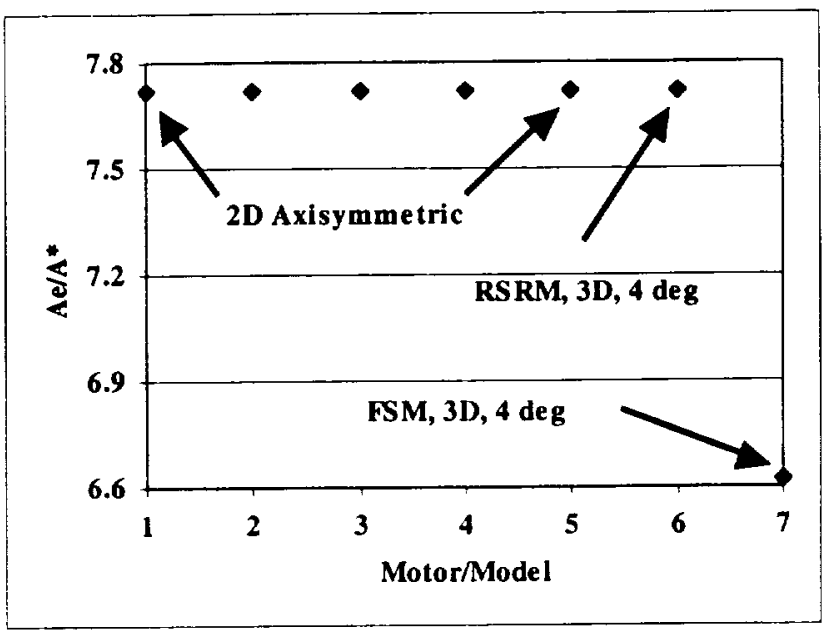

Fig. 14b Nozzles expansion area ratio.

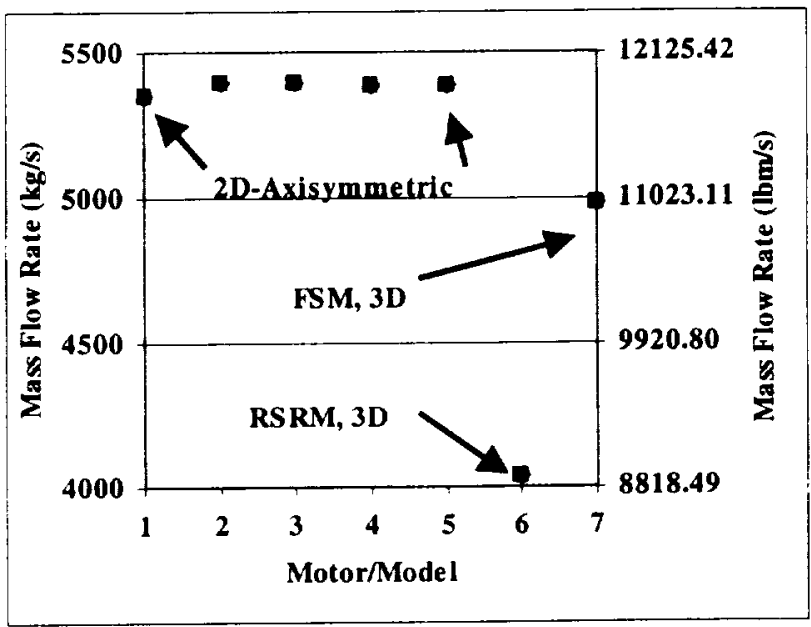

Fig. 14c Calculated mass flow rates. 


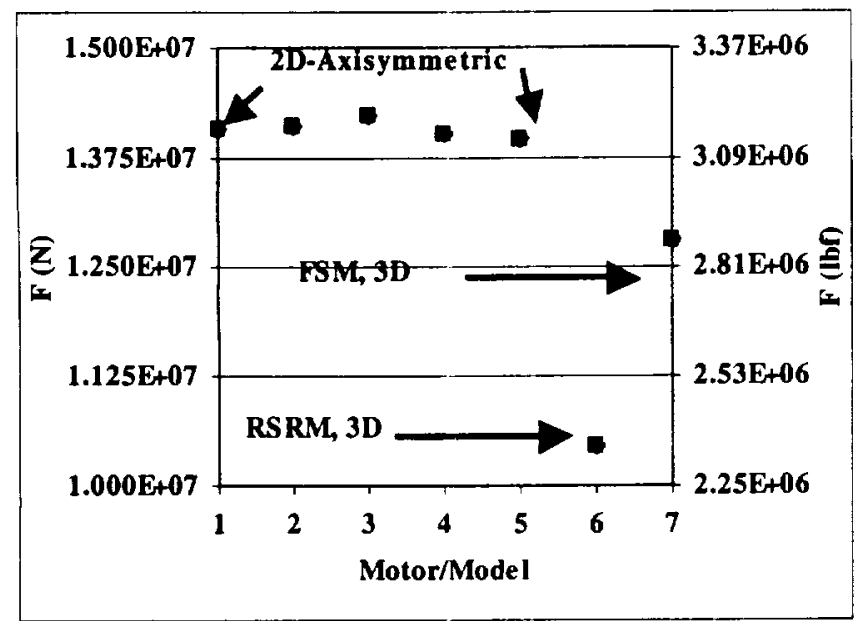

Fig. 14d Calculated vacuum thrust.

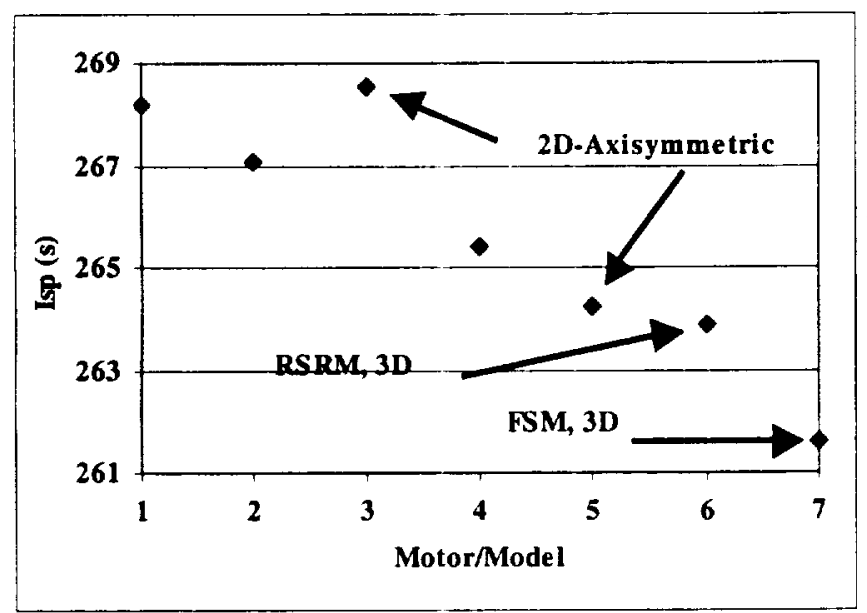

Fig. 14e Calculated vacuum specific impuise. 